\title{
CORRUPTION AND FIRMS
}

\author{
EMANUELE COLONNELLI* AND MOUNU PREM ${ }^{\ddagger}$
}

December 2020

\begin{abstract}
We estimate the causal real economic effects of a randomized anticorruption crackdown on local governments in Brazil using rich micro-data on corruption and firms. After anti-corruption audits, municipalities experience an increase in the number of firms concentrated in sectors most dependent on government relationships. Through the estimation of geographic spillovers and additional tests, we show that audits operate via both a direct detection effect as well as through indirect deterrence channels. Politically connected firms suffer after the audits. Our estimates indicate the anti-corruption program generates significant local multipliers which are consistent with the presence of a large corruption tax on government-dependent firms.
\end{abstract}

JeL Classification Codes: D72, D73, G38, H57, H83, K00, L22, O10, O43

\footnotetext{
We thank Shai Bernstein, Nick Bloom, Pascaline Dupas, Joshua Rauh, and Amit Seru for their invaluable advice. We also thank Eliot Abrams, Diogo Britto, Arun Chandrasekhar, Francesco Decarolis, Marcel Fafchamps, Claudio Ferraz, Frederico Finan, Spyros Lagaras, Borja Larrain, Stephan Litschig, Elisa Maffioli, Davide Malacrino, Sauro Mocetti, Marcus Opp, Rohini Pande, Nicola Pierri, Paolo Pinotti, Luigi Pistaferri, Paolo Pinotti, Jacopo Ponticelli, Tomás Rau, Cian Ruane, Andrei Shleifer, Michelle Skinner, Isaac Sorkin, Amir Sufi, Edoardo Teso, Margarita Tsoutsoura, Rob Vishny, Austin Wright, and seminar participants at Harvard Business School, Columbia Business School, MIT Sloan, Northwestern Kellogg, Yale SOM, Chicago Booth, UPenn Wharton, Princeton, Berkeley Haas, LSE, Indiana Kelley, Dartmouth Tuck, U of Michigan Ross, U Pompeu Fabra, U Kentucky Gatton, U Maryland Smith, UT Austin McCombs, ESMT Berlin, Tsinghua U PBC, Peking U Guanghua, Osaka U, Hitotsubashi, GRIPS, U Warwick, U del Rosario, CEIBS, Insper, FGV-EAESP, PUC-Rio, PUC-Chile, U de Chile, U de Talca, U Washington Foster, Bank of Italy, Stanford, SFSU, USF, and conference participants at Northwestern Development Rookiefest, LACEAPEG Montevideo, Copenaghen Business School, NEUDC-MIT, DEVPEC, TADC-LBS, USC Marshall, EEA-ESEM, EMCON, ESSFM Gerzensee, FinanceUC, and the AEA for helpful comments and suggestions. Naoko Yatabe and Valdemar Pinho Neto provided superb research assistance. We are grateful to the CGU director Gustavo de Queiroz Chaves and CGU officials, and to the Stanford SEED, SCID, and IRiSS centers, the CEPR-PEDL Initiative, the J-PAL Governance Initiative, The University of Chicago Booth School of Business, and Universidad del Rosario for financial support.

* Corresponding Author. The University of Chicago Booth School of Business. email: emanuele.colonnelli@chicagobooth.edu. Tel: +16505759917. Mailing Address: 5807 S Woodlawn Ave, Room 414, Chicago, IL 60637.

$\ddagger$ Department of Economics, Universidad del Rosario. email: francisco.munoz@urosario.edu.co.
} 


\section{INTRODUCTION}

Corruption is at the center of international policy debate, as epitomized by World Bank Group President Jim Yong Kim's 2013 statement defining it as "public enemy number one." Since the late 1990s, a number of resources and a tremendous amount of effort have been devoted to fighting corruption, ranging from international transparency initiatives and regulations to numerous national anti-corruption programs. One of the main goals of these policies is to spur private sector development, yet their effectiveness remains a controversial topic as some argue such policies may backfire. ${ }^{1}$

In this paper, we ask: how does a national anti-corruption crackdown affect local economic activity? Answering this question is not only important from a policy perspective, but can allow us to shed light on the mechanisms linking government corruption to firm growth and resource allocation.

Although an active body of theoretical and empirical literature has investigated the interplay between economic development and corruption -commonly defined as the (illegal) abuse of public office for private gain- establishing causality has proven extremely difficult due to the equilibrium nature of corruption. ${ }^{2}$ As a result, both cross-country and firm-level studies typically suffer from endogeneity issues that make it difficult to pin down specific channels. Anti-corruption initiatives also tend to present similar challenges as they are often anticipated, and at times manipulated, by the corrupt agents they target in the first place.

We circumvent these obstacles by focusing on the unique context of Brazil, where the federal government randomly audited local public spending to crackdown on corruption in local governments from 2003 to $2014 .^{3}$ These audits are randomized across municipalities and have been shown to have a lasting ability to reduce corruption (Avis et al., 2018). By exploiting exogenous spatial and time variation, we identify the causal impact of the audit program on various outcomes at the level of the local economy and the firm.

\footnotetext{
${ }^{1}$ See, for example, When corruption is good for the economy (Fortune, 2014), Why corruption is a messy business (Financial Times, 2014), and Where do you turn when the anti-corruption crusaders are dirty? (The New York Times, 2019).

${ }^{2}$ For extensive reviews of the literature, see Bardhan (1997), Jain (2001), Svensson (2005), Hanna et al. (2011), Olken and Pande (2012), Banerjee et al. (2012), Rose-Ackerman and Palifka (2016), and Fisman and Golden (2017).

${ }^{3}$ Audits are one of the most common tools governments adopt to monitor and punish corrupt activities. Supreme Audit Institutions (SAIs), i.e., specific agencies dedicated to anti-corruption audits, are present in almost every country in the world (http://www.intosai.org/about-us/organisation/ membership-list.html).
} 
As a first step toward understanding how corruption affects local government-firm relationships, we create and gather data from various sources. To construct our primary outcome measures at the municipality and firm level, we use matched employeremployee administrative data for the entire Brazilian formal sector from the period 2002-2017. We also rely on a number of confidential datasets (such as the administrative censuses of retail and service sector firms), and publicly available ones (such as data on politicians and campaign contributions as well as surveys of informality and data on public procurement contracts).

In the first part of this paper, we estimate the impact of Brazil's anti-corruption crackdown on firms. In a staggered difference-in-differences framework, we compare outcomes in a municipality that was randomly drawn to be audited (treatment) to those in municipalities that were eligible, but were either randomly chosen to be audited later or were never audited (control). We confirm the validity of our research design by showing that a range of local economic, demographic, and political characteristics cannot predict audits, and we illustrate parallel trends in the outcome variables prior to the audit. After an anti-corruption crackdown, treatment municipalities experience higher levels of economic activity relative to control municipalities. On average, we observe a $0.9 \%$ increase in the number of firms and business establishments operating in treated municipalities in the three years after the audit. ${ }^{4}$

The information contained in the detailed audit reports describing all irregularities uncovered by the auditors indicate that most corruption cases involve either theft of local funds by politicians, or irregularities and bribes in public procurement. As a result, a direct implication of our analysis is that the effects of the anti-corruption audits should primarily affect the economic sectors that most rely on government relationships and local spending. Indeed, we show that our effects are larger and fully concentrated in those sectors. We do so by adopting two primary definitions of government dependence: (i) sectors that are highly represented in government procurement, and (ii) sectors that are identified as corrupt via the manual reading of all irregularities involving firms uncovered by the auditors and reported in the audit reports. We show that while the number of firms operating in government-dependent sectors increases by around $1.4 \%$, there is a zero effect elsewhere.

To confirm that audits do increase real economic activity, we show that aggregate measures of firm output coming from distinct administrative sources are positively

\footnotetext{
"We often use the terms "firms" and "business establishments" interchangeably. Results, as shown in this paper, are extremely similar both quantitatively and qualitatively across the full analysis.
} 
affected by the audits: total sales by local firms increase by about $6 \%$. Additionally, the total volume of lending and deposits in local banks rise by about $3 \%$.

Within this framework in which audits cause a shift from a higher to a lower level of corruption, our findings provide some of the first causal evidence against long-standing "efficient corruption" arguments, which state that corruption may be beneficial for firms that operate in second-best contexts plagued by red tape and unnecessary regulations (Leff, 1964; Huntington, 1968). Instead, the fact that anticorruption efforts increase local economic activity suggests that theories of corruption hampering economic growth are at play (Murphy et al., 1991; Shleifer and Vishny, 1993; Svensson, 2005).

We investigate mechanisms noting that anti-corruption audits may operate through a direct detection channel -by leading public officials to be replaced or to change behavior- or through an indirect deterrence channel -by increasing the salience of audit risk. We isolate these mechanisms by estimating the spillover effects of audits onto nearby municipalities, under the assumption that physical proximity to an audited municipality raises the salience of audit risk. We uncover the presence of large spillover effects, as a nearby audit has an impact on non-audited municipalities that is similar in magnitudes to our main effects, that is a $1.2 \%$ increase in the number of firms. By re-estimating our main specification using a control group of municipalities that never neighbor an audited one, we show that, once accounting for spillovers, the impact of audits would be about double what our average estimates indicate. These findings suggest the effects of direct detection as well as the effects of indirect deterrence equally contribute to the impact of the anti-corruption program. A study of heterogeneity across the political cycle further indicates that direct effects are driven by the presence of both disciplining and selection effects of the audits on politicians.

We conclude the analysis of the local economy with a discussion of the economic magnitudes of our effects. First, back-of-the-envelope calculations indicate output multipliers of the audits in the range of 1.46-4.60. These results are in line with, but slightly larger than, recent estimates of regional multipliers in Brazil by Corbi et al. (2019), consistent with corruption leading to the inefficient waste of local public spending. Second, through the lens of a stylized model of firm heterogeneity with monopolistic competition, we show that our magnitudes can be rationalized by an average corruption tax on firms in the range of $5-23 \%$, which is similar to other estimates of leakage through corruption and bribes in different contexts, such as 
Svensson (2003) (8\%), Olken (2007) (24\%), Olken and Barron (2009) (13\%), Sequeira and Djankov (2014) (14\%), and Decarolis et al. (2019) (17\%).

In the final part of the paper, we provide a set of additional results to further characterize our findings. We start by uncovering a large degree of heterogeneity depending on the effectiveness of audits. The positive effects of the program are fully concentrated in areas where audits are effective at detecting corruption. We find suggestive evidence that unsuccessful audits may even backfire and have negative consequences when they fail to uncover local politicians' malfeasance.

Second, we provide evidence that alternative explanations that are unrelated to corruption are unlikely to account for our findings. We show that our effects are not driven by firms involved in litigation activity generated by the audits. There is also little evidence that a shift from informal to the formal sector explains all our results. Finally, we show that the central government does not change its allocation of federal funds in response to the audits.

We conclude with a firm-level analysis aimed at uncovering more granular heterogeneity that is informative of the role of corruption as a source of misallocation across firms. Consistent with the presence of a corruption tax, we find that incumbent firms in government-dependent sectors grow the most after an audit. On the other hand, politically connected firms, such as campaign donors or firms whose manager is an elected politician, shrink considerably, suggesting that a potential channel through which corruption affects local economic activity is by allowing connected but inefficient firms to operate and stifle competition. ${ }^{5}$

Our paper relates to three main strands of literature. First, we contribute to the vast literature on corruption. In particular, we relate to studies that focus on the role of corruption in firm growth and economic development and to those studies regarding the effectiveness of government audits in reducing corruption. ${ }^{6}$ Compared to previous studies, we exploit quasi-experimental variation in corruption levels generated by the

\footnotetext{
${ }^{5}$ Consistent with these findings, Colonnelli et al. (2020b) find that the vast majority of firms involved in irregularities with the government are not the active perpetrators of corruption. The analysis in Colonnelli et al. (2020b) is complementary to ours as they focus exclusively on the set of firms located in never-audited municipalities.

${ }^{6}$ Examples of the former are Wade (1985), Shleifer and Vishny (1993), Shleifer and Vishny (1994), Mauro (1995), Bliss and Di Tella (1997), Kaufmann and Wei (1999), Svensson (2003), Fisman and Svensson (2007), Olken (2007), Olken and Barron (2009), Cole and Tran (2011), Sequeira and Djankov (2014), Weaver (2016), Smith (2016), Bai et al. (2017), and Decarolis et al. (2019). Anticorruption audits in Brazil are the focus of Ferraz and Finan (2008), Bologna and Ross (2015), Lichand et al. (2016), Zamboni and Litschig (2018), and Avis et al. (2018). Studies on related anticorruption initiatives in other countries include Bobonis et al. (2016), Zeume (2017), Giannetti et al. (2017), and Chen and Kung (2018), among others.
} 
anti-corruption audits to estimate the impact on local economic activity and firm dynamics. Additionally, we assemble a new dataset that combines multiple sources of micro-data to shed light on the mechanisms linking corruption and firm activity.

We also contribute to studies that assess the importance of political connections to firms. ${ }^{7}$ Our causal evidence that politically connected firms suffer large losses after an anti-corruption crackdown is novel, and it is consistent with the large body of work -starting with the seminal work by Fisman (2001)- which argues that politically connected firms benefit from corruption. However, our paper adds an additional wrinkle to this argument by highlighting that corruption represents an extra cost of doing business for incumbent government-dependent firms. Our study differs from most papers in this literature as they restrict their attention to the set of politically connected firms, and especially large, publicly listed ones connected to top politicians. Important exceptions are the studies of private firms in Italy by Cingano and Pinotti (2013) and Decarolis et al. (2019). In this sense, our paper is instead closer to Svensson (2003) and Fisman and Svensson (2007), who use survey evidence to uncover large costs of corruption for small and medium firms. Our ability to further observe firm-level outcomes and political connections for the full formal sector represents a significant leap forward from previous work in this area.

Finally, we relate to the literature examining the causes and consequences of resource misallocation in the economy (Restuccia and Rogerson, 2008; Hsieh and Klenow, 2009; Bartelsman et al., 2009; Syverson, 2011; Hsieh and Klenow, 2014). Our paper emphasizes the role of one important but arguably understudied friction, corruption. Our estimates of potentially significant firm-level distortions generated by the presence of corruption highlight its importance for models of firm dynamics that aim to take the interactions between government and firms into account.

This paper is organized as follows. In Section 2 we illustrate the institutional context, while in Section 3 we describe the primary data sources. Section 4 illustrates our empirical strategy. Section 5 presents the main results of the paper. In Section 6 we discuss additional results. Section 7 concludes.

${ }^{7}$ Examples include Fisman (2001), Khwaja and Mian (2005), Faccio (2006), Faccio et al. (2006), Claessens et al. (2008), Goldman et al. (2008), Cooper et al. (2010), Duchin and Sosyura (2012), Akey (2015), Fisman and Wang (2015), Schoenherr (2018), Akcigit et al. (2018), and González and Prem (2020). 


\section{The CGU Anti-Corruption Program}

In May 2003 under the administration of Luis Inácio Lula da Silva, the Brazilian central government launched a large anti-corruption program to fight the rampant corruption in the waste of public resources by local governments. The program consisted of 39 rounds of randomized audits of municipalities' expenditures -with replacementover the 2003-2014 period, followed by anti-corruption enforcement activity such as the suspension of corrupt public officials and politicians.

The audits are conducted by the Office of the Comptroller General (Controladoria Geral da União (CGU)), which is the federal agency responsible for ensuring transparent use of public funds and is considered the main anti-corruption body in Brazil. At each audit round, approximately 60 municipalities were randomly selected, with replacement. ${ }^{8}$ As of 2014, more than $99 \%$ of Brazil's 5,570 municipalities were eligible, and 1,881 had been selected at least once. Only municipalities below a certain population threshold were eligible for the program, and state capitals were excluded. ${ }^{9}$

The audit process begins immediately after the random draw, with the federal CGU office detailing the audit to the various CGU state offices by means of a number of inspection orders. The state offices must then send a team of auditors to the selected municipalities within days of the lottery. The audits investigate how the federal transfers from the central government to the municipality are spent and focus mostly on the previous three years. ${ }^{10}$ There is no management training as part of the audit.

During an intense few weeks of field works, the auditors analyze all relevant documents and receipts related to the spending of federal funds, interview local people, bureaucrats, and other relevant parties, solicit direct anonymous complaints about malfeasance, and take pictures to document the quality of public service delivery. Following this fieldwork, the auditors write a detailed audit report following the meticulous instructions from the federal CGU. These publicly available reports can span up

\footnotetext{
${ }^{8}$ The randomization is linked to the draw of a popular national lottery. The implied audit probability in any given round, which is constant within a state, is therefore quite low (1\% within a round, and $3 \%$ within a year). Additionally, there is a small exception to the random draw with replacement, as municipalities cannot be selected if they were selected in one of the previous three rounds.

${ }^{9}$ The population threshold was originally 100,000, but it was successively increased to 300,000 soon after the launch, and then rose to 500,000 for the remaining years of the program.

${ }^{10}$ All federal transfers tend to be audited for smaller municipalities, while often just a subset of the transfers can be audited for larger municipalities. The details of each inspection order and the sectors that are audited can change over time, at the CGU central office's discretion.
} 
to 300 pages and include organized analyses of all the information gathered during the weeks-long audit.

The audits may have severe legal consequences, which most often target corrupt politicians and officials. In particular, the CGU discuss the audit findings directly with state and federal prosecutors and the Ministries whose transfers have displayed irregularities. These agencies then analyze the irregularities and decide on anticorruption enforcement activity. The most common consequences of CGU audits are temporary or indefinite suspension of officials from public posts, the impeachment of the mayor by the local office, or the mayor's loss of mandate.

In Figure 1, we illustrate the yearly variation of the program over time using administrative data from the CGU. We can see from Panel A that the intensity of the program was higher in the first three years and significantly lower in the final three years. Panel B plots the total amount of audited federal transfers to municipalities (in millions of USD), showing spikes of around 1.5 billions USD in 2004, 2009, and 2010. Panels C and D display the total number of mismanagement and corruption irregularities, respectively, following the CGU split between minor and more severe irregularities and the language of Avis et al. (2018). ${ }^{11}$ Figure 2 shows the wide geographical variation of audits and corruption across Brazil.

\section{DATA}

The main outcome measures used in the analysis come from matched employeremployee administrative data, which we expand using confidential firm-level government censuses and several other datasets.

3.1. Matched Employer-Employee Data. The principal source of firm- and workerlevel data is obtained from the Brazilian Ministry of Labor's RAIS (Relação Anual de Informações Sociais) database. It is widely considered a high-quality census of the formal labor market (Menezes-Filho et al., 2008, Dix-Carneiro, 2014, Helpman et al., 2017). Except for the informal sector and a subset of self-employed individuals, its coverage is almost universal. Data quality and coverage improved dramatically in 2002 when individual tax identifiers and additional variables were incorporated into RAIS. We therefore focus on the years 2002-2017, which is the same period the primary datasets discussed below are available.

Each individual is assigned a unique administrative worker identifier, which allows for tracking of the individual over time and across firms as well as establishments of

${ }^{11}$ The CGU started collecting data on the specific types of corruption in 2006. 
the same firm. RAIS contains information on the tax identifiers of both the firm and the establishment of the worker, their locations and industry, and on several other establishment- and firm-specific variables. We use these variables to aggregate the measures at the establishment, firm, and municipality level in the analysis. Similar to other employer-employee matched data, we observe wages and hiring and firing dates, but also gender, nationality, age, and education, as well as data on hours worked, reason of hiring and firing, and contract details. Finally, each worker is assigned an occupational category specific to her current job.

Our analysis focuses on the full set of 5,526 Brazilian municipalities that are eligible for the program, excluding only the 44 larger, ineligible municipalities (i.e., state capitals and those with population above the program's threshold). Of these, 1,881 municipalities are audited at least once during the 2003-2014 period. Table 1 displays summary statistics for this sample (Panel B), as well as for all municipalities eligible for the program (Panel A). Eligible municipalities have an average (median) of 251 (43) business establishments and 239 (41) firms and 2,816 (324) private sector workers who have a wage of BRL 461 (418) per month. The average (median) firm has 16 (3) employees. As displayed in Panel B, the distribution of audited municipalities (i.e., excluding those eligible but never audited) is extremely similar.

3.2. Firm-level Data on Retail and Service Sectors. The primary advantage of RAIS is its nearly complete coverage of private sector firms. However, RAIS lacks balance sheet information that is especially important to construct measures of aggregate economic activity. We therefore rely on two unique yearly datasets collected by the Brazilian Institute of Statistics (IBGE), the primary data collection government agency in Brazil. We have access to the two datasets, the Annual Survey of Retail (PAC: Pesquisa Anual de Comércio) and the Annual Survey of Service (PAS: Pesquisa Anual de Serviços), for the 2002-2014 period.

These data are generated by PAC and PAS from surveys aimed at monitoring firm performance in the retail and service sectors, respectively. ${ }^{12}$ Both PAC and PAS surveys are constructed using two strata: the first stratum (estrato amostrado) includes a nationally representative sample of single-establishment, single-state firms with less than 20 employees; the second stratum (estrato certo) consists of all other

${ }^{12}$ Using the CNAE 2.0 classification, PAC covers Section G, while PAS covers Sections E, H, I, J, L, M, N, R, S. More details on the PAC and PAS survey instruments can be found on the IBGE website at their respective links (accessed December 2020): https://www.ibge.gov.br/estatisticas/ economicas/comercio/9075-pesquisa-anual-de-comercio.html and https://www.ibge.gov. br/estatisticas/economicas/servicos/9028-pesquisa-anual-de-servicos.html. 
firms (i.e., firms with at least 20 employees or those with establishments in more than one state), which are sampled with probability one. To ensure our data are representative at the municipality level in the analysis, we use only firms in the estrato certo. As of 2014, i.e., the last year of audits in our sample, a total of 131,702 firms are included in the PAC and PAS estrado certo surveys. The advantage of using these data is that they contain financial information on firm performance, such as sales and investment.

3.3. Other Data Sources. We rely on a variety of complementary data sources, which we introduce in different parts of this paper and summarize below.

Surveys of Informality. We obtain information on informality from the National Household Survey (PNAD: Pesquisa Nacional por Amostra de Domicílios), which is an annual survey first made available in 2002 by IBGE. Unfortunately, these data are only available at the state-year level. Therefore, we impute informality measures at the municipality-year level using both population shares from IBGE annual surveys and pre-existing informality shares that we can measure directly in the 2000 Decennial Census. ${ }^{13}$

Elections, Political Connections, and Campaign Contributions. Electoral data on municipal and federal elections are obtained from the Tribunal Superior Eleitoral (TSE). TSE also provides detailed data on both individual and corporate campaign contributions over the same period in addition to individual-level data on both elected and unelected political candidates. We use various measures based on these data, which we describe in more depth in Colonnelli et al. (2020d), to explore effects across the electoral cycles and to identify politically connected firms. We also complement these data with further TSE data on the party affiliation of workers and managers in the private sector (Colonnelli et al., 2020c).

Public Procurement. We construct measures of sectoral government dependence using contract-level data from federal public procurement. These data are obtained from the Ministry of Planning, Budget, and Management (MP: Ministério do Planejamento,

\footnotetext{
${ }^{13}$ To validate our imputations, we show that the average between our 2009 and 2011 imputations are highly correlated with the actual measures of informality and formality directly observed in the 2010 Decennial Census. In Figure A1, using outcome variables in logarithmic terms, we report both the estimated coefficients and the R-squared of the linear regression of the actual Census measures on our imputations. The binscatter plots show elasticities extremely close to one, and R-squared in the range of 0.89-0.94. These findings hold both when using imputations that rely on annual population shares (Panels A and C) as well as pre-existing actual informality shares measured in the 2000 Decennial Census (Panels B and D).
} 
Orçamento e Gestão). We have access to the universe of federal contracts from 2000 to 2014. We complement these data with municipality-level contract data for municipalities in the state of Sao Paulo since 2008; these data are made publicly available by the Court of Auditors of the State of Sao Paulo (TCE-SP).

Loans and Banking Sector. Municipal-level data on the total amount of local loans to both businesses and individuals, and on the total amount of deposits in local banks by both business and individuals, are obtained from the Brazilian Central Bank (BCB: Banco Central do Brasil), through their ESTBAN dataset, for the period 2002-2017.

Other. We use administrative data on audits and irregularities from the CGU. We complement these data with new manually collected data on all firms involved in irregularities uncovered by the CGU auditors (Colonnelli et al., 2020b). Data on federal transfers come from the National Treasury's FIMBRA dataset, while data on block grants to municipalities come from the CGU.

\section{Empirical Design}

In this section, we illustrate our identification strategy, which relies on the randomization of anti-corruption audits across municipalities over time. The key identification concern is that unobserved confounding factors may be correlated with both corruption and economic outcomes. For example, poor economic conditions may lead public officials to seek bribes from local firms, thus preventing us from causally estimating whether corruption affects the local economy. This has arguably been the main limitation to empirical work on corruption and economic development.

Since we are unable to observe municipal corruption levels over time -given that corruption is only observed conditional on the audit taking place--, we cannot causally estimate the impact of corruption per se. However, assuming audits are effective at reducing corruption, we can estimate the policy-relevant reduced-form impact of the audits, and explore the economic mechanisms at play.

The context we study is unique in that anti-corruption audits are randomized across municipalities over time. The design of the program therefore lends itself to a municipality-level event-study estimation method. After removing the few municipalities that are ineligible for the program, we have a set of treated (at different points in time) and never-treated municipalities. Then, at the same point in time $t$, we can compare the outcomes of municipalities that are audited at time $t$ to those audited at time $t+\mu(\mu>0)$ and to the never-treated municipalities. 
Since the median number of audit rounds in a year is three, we aggregate the main outcome data at the quarter level whenever possible (e.g., when using data from RAIS), or at the year level whenever that is the frequency of the data (e.g., when using the firm censuses). Moreover, since most data sources begin in 2002 and end in 2017, our main estimation window covers the period of $[-4,12]$ quarters (or $[-1,3]$ years) around the audit. ${ }^{14}$

4.1. Estimating Equations. We estimate both non-parametric and parametric event study models. The former allows us to capture the dynamics of real economic outcomes relative to the time of audit, and we estimate it as follows:

$$
y_{m t}=\alpha_{m}+\alpha_{t}+\sum_{k=-4}^{k=-1} \mu_{k}+\sum_{k=1}^{k=12} \mu_{k}+\epsilon_{m t},
$$

where $m$ and $t$ stand for municipality and quarter, respectively, and $\left\{\mu_{k}\right\}$ captures the relative event-time indicators. ${ }^{15}$ That is, $\mu_{k}$ is an indicator variable taking value 1 if it is quarter $k$ relative to the audit quarter. These indicator variables are always 0 for municipalities that are never audited. As is typical in event study frameworks, we make the normalization $\mu_{-1}=0$, so that all coefficients represent differences in outcomes relative to the quarter before the audit. The specification includes municipality fixed effects $\left(\alpha_{m}\right)$ and quarter fixed effects $\left(\alpha_{t}\right)$, which absorb fixed differences across space and time. The latter are especially important since the scope of the audits may change over time, for example due to fluctuations in the CGU budget. $\epsilon_{m t}$ are standard errors clustered at the level of the municipality (Bertrand et al., 2004).

A parametric specification, on the other hand, allows us to better analyze the statistical significance and magnitude of the estimates. We estimate the following model:

$$
y_{m t}=\alpha_{m}+\alpha_{t}+\beta \times \text { PostAudit }{ }_{m t}+\epsilon_{m t},
$$

where again $m$ and $t$ stand for municipality and quarter, respectively, and PostAudit ${ }_{m t}$ is an indicator variable taking value 1 for all quarters after the audit in the audited municipality, and 0 otherwise. PostAudit ${ }_{m t}$ is always 0 for never-treated municipalities. The parameter of interest is $\beta$, which measures the change in the outcome

${ }^{14}$ As discussed later, the results are robust to multiple other estimation windows, including an unconstrained window around the event.

${ }^{15}$ By quarter, unless otherwise specified, we mean the specific year-quarter, so that we have 48 quarters in the estimation period 2002-2017. 
variables of the audited municipalities compared to the yet-to-be-audited and eligiblebut-never-audited municipalities, conditional on the set of municipality and quarter fixed effects. ${ }^{16}$

4.2. Identifying Assumptions. The interpretation of $\beta$ (or the $\left\{\mu_{k}\right\}$ indicators of equation 4.1) as the causal impact of the anti-corruption audits requires the identifying assumption that the timing of the audit is uncorrelated with municipal economic outcomes, conditional on the set of municipality and time fixed effects. For example, an audit that is anticipated by either corrupt officials and politicians, or by firms, would violate the identifying assumption.

However, the design of the program limits these concerns, as the audits are randomized across the pool of eligible municipalities by means of a public lottery, and previous work has strongly established the validity of this randomization (Ferraz and Finan, 2008; Litschig and Zamboni, 2008; Ferraz and Finan, 2011). We also test for this in the data in Table 2, where we regress an indicator for whether the municipality is audited on state fixed effects and a host of local economic, demographic, and political characteristics. For example, we show in column 1 audited municipalities are similar based on observable characteristics to never-audited municipalities: none of the covariates we use in the regression, which are measured at the beginning of the sample and cover economic, demographic, and political measures, are statistically significant, and the magnitudes of each coefficient are small. All covariates are standardized by their mean and standard deviation. In columns 2-5, we repeat a similar exercise for different audit cohorts, adding covariates measured the year before the audit, and find analogous results: at most one coefficient per audit cohort is statistically significant, and magnitudes are small. Overall, the patterns in the data strongly indicate that the randomization of the audits was successful.

We can also directly assess this assumption in the data by analyzing the dynamics in the $\mu_{k}$ coefficients of equation 4.1, as we illustrate in the next section. For our research design to be valid, audited and control municipalities should follow parallel trends in the period prior to the audit, which implies that the pre-period $\mu_{k}$ indicators should not be statistically different from zero.

\footnotetext{
${ }^{16}$ When studying heterogeneous effects based on differential preexisting characteristics, we estimate the following interacted specification:

$$
y_{m t}=\alpha_{m}+\alpha_{t}+\beta_{1} \times \text { PostAudit }_{m t}+\beta_{2} \times Z_{m} \times \text { PostAudit }_{m t}+\epsilon_{m t}
$$

where $Z_{m}$ is a characteristic of the municipality measured pre-audit, unless otherwise specified.
} 


\section{The Impact of Anti-corruption Audits on the Local Economy}

The central part of our analysis investigates the impact of anti-corruption audits on the local economy. We show that they positively affect various municipal-level economic outcomes, and that the effects are concentrated in government-dependent sectors. We then discuss mechanisms, with a focus on disentangling the direct effects from the indirect effects of the audits. We conclude by interpreting the economic magnitudes of our findings.

5.1. Conceptual Framework. The long-standing debate on the relationship between corruption and firms centers around two opposing views. On the one hand, "efficient corruption" theories by Leff (1964) and Huntington (1968) posit that, in the context of pervasive and cumbersome regulations, firm activity would be higher in a corrupt equilibrium where it is easier for firms to (illegally) bypass bureaucratic obstacles. Several variations of these arguments depict corruption as "grease in the wheel" or "speed money," such as in the queuing model by Lui (1985). On the other hand, other theories illustrate several ways through which corruption may be damaging to firm activity, often describing it as a tax that limits entry and firm growth (Murphy et al., 1991; Shleifer and Vishny, 1993; Romer, 1994). ${ }^{17}$

Brazil represents an appealing institutional setting to study these theories: it ranks among the highest for government regulation, and corruption at various levels of the government is pervasive, thus providing ambiguous predictions regarding the impact of an anti-corruption program. ${ }^{18}$ Focusing on our specific context of local public spending, the audit reports offer rich qualitative evidence to inform our analysis. Specifically, in addition to minor mismanagement irregularities, corruption mostly occurs as (i) theft of public funds by politicians and officials, and (ii) illegal interactions between politicians, officials, and firms.

This context can be illustrated through a stylized model of firm heterogeneity with monopolistic competition, where a fraction of government spending is stolen and corruption appears as a wedge in the production process of firms (Restuccia and Rogerson, 2008; Hsieh and Klenow, 2009). The theft of public funds is obviously unlikely to benefit firms, as it rather indicates lower actual spending on the local

\footnotetext{
${ }^{17}$ For more details on corruption theories, we refer the reader to the excellent comprehensive reviews of the literature by Bardhan (1997), Olken and Pande (2012), Burguet et al. (2016), and Fisman and Golden (2017).

${ }^{18}$ At the end of our study period in 2014, Brazil ranks 143rd out of the 144 countries listed in the Global Competitiveness Index in terms of regulation, and 69th out of 174 countries listed in the Corruption Perception Index by Transparency International.
} 
economy, which would therefore limit the number of operating firms. At the firm level, instead of $q$, each firm's production would be $q(1-\tau)$ in a context with corruption. While $\tau>0$ implies that corruption is like a tax, $\tau<0$ implies that corruption is a subsidy to the firm. In the context of public procurement, $\tau>0$ may indicate a firm that pays extra costs of doing business with the government (e.g., bribes), while $\tau<0$ may indicate a firm that faces less bureaucratic barriers and delays. Heterogeneity in $\tau$ across firms would be indicative of misallocation in the local economy. ${ }^{19}$

Within this setting, we can leverage the randomized audits to identify the channels linking corruption and firms. For this purpose, a key assumption is that audits reduce corruption frictions $\tau$, i.e., $|\tau| \downarrow$. This assumption that audits are effective is supported by the findings of Avis et al. (2018), who show that audits lead to a reduction of severe corruption irregularities, while less severe mismanagement irregularities are unaffected. As a result, if we were to find that lower corruption levels lead to lower (higher) economic activity, this would indicate that the ability of firms and officials to engage in illegal interactions helps (hinders) the local economy.

5.2. Main Results: Audits, Corruption, and Firms. Motivated by our conceptual framework in Section 5.1, our analysis starts by focusing on the average effect of the audits as a baseline test for theories of efficient corruption. We study the impact of anti-corruption audits using the total number of private sector business establishments and the total number of private sector firms as primary outcomes, which we express in logarithmic terms. ${ }^{20}$

We first explore the dynamics in the raw data for our main outcome variables. Panels $\mathrm{A}$ and $\mathrm{D}$ of Figure 3 display the raw data over the window of $[-4,12]$ quarters around the audit, where we de-mean the variables by their average value over the four quarters leading up to the audit. The figures provide a visual test for our identification strategy, as we observe parallel trends in the pre-period for both our measures of business establishments and firms. The raw data also illustrate the positive impact of the audits. We explicitly plot the difference between the treated and control outcomes in Panels B and E, which highlight the widening gap in quarters after the audit takes place. We then identify these dynamics more precisely by plotting the point estimates obtained from the estimation of equation 4.1, as in Panels $\mathrm{C}$ and $\mathrm{F}$ of Figure 3. The figure shows that pre-trends are parallel in our preferred baseline

\footnotetext{
${ }^{19}$ For the sake of brevity, we leave the details of this standard model to Appendix A.2. In Section 5.4 , we use the model to better quantify the economic effects we uncover.

${ }^{20}$ Unless otherwise specified, before taking the logs, the raw variables are winsorized at the $0.5 \%$ of the empirical distribution to reduce the impact of outliers.
} 
event study specification as well, with the positive effect of the audits materializing gradually over the 12 quarters after the audit.

We interpret the magnitude of the findings by estimating the parametric eventstudy equation 4.2, reported in Table 3 . We see that the audits have a positive and statistically significant impact on both outcome measures: columns 1 and 2 show an increase of around $1 \%$ in response to the audit. The magnitudes and dynamics for both establishments and firms are extremely similar, as in practice we see that most firms in these local economies are single-establishment firms. These similarities also indicate that the effects are primarily driven by an increase in singleestablishment firms rather than a reallocation of activity across municipalities by large, multi-establishment ones.

5.2.1. Lower Corruption Leads to Growth in Government-Dependent Sectors. A key prediction of a framework whereby audits affect firms by reducing corruption levels is that sectors more exposed to government interactions should be more affected. We therefore enrich the main analysis by showing how the audits impact different sectors of the local economy. The importance of differential exposure to corrupt officials across sectors and firms is lucidly illustrated in one of the first studies of firm-level corruption by Svensson (2003). We measure firms' exposure to corruption in local governments using the information on the four-digit industry of each firm and by proposing two definitions of "government-dependent" (GD) sectors. Both definitions are based on the distribution of the data across the entire country to avoid endogeneity and reverse causality concerns if only municipality information was used.

First, given the importance of public procurement for local public spending and its pervasiveness in corruption cases uncovered by the audits, we create a measure of procurement intensity. We believe this is an obvious measure of the extent of interactions between firms and the government. Notice that, ex-ante, audits target all usage and spending of federal resources by the local municipality, and not just the funds disbursed through public procurement (Ferraz and Finan, 2008, 2011; Brollo et al., 2013). Using data on the universe of federal procurement contracts over the 20002014 period, we create the distribution by sector of awarded contracts, scaled by the total number of establishments within each sector -we define as "GD-Procurement" those sectors that are above the median of this distribution.

Second, we leverage the richness of the data in the audit reports to create a direct measure of industry exposure to local corruption. Using the data constructed by Colonnelli et al. (2020b) on firms directly involved in corruption irregularities, we 
identify the sectors of firms involved to any extent in an irregularity appearing at any point in the audit reports, and we define as "GD-Corrupt" those sectors that are above the median in terms of the number of irregularities over the number of establishments. This measure not only captures procurement irregularities but also other instances of corruption in interactions between firms and local governments (e.g., business licenses and construction permits).

Overall, out of a total of 622 sectors in the data, we have 311 and 177 four-digit GD-Procurement and GD-Corrupt sectors, respectively, with an overlap of 126 of them and a correlation of 0.27 (Appendix Table A1). The top three examples of GDProcurement are related to the wholesale retail of medical products and equipment, and office supplies, while in the case of GD-Corrupt, they are related to the wholesale retail of pharmaceutical products, maintenance and repair of railway vehicles, and road construction. In Table A2 and Table A3, we compile the ranked full lists of the top 50 and bottom 50 of GD-Procurement and GD-Corrupt sectors, while additional summary statistics on the size of these sectors are in Table 1.

In columns 3-10 of Table 3, we find the results are stronger and fully concentrated among government-dependent firms, consistent with the audits primarily affecting firms that strongly depend on government relationships. Depending on which GD definition we use, we observe an increase of $1.2-1.4 \%$ in the number of firms in GD sectors, compared to a zero and insignificant effect in non-GD sectors. ${ }^{21}$ Importantly, Figure 4 provides further support of our empirical strategy, as it shows that treated and control municipalities also follow parallel trends in the dynamics of GD sectors in the period leading up to the audit.

The above results strongly support public procurement's central role in explaining our findings. However, testing directly for the impact of audits on the local procurement market requires data on the universe of municipal contracts between firms and audited municipalities, which are not available for our full sample. We can offer further supporting evidence focusing on the state of Sao Paulo, which provides yearly data on local procurement contracts for all of its 644 municipalities starting in 2008. The analysis in Table A4, based on the estimation of equation 4.2, shows results that are consistent with our previous findings. We find an overall increase in the number of firms obtaining procurement contracts from the local municipality that is similar in magnitude to our average main effect, namely $1.3 \%$, even though the estimate is

\footnotetext{
${ }^{21}$ The differences across sectors are statistically significant at different levels depending on the specification, as reported by the p-values in the table, with the exception of GD-Corrupt firms where the difference is marginally insignificant.
} 
not statistically significant. On the other hand, we find large positive and statistically significant effects of the audits on the number of firms that have never done business with the specific municipality $(5.7 \%)$, and on the number of firms that have never engaged in local public procurement prior to the audit (8.6\%). These findings indicate corruption as an important barrier to entry for firms into the market for government contracts. While the local procurement results of Table A4 are more suggestive than our primary analysis - given that they are based on a shorter panel for only one state--, they lend additional support to one specific channel: audits reduce corruption in local public procurement interactions, thereby allowing more firms to provide goods and services to the municipality and to operate profitably.

In sum, our main findings indicate that corruption is an important friction to the growth of the local economy because it limits the number of firms operating in sectors that are most exposed to interactions with government officials and politicians. Within the context of our stylized framework, the evidence points to corruption acting like a tax on firms in government-dependent sectors. Such evidence is therefore largely inconsistent with long-standing "efficient corruption" arguments, which state that corruption may be beneficial for firms that operate in second-best contexts plagued by red tape and unnecessary regulations (Leff, 1964; Huntington, 1968).

5.2.2. Additional Measures of Economic Activity. Our main results rely on the number of firms and business establishments as primary outcome measures. While it would be important to additionally observe measures of firms' output and value added, these measures are unavailable for the full set of firms in Brazil. However, we can leverage yearly outcome data from the administrative firm censuses PAC (Retail) and PAS (Services) and from the Brazilian Central Bank, which we introduced in Section 3. Table 4 reports the results from the estimation of equation 4.2 using additional outcome variables from these datasets, which are all generated by different agencies for different purposes and capture a different dimension of economic output than just the total number of firms.

In column 1 of Table 4 we find that, after the anti-corruption audits, total revenues generated by local firms increase by approximately $6.2 \%$. Similarly, investment rates (i.e., the share of capital expenditures over total assets) increase by a sizable $14.8 \%$, even though this coefficient is not statistically significant (column 2). A caveat of this analysis is that the sample is different from the main RAIS sample, as discussed in 
Section 3.2. ${ }^{22}$ In Table A5, we show that our main results hold, and if anything are slightly larger in magnitude, when we restrict the sample to firms that have at least 20 employees, so as to overlap with the PAC and PAS databases.

With the same goal of measuring economic activity more broadly, in columns 3 and 4 of Table 4 we explore the impact of the audits on the two primary measures of financial development collected by the Central Bank, namely the total volume of local credit to firms and individuals and the total deposits by firms and individuals in local bank branches. In both cases, we find an increase of approximately $2.4 \%$ and $3.2 \%$, respectively, in the three years after the audit takes place.

5.2.3. Robustness. We probe the robustness of our main results to various alternative specifications in Appendix Table A6. In Panel A, we show that the impact of the audits on total number of firms is also positive and statistically significant when we make no time restriction on the estimation window (columns 1 and 2), and when we exclude all municipalities audited more than once (columns 3 and 4). Additionally, given the slight changes in eligibility requirements in the first two years of the program, and the drop in program intensity in the last three years, we also show that our results hold when excluding years 2003 and 2004 (columns 5 and 6), and when excluding years 2012, 2013, and 2014 (columns 7 and 8). In Panel B of Appendix Table A6, we also show that the effects are robust to the estimation within the sample of just audited municipalities (columns 1 and 2), and to not winsorizing the dependent variables (columns 5 and 6), or winsorizing at the $5 \%$ level to drop a larger set of potential outliers (columns 7 and 8). In columns 3 and 4 of Panel B, we also show that our results are essentially unchanged when we add a control for the municipalitylevel implied probability of being audited in the given year-quarter. In terms of magnitudes, we find that the estimated effects of these alternative specifications are often larger than the baseline effects of Table 3 .

An additional set of robustness tests refer to our definitions of government dependence (GD). We create six additional measures using both the federal procurement data and the corruption measures. ${ }^{23}$ We show the correlation matrix across all eight

\footnotetext{
${ }^{22}$ Specifically, the analysis of Table 4 relies on a sample of 2,929 municipalities, 750 of which were audited. Within this sample, each eligible (audited) municipality has an average of 31.2 (30.8) firms appearing in PAC and PAS in a given year.

${ }^{23}$ Reliable value measures (e.g., size of the contract) are only available for the procurement data. Therefore, the first three additional measures we create are analogous to the main GD-Procurement measure. However, we do not scale by number of firms in the sector (GD-Procurement-NS), and we use total value rather than number of contracts (GD-Procurement-Value-S and GD-ProcurementValue-NS for the scaled and unscaled version, respectively). The fourth measure is the baseline
} 
GD measures in Appendix Table A1. Consistent with our main findings, even though the differences are not always statistically significant, Table A7 shows that the effects are mostly concentrated in GD sectors, as also reflected in the dynamic point estimates of Appendix Figures A2 and A3.

5.3. Mechanisms. In this section, we discuss the mechanisms through which audits affect corruption, and in turn firms. ${ }^{24}$ As outlined by Olken and Pande (2012), following the intuition behind standard models of crime (Becker, 1968; Becker and Stigler, 1974), anti-corruption audits are typically designed with a dual objective. On the one hand, they can reduce corruption by detecting malfeasance through the physical investigation of public expenditures, which might lead public officials to be replaced or to change behavior. On the other hand, audits can lower corruption even without any direct action, thanks to their deterrence effect. That is, the mere salience of an audit program raises the threat of anti-corruption enforcement for all public administrations that might be subject to the audit, as illustrated for example in the seminal study by Olken (2007). The difficulty and importance of disentangling the direct (or detection) and indirect (or deterrence) effects of anti-corruption programs on the real economy is at the core of the policy debate on best practices to fight corruption (Dye, 2007; Hanna et al., 2011; TransparencyInternational, 2018).

5.3.1. Direct Effects and The Role of Political Incentives. By design, our baseline empirical setting is better suited to capture the direct effects of the audits. In fact, when the program was announced in 2003, all municipalities in Brazil were subject to an increased audit threat. Therefore, a key deterrence component of the audits cannot be isolated, and the average effects we estimate in Section 5.2 are likely underestimating the true effects of the program.

A leading explanation for why the direct experience of an audit might have an effect is the presence of political incentives, as outlined by several standard political agency models and a large literature on the importance of political institutions to limit rentseeking (Persson and Tabellini, 2002; Besley, 2007). Audits may have an impact on political selection because they lead to an overall better pool of candidates (Ferraz and Finan, 2008; Cavalcanti et al., 2018). Moreover, audits may have a disciplining

measure of GD-Corrupt, but without scaling by the number of firms (GD-Corrupt-NS). The fifth (scaled by number of establishments in the sector) and sixth (unscaled) versions are created using the sectoral distribution in terms of number of unique firms involved in corruption cases (rather than number of irregularities).

${ }^{24}$ To improve the readability of the output in this and the next sections, we use only the total number of firms as a dependent variable, rather than both firms and establishments. 
effect because mayors may be up for re-election and thus have an incentive to reduce corruption after an audit (Ferraz and Finan, 2011).

One approach to test for the relative importance of selection and disciplining channels is to study how our effects vary across the electoral cycle. ${ }^{25}$ If disciplining channels dominate, we should expect audits to have a stronger effect when they occur late in a mayor's term because the malfeasance can be more directly linked to the current administration (since audits cover mostly the previous two years of municipal expenses), and when the mayor is in her first term and up for re-election. Selection channels, on the other hand, do not predict a strong heterogeneity on these margins and have more ambiguous predictions. ${ }^{26}$

We test for these differential effects in Table 5, where we rely on additional data on local elections and politicians described in Section 3.3. In Panel A, we show results on the effects of audits that take place in the first half of the mayor's electoral term, while Panel B focuses on audits in the second half of the electoral term. That is, Early Years indicate audits that take place in the first two out of the four years of a typical mayoral mandate, which comprise $56 \%$ of all audits. In contrast, Final Years refer to audits that occur in the last two years during which a mayor is in power in a given electoral term. In this split-sample analysis, we find a statistically significant impact of the audits only when the mayor is near the end of her term, while the effect is positive but insignificant otherwise. We report a similar analysis in Panels $\mathrm{C}$ and $\mathrm{D}$ of Table 5, where we split the sample depending on whether the audit occurs at a time in which the mayor is in her first (Panel C) or second (Panel D) term. We find a positive and statistically significant effect concentrated in a mayor's first term, i.e., when she is up for re-election.

We interpret the evidence in Table 5 as suggestive of an important role played by the audits' disciplining consequences. However, this evidence is not conclusive, as the differences across the various sub-samples are largely not statistically significant (as reported by the p-values at the bottom of the table). In fact, the results indicate a

${ }^{25}$ Notice that Brazil has a two-term limit, with each term lasting four years. Three-fourths of the audits target first-term mayors.

${ }^{26}$ We refer to Bobonis et al. (2016) and Avis et al. (2018) for a detailed discussion on the selection and disciplining effects of anti-corruption programs. 
widespread positive impact of audits, as also reflected in the event study plots in Appendix Figures A4 and A5 displaying noisy but consistently positive point estimates that materialize right after the audit. ${ }^{27}$

One additional approach to isolate these channels would be to focus on municipalities that change mayor or party in power after the audits, as in such a case the effects would necessarily be driven by selection. The problem with this analysis is that a large body of previous work, starting with Ferraz and Finan (2008), shows that audits affect political outcomes, therefore making this split endogenous. Nevertheless, we provide largely suggestive evidence along these lines in Appendix Table A8, where we report the analysis splitting the samples based on the political consequences of the audits. In short, we find larger and significant estimates in areas where there is no change of mayor or party, consistent with the relevance of a disciplining channel. Yet, the point estimates are once again largely positive throughout, and most differences are not statistically significant.

Together, the evidence in this section points to both selection and discipline effects being likely determinants of the effects of the anti-corruption program on firms, an interpretation consistent with the structural estimates by Avis et al. (2018). ${ }^{28}$

5.3.2. Indirect Effects and the Deterrence Impact of Audits. While the previous analysis indicates that direct anti-corruption effects driven by political incentives matter, an additional explanation for the positive average effects we observe is that the direct experience of an audit raises the salience, and therefore the threat, of future audits. We can use this intuition to disentangle the deterrence impact of audits, by relying on the unique features of the institutional context we study.

We hypothesize that, even after the program announcement in 2003, audits are not fully salient to mayors, but they become more salient after their municipality or a nearby municipality experiences an audit. There are two main arguments in support of this hypothesis. One, mayors may not be perfectly informed about audit probabilities, because they do not know in advance the details of a specific lottery taking place and because the likelihood of future lotteries changes significantly from round to round. Two, mayors might not know the costs and consequences of an audit,

\footnotetext{
${ }^{27}$ Analyzing the differences across sectors paints a similar picture. We find that the positive effects are mostly concentrated in government-dependent sectors, with larger estimates late in a mayor's term or in the first term when a mayor is up for re-election.

${ }^{28}$ Avis et al. (2018) focus on the small set of municipalities audited more than once and estimate a structural model to disentangle the various channels, finding that several mechanisms are relevant. They also further point to the key role played by legal consequences that discipline the mayor to behave better.
} 
considering that this was the first anti-corruption program of its kind targeting local governments. In both cases, the own or nearby experience of an audit leads mayors to update their beliefs about audit risk, which might affect corruption through an indirect deterrence effect. These arguments are consistent with several political economy papers studying anti-corruption audits of local governments, such as Bobonis et al. (2016), Zamboni and Litschig (2018), and Avis et al. (2018). A testable implication of this framework is that, for the audits to have a deterrence effect, we should observe spillover effects of an audit onto nearby municipalities which are not directly audited.

We proceed in two steps. First, we isolate spillover effects onto nearby municipalities that are not subject to any audit. Because mayors in nearby non-audited municipalities do not face any direct consequence in terms of legal or electoral punishment, such spillovers only capture the deterrence effects of audits. Second, we re-estimate the impact of audits on the audited municipalities after removing from the control group nearby municipalities. By doing so, the estimated effects will include both the direct and indirect effects of the audits, thus better identifying the policy-relevant impact of the program.

To identify spillovers, we rely on the geographical categorization of Brazil into 5,570 municipalities and 558 micro-regions, which the national statistical agency (IBGE) defines as the best approximation of a local market. Hence, we define as "neighboring" all municipalities in the same micro-region of an audited one, and we study how audits affect neighboring municipalities. More specifically, we study the impact of the audit of one or more municipalities, in a given micro-region, on all other municipalities that are not audited and are in the same micro-region. The control group consists of municipalities in micro-regions that are audited later or that are never audited. ${ }^{29}$

We report the results of our spillover analysis in Panel A of Table 6. We uncover the presence of large spillover effects in column 1, as a nearby audit has an impact on non-audited municipalities that is similar in magnitudes to our baseline effects, i.e., a $1.2 \%$ increase in the number of firms. Importantly, we also split the effects by government-dependent versus other sectors (columns 2 to 5 ). There is suggestive evidence that spillover effects are concentrated primarily in government-dependent sectors. In particular, we see a positive $2.1 \%$ impact in GD-Procurement sectors, which is statistically different than the zero spillovers we observe in non-GD-Procurement sectors, as illustrated by the p-values at the bottom of the table. On the other hand,

\footnotetext{
${ }^{29}$ We only consider a micro-region to be treated the first time one (or more) of its municipalities is randomly drawn to be audited.
} 
while the results are qualitatively similar, we do not find a significant difference in the split of GD-Corrupt sectors.

Showing that spillover effects are quantitatively meaningful indicates that the deterrence role of audits is a crucial mechanism via which the anti-corruption program affects firms. Therefore, with the goal of capturing the impact of audits that includes both its direct and indirect effects, we re-estimate our main equation 4.2 accounting for spillovers. We do so in Panel B of Table 6, where we remove from the main estimation sample all never-audited municipalities who ever neighbor an audited one, thus effectively making our estimates relative to a group of municipalities that was plausibly not affected by the audit in neither a direct nor an indirect way. As expected, we find the effects of audits on the number of operating firms to be strong and positive. After an audit, the number of private sector firms increases by $2.2 \%$ on average (column 1), by $3 \%$ in GD-Procurement sectors, and by $2.5 \%$ in GD-Corrupt sectors. ${ }^{30}$ Consistent with our hypotheses, these effects are larger than both the spillover effects of Panel A and the average effects of audits we identified in Section 5.2. Even though Table 6 does not allow for a precise decomposition, since the samples change across specifications, a rough comparison of the main spillover estimate $(1.2 \%$, as per column 1 of Panel A) and the main full estimate (2.2\%, as per column 1 of Panel B) suggest that audits operate in equal parts through a direct, or detection, and an indirect, or deterrence, effect.

Taken together, our evidence suggests that a comprehensive analysis of the anticorruption program should account for both direct and indirect effects. This point is related to that of Lichand and Fernandes (2019), who focus on the state of Sao Paulo over 2011-2015 to highlight the importance of estimating spillover effects in a context where government vendors provide goods and services to multiple municipalities. Our findings suggest that once accounting for general equilibrium effects, if anything, the main effects of the CGU program would be larger than what the estimates from Section 5.2 suggest.

5.4. Economic Magnitudes. Given the relevance of the audit program for policy, and in light of the heated debate over the need for and effectiveness of anti-corruption policies around the world, it is important to provide an economic interpretation of the magnitudes of our results and to benchmark them to related studies.

\footnotetext{
${ }^{30} \mathrm{As}$ reported at the bottom of the table, the effect in government-dependent sectors is statistically different from the effect in other sectors, at the $2 \%$ and $8 \%$ level, for GD-Procurement and GDCorrupt sectors respectively.
} 
Our baseline approach consists of computing local value added multipliers similar to the literature on fiscal spending multipliers. ${ }^{31}$ The motivation behind this approach is that, in our context, corruption mostly acts as a way for politicians to steal or divert local funds, and the CGU anti-corruption program aims at limiting such wasteful activity. Importantly, Avis et al. (2018) show that - for a given municipality in a given year- CGU audits lead to a reduction of approximately $\$ 110,000$ in local spending that is affected by corruption. We can therefore use this number to compute an "anticorruption multiplier" based on the extra value added the audits generate according to our findings. ${ }^{32}$ Similarly, Zamboni and Litschig (2018) estimate that the direct cost from a CGU audit (i.e., including only transportation costs, salaries, and per diem for the auditors) is approximately $\$ 50,000$, which allows us to also compute a "cost-benefit multiplier."

We start by estimating the value added generated by a given firm in our sample using two widely used sources of data. First, we rely on the aggregate value added data from the Brazil's socio-economic accounts of the World Input-Output Database (WIOD) and the Brazilian Statistical Institute (IBGE). Using these two sources of data, we obtain estimates of value added for the median firm in a municipality eligible for the CGU program of $\$ 96,000$ and $\$ 71,000$, respectively. ${ }^{33}$ Given the average increase in the number of firms caused by the audits, this implies an average of $\$ 216,959(\$ 160,459)$ extra value added per municipality in a given year after the audit using the WIOD (IBGE) measure. ${ }^{34}$ As a result, we find by relying on the WIOD (IBGE) estimate that one less dollar linked to corruption generates an anticorruption multiplier of 1.97 (1.46) dollars of local value added, obtained by dividing the extra value added by the $\$ 110,000$ reduction in corruption. ${ }^{35}$ We can alternatively compute cost-benefit multipliers, rather than anti-corruption multipliers, by using the estimated cost of an audit $(\$ 50,000)$ as the denominator (instead of $\$ 110,000)$. In

\footnotetext{
${ }^{31}$ See Chodorow-Reich (2019) for a review of this literature.

${ }^{32}$ The dollar amount is obtained by converting the $\mathrm{R} \$ 355,000$ in Avis et al. (2018) to USD for the sample period under study. "Local spending affected by corruption" refers to the amount of federal funds that are audited and that are found to be diverted because of moderate or severe corruption irregularities. Mismanagement irregularities that do not impact the actual local spending are excluded.

${ }^{33}$ Notice that the WIOD and IBGE data are representative at the industry and state level, and more details are provided by Timmer et al. (2015) and at https://www.ibge.gov.br/estatisticas/ economicas/contas-nacionais/9088-produto-interno-bruto-dos-municipios.html?=\&t= o-que-e, respectively.

${ }^{34}$ We compute the extra value added as $\$ 216,959=\$ 96,000 * 251.11 * 0.009$ and $\$ 160,459=$ $\$ 71,000 * 251.11 * 0.009$, respectively.

${ }^{35}$ That is, $\$ 216,959 / 110,000=1.97$ and $160,459 / 110,000=1.46$.
} 
this case, the multipliers would be 4.33 and 3.21 , respectively. ${ }^{36}$ We report all these estimates in Table 7.

In Table 7, we also report a version of the anti-corruption and cost-benefit multipliers that account for geographic spillovers, that is using the estimates from Panel B of Table 6 documented in the previous section. Given the larger effect of the audit program after accounting for spillovers, we find our anti-corruption multipliers increase significantly to 4.82 (WIOD) and 3.57 (IBGE) ${ }^{37}$ Similarly, the cost-benefit multipliers approximately double once we rely on the impact of the audits that excludes nearby municipalities.

To better interpret these magnitudes, we benchmark them to previous studies. By focusing on Brazilian municipalities like we do, Corbi et al. (2019) show that federal transfers to municipalities generate a local multiplier of around 2, which they compute using a methodology proposed by Chodorow-Reich (2019). In Table 7, we also report our multipliers computed using the exact same methodology, and we find an anticorruption multiplier of 2.09 and a cost-benefit multiplier of $4.60 .{ }^{38}$ Other estimates of local multipliers from previous studies surveyed by Chodorow-Reich (2019), which mainly focus on richer countries, range from 1 to 2.5. A particularly close example to our own is the study by Acconcia et al. (2014), who focus on a related context of Mafia-affected municipalities in Italy and find a multiplier of around 1.9.

In sum, the fact that our estimates of local multipliers are in line with other studies of local fiscal multipliers is indicative of corruption being extremely damaging to the local economy. Some of our estimates, namely those that account for spillovers, are considerably larger, which may be consistent with corruption inducing not only a theft of public funds, but also additional potential distortions in the local economy.

We conclude the analysis of magnitudes using the stylized model of firm heterogeneity that we report in Section A.2. We can calibrate this model to put bounds on the average corruption tax that would be needed to rationalize our empirical results. Depending on the specific empirical estimate we use, as discussed in Appendix

\footnotetext{
$\overline{36}$ Notice that the $\$ 50,000$ estimate only accounts for the costs of the actual audit process, but excludes the extra legal costs that may be needed for the audits to be effective, as these latter costs are difficult to determine.

${ }^{37}$ Specifically, the extra value added in this case would be computed as $\$ 530,344=\$ 96,000 *$ $251.11 * 0.022$ and $\$ 392,234=\$ 71,000 * 251.11 * 0.022$, respectively. As a result, the multipliers are $\$ 530,344 / 110,000=4.82$ using the WIOD data and 392,234/110, $000=3.57$ using the IBGE data. ${ }^{38}$ The methodology by Corbi et al. (2019) assumes a neoclassical production function that is parameterized using estimates of capital share, elasticity of hours to total employment, and the ratio of income to output per worker from the literature. For brevity, we refer to their paper for more details on their approach.
} 
subsection A.7, the model predicts the presence of an average corruption tax in the range of 5\%-23\% (Table A21). While this computation relies on a host of model assumptions, interestingly the magnitude is similar to other studies that measure bribes and corruption costs for firms in other contexts. For example, Svensson (2003) find that firms in Uganda pay an average of $8 \%$ of total costs in bribes, Olken (2007) show that $24 \%$ of expenditures for road construction projects in Indonesia go missing, Olken and Barron (2009) show that truck drivers in Indonesia incur illegal payments that amount to $13 \%$ of their total costs for each trip, Sequeira and Djankov (2014) find bribes amount to $14 \%$ of total shipping costs in Mozambique, and Decarolis et al. (2019) uncover that 17\% of public works contracts in Italy are awarded to investigated firms.

\section{Additional Results}

In this section, we collect a set of additional results that further characterize our findings. First, we show how our effects vary depending on the amount of corruption detected by the audits. Second, we discuss a few possible alternative explanations for our findings. Third, we report the results of a firm-level analysis where we study the heterogeneous effects of the program across firms within audited municipalities.

\subsection{Heterogeneous Effects By Amount of Corruption Detected. Our find-}

ings show that anti-corruption audits lead to more firms in government-dependent sectors. For our results to imply that corruption acts as a barrier to local economic growth, an implicit assumption is that audits are effective at detecting and therefore reducing corruption, as shown by Avis et al. (2018). However, it is plausible that not all audits are effective, and several studies highlight the importance of capturing such heterogeneity. ${ }^{39}$ More generally, for both direct and indirect effects of audits to be at play, we would expect our findings to be concentrated in areas where high levels of corruption are detected.

We report these heterogeneous effects of the audits for the main results, the main results excluding spillovers, and the spillover results in Appendix Tables A9, A10, and A11, respectively.

\footnotetext{
${ }^{39}$ For example, Fenizia and Saggio (2020) show that an aggressive crackdown on Mafia-infiltrated local administrations can have significantly larger effects than policies (like the one we study) that target all regions independently of existing levels of malfeasance. More broadly, as Olken and Pande (2012) state in their review paper, "just because people are audited does not necessarily mean that auditors will find enough evidence to actually impose a punishment, even if corruption was taking place."
} 
Appendix Table A9, Panel A, reports the heterogeneous effects estimated using the interacted specification 4.3. We capture the amount of corruption detected in each audit using the number of irregularities uncovered scaled by the number of firms at the time of the audit. ${ }^{40}$ We find that the positive effects of the program are large and fully concentrated in municipalities with above-median levels of corruption detected. Perhaps surprisingly, we find a $2.3 \%$ negative and significant impact of audits in municipalities where little or no corruption is detected, as captured by the PostAudit coefficient in the regression. The estimates in columns 2-5 confirm our earlier findings that effects are mainly concentrated in government-dependent sectors. One caveat with this analysis is that while audits are random, the amount of corruption detected is not. To alleviate these endogeneity concerns, we therefore also report a version of this specification where we predict using machine learning which municipalities are ex-ante more likely to have high levels of corruption detected. ${ }^{41}$ As shown in panel B of Table A9, we find that municipalities with average predicted levels of corruption detected experience an increase of $0.8 \%$ in the number of firms, with the interacted coefficient once again indicating a high degree of heterogeneity. ${ }^{42} \mathrm{We}$ conduct an analogous analysis in Appendix Table A10 accounting for spillovers, i.e., removing nearby non-audited municipalities from the estimation sample following the methodology of Section 5.3.2. We again uncover a large degree of heterogeneity across municipalities, even though the negative effects in areas with little to no corruption are considerably weaker when spillovers are accounted for.

The results in Appendix Tables A9 and A10 suggest that audits impact real outcomes only to the extent that they are able to detect corruption in the first place. If anything, our findings show that detecting little to no corruption may even backfire. Understanding the specific reasons why certain audits may backfire is beyond the scope of our paper. One possible explanation for these heterogeneities is that priors matter, and that failure to detect corruption in areas perceived to be corrupt may

\footnotetext{
${ }^{40}$ The number of irregularities, as discussed in Section 3, is obtained directly from the CGU. Since the CGU construct these measures only starting in 2006, we compute the number of irregularities in the 2003-2005 audits using the manually constructed data in Colonnelli et al. (2020b).

${ }^{41}$ Specifically, following the approach of Colonnelli et al. (2020a), we estimate a LASSO model using a set of 147 municipality characteristics and a ten-fold cross-validation to find the parameter that best fits the data. We then standardize the predicted probability by subtracting its mean and dividing by its standard deviation.

${ }^{42}$ Using numbers from the empirical distribution of the standardized share in the data, we can compute that municipalities with predicted levels of detected corruption in the bottom 10th percentile of the distribution experience a negative effect on total firms of $4.3 \%$. On the other hand, we observe an increase of $6.6 \%$ for municipalities in the top decile of the distribution.
} 
lead to perverse consequences. ${ }^{43}$ Another possibility is that audits have unintended consequences because they distort the behavior of honest local administrations. ${ }^{44}$

We further investigate the importance of detecting corruption in Appendix Table A11, where we estimate how geographic spillovers vary depending on the intensity of anti-corruption activity in nearby areas. In Panel A, we illustrate how spillovers vary depending on the share of nearby municipalities that are audited, which is an immediate proxy of the strength of deterrence. ${ }^{45}$ We find spillovers to be higher the higher the share of nearby municipalities that are audited. As shown by the PostAudit coefficient, a municipality in a microregion with an average share of audited municipalities sees an increase of $2 \%$ in the number of firms, while a one-standard-deviation increase in that same share is associated with a $1.8 \%$ increase in firms. We do not observe much heterogeneity across sectors using this specification. Panel B provides a similar analysis using a standardized heterogeneity share measure for the quantity of corruption detected in the micro-region, with largely similar findings. ${ }^{46}$ Importantly, unlike the previous analysis, we do not find any backfiring effects in the analysis of spillovers. For example, Panel B indicates that the spillover effects in the micro-region with the lowest amount of corruption detected are still positive. ${ }^{47}$

6.2. Alternative Explanations. In addition to reducing corruption, the audits may have additional effects on firms through other channels. We identify three main alternative explanations.

6.2.1. Litigation Activity and Short-Lived Effects. First, audits may have knock-on effects on local firms due to the litigation activities they may trigger. For example, the effects we observe may be driven by an increase in the number of law and consultancy services following audit-generated litigation.

\footnotetext{
$\overline{43}$ For example, experimental evidence by Arias et al. (2018) in Mexico lends support to this explanation in the context of politicians' malfeasance and voter learning. Cavalcanti et al. (2018) study our same CGU program and show that detecting little corruption justifies political parties to present a pool of politicians that is of lower quality.

${ }^{44}$ For instance, audits may lead politicians to under-spend or they may discourage them to use audit-sensitive but potentially efficient procurement procedures, as shown by Lichand and Fernandes (2019) and Gerardino et al. (2017), respectively.

${ }^{45}$ We standardize the share by its average and standard deviation.

${ }^{46}$ For consistency with the analysis in Appendix Tables A9 and A10, we measure amount of corruption by the total number of irregularities detected, scaled by the number of firms in the micro-region at the time of the first audit.

${ }^{47}$ To see this, notice that the minimum value for the standardized share in the data is -.3841059 , and therefore the minimum spillovers would be equal to $0.014+0.016 *(-.3841059)=0.0079$.
} 
We test for this alternative explanation directly in Table A12, where we show that the impact of audits on firms cannot be accounted for by activity in litigation-related sectors. Specifically, we compute our outcome variables after excluding various sectors covering the legal activities (Panel A); legal, accounting, and auditing activities (Panel $\mathrm{B})$; legal, accounting, auditing, and management activities (Panel C); and the full service sector (Panel D). ${ }^{48}$ Our results are mostly unaffected by these exclusions, suggesting that the litigation activity potentially triggered by the audits is unlikely to drive our effects.

Moreover, we would expect mechanical effects driven by litigation and related activities to be short-lived. Hence, in Table A13, we re-estimate our main specification expanding the estimation window to six and ten years after the audits. The table shows a positive and significant effect for both longer-term windows, with a gradual increase in the magnitude of the effects.

6.2.2. Informality. A second potential alternative explanation is that audits generate a behavioral response by the local informal sector. That is, informal firms may associate anti-corruption audits with a higher risk of tax audits and respond by formalizing their business (Bologna Pavlik and Harger, 2018). This would lead to more firms being registered in our main dataset (RAIS). Anecdotal evidence and discussions with CGU officials suggest this is likely a minor concern, as anti-corruption audits are not used by the tax collection agency. Moreover, it is unlikely a firm's move away from the informal to the formal sector would account for the increase in economic activity observed through datasets such as those by the Central Bank and the Statistical Institute, as shown in Table 4. Nevertheless, conclusively testing for informality patterns using administrative data is not possible. In this section, we provide a few tests to better gauge the extent of this issue.

First, we study how the number of firms changes in response to the audits depending on the pre-existing levels of informality. In Table A14, we find that the positive effects of the audits are significantly stronger in areas with higher shares of informality. This analysis, while purely descriptive due the fact that pre-existing informality correlates with several other characteristics of the local economy, suggests that the informal sector might play a role in our context. ${ }^{49}$

\footnotetext{
${ }^{48}$ Specifically, Panel A excludes CNAE 69117, Panel B excludes CNAE 69, Panel C excludes CNAE 69 and 70, and Panel D excludes all the CNAE codes related to the services sector.

${ }^{49}$ Table A14 reports our main results obtained from the estimation of the interacted specification 4.3. The interaction variable is the standardized share of informal over formal employment, computed using the 2000 Decennial Census described in Section 3.
} 
We therefore attempt to provide more direct tests in Table A15, where we rely on surveys of informality from the National Household Survey (PNAD). These surveys include counts of informal and formal employment, which we impute at the municipality level as discussed in Section 3. Table A15 shows that both such outcome measures increase. Under the assumption that people only work in either the formal or informal sector and that overall employment is increasing, the evidence in Table A15 would indicate that our results are unlikely to be driven by a shift from the informal to the formal sector, since that would imply that informality should shrink. ${ }^{50}$

We provide a further qualitative analysis by manually reading through all the audit reports to identify firms that were involved in irregularities and were informal the year the audit took place. We identify 4,259 such firms. ${ }^{51}$ We then match these firms to our administrative data to analyze whether they become formal in the years after the audit. We find that only a small fraction of these firms, that is a total of 94 firms across the entire country, register their business in the three years after the audit.

Overall, our evidence regarding informality remains suggestive due to data limitations, and future work in contexts better suited to the analysis of informality is needed to fully pin down the link between anti-corruption activity and the informal sector.

6.2.3. Reaction by the Central Government. A third alternative explanation for why we observe more firms after an audit is that the federal government may react positively, expecting improved outcomes after cracking down on corruption, and thus channeling more resources locally. This is a relevant concern to account for in Brazil, where a significant amount of municipal resources are linked to transfers from the federal government (Brollo et al., 2013).

Since the main source of federal support to municipalities consists of transfers and block grants from the central government, we can test for this directly using municipality-level data from the CGU and the National Treasury. In Appendix Table A17, we find no evidence that municipalities experience a higher inflow of various

${ }^{50}$ In Table A16, we report the results on employment using RAIS. We find that while positive and similar in magnitudes to our effects on firms, we do not see a significant impact of audits on employment within three years. However, we observe a positive and significant effect when we extend the window to longer horizons of six and ten years. Table A16 also shows little effects on firm hiring and firing decisions, with larger effects on the hiring margin.

${ }^{51}$ Auditors are instructed by CGU to always report the tax identifier (CNPJ) of firms when compiling the reports. If the firms are not registered as formal firms, then the auditors are instructed to report the firm name. Hence, we search for informal firms by looking for all synonyms of the word "firm," and by then manually verifying all such cases and collecting data on the confirmed informal firms. 
federal transfers (columns 1, 2, and 3) nor of block grants or their share that is disbursed (columns 4 and 5) after the audits. Similarly, we find no effect on another margin of the central government's reaction to the audits, namely the allocation of federal public procurement contracts to local firms (column 6).

6.3. Firm-Level Evidence. The analysis in Section 5 concludes that anti-corruption audits positively affect the local economy. Yet, these aggregate effects may mask significant heterogeneity relevant to firm-level theories of corruption. ${ }^{52}$ As illustrated by our stylized framework of Section 5.1, uncovering heterogeneity at the firm level can help us further understand the mechanisms via which corruption introduces frictions, and it is crucial to make statements about resource misallocation. Indeed, in presence of misallocation we should expect, after the audits, that firms who were subject to a corruption tax (subsidy) improve (worsen) performance. In the absence of misallocation across firms, we would expect little heterogeneous effects. While limited by the lack of the data on firm productivity, in this section we present a suggestive analysis to shed more light on corruption and firm-level growth.

We proceed by studying the impact of the CGU program across firms within audited municipalities to explore which firms benefit and/or suffer most from the anticorruption crackdown. We focus on three main margins of heterogeneity. First, the presence of a corruption tax would indicate that, on average, firms in governmentdependent (GD) sectors should benefit the most. Second, a large literature points to political connections as a source of misallocation that benefits only a few connected and possibly inefficient firms to the detriment of a more competitive business environment. Third, the effects of the program may vary depending on whether the firm is a long-standing incumbent or not. That is, incumbent firms that have operated in presence of corruption should be more exposed to corruption frictions relative to younger firms.

We estimate the following econometric specification:

$$
\begin{aligned}
y_{f m t} & =\alpha_{f}+\alpha_{t}+\gamma_{1} \times Z_{f} \times \text { Incumbent }_{f} \times \text { PostAudit }_{m t} \\
& +\gamma_{2} \times \text { Incumbent }_{f} \times \text { PostAudit }_{m t}+\gamma_{3} \times Z_{f} \times \text { PostAudit }_{m t} \\
& +\beta \times \text { PostAudit }_{m t}+\epsilon_{f m t}
\end{aligned}
$$

where $f, m$, and $t$ stand for firm, municipality, and quarter, respectively, and PostAudit ${ }_{m t}$ is an indicator variable taking value 1 for all quarters after the audit in the audited

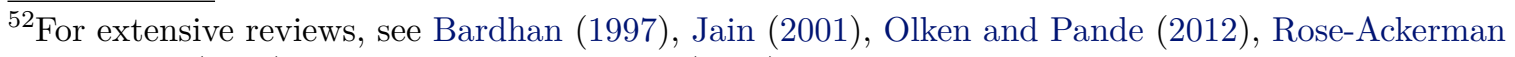
and Palifka (2016), and Fisman and Golden (2017). 
municipality, and 0 otherwise. ${ }^{53}$ PostAudit $_{m t}$ is always 0 for never-treated municipalities. Incumbent $f$ is an indicator variable equal to one for those establishments alive in the year-quarter of the audit and at least the previous two quarters. Subsequently, non-incumbent firms are those who entered just before the audit (i.e., the quarter of or the quarter before) and were therefore plausibly less affected by corruption in their operations. $Z_{f}$ are a set of indicator variables that are fixed within firms and that aim to capture the two other sources of heterogeneity we are interested in. That is, $Z_{f}$ indicates whether firms are government-dependent or politically connected, depending on the specification. $\alpha_{f}$ and $\alpha_{t}$ are firm and year-quarter fixed effects, respectively. Standard errors are clustered at the municipality level to account for correlation across time and across firms in the same municipality. We are interested in measuring the impact of audits on firm performance, but there is no detailed balancesheet information that is available for all firms. Hence, our main outcome measure is the log of total employment in the firm. The final sample includes almost 4 million unique establishments across 5,524 eligible municipalities over the 2002-2017 period, and the estimation window covers the $[-4,12]$ quarters around the audit.

We present the results of this analysis in Table 8. The first two columns focus on the differential effects across incumbent and government-dependent firms. As reported in column 1, incumbent firms in GD-Procurement sectors grow the most, as shown by the $1.4 \%$ relative increase in the top row combined with the positive estimates on both the GD-Procurement and Incumbent interaction terms. Interestingly, the negative coefficient on PostAudit ${ }_{m t}$ indicates that a share of firms in non-GD-Procurement sectors shrink in size following the audit. We find a similar pattern and closely aligned magnitudes in column 2, where we focus on the heterogeneity with respect to firms in GD-Corrupt sectors. One interpretation of these results is that, at the firm-level, the anti-corruption program generates a reallocation of economic activity towards government-dependent firms that is partly due a shift away from other sectors of the economy. We also find that incumbent firms, who were able to profitably operate despite the presence of a corruption tax, grow more relatively to firms who entered in the months just prior to the audits. However, employment per se might not be indicative of actual economic output or value added. To alleviate this concern and dig deeper into firm-level growth, we report in Table A18 the effects on sales and investment for the sample of firms in the PAC and PAS databases (which are described

\footnotetext{
${ }^{53}$ More precisely, the unit of observation is an establishment, rather than a firm, since the former can always be linked to a specific municipality. As discussed earlier, most firms have a single establishment, and this choice is inconsequential for the results.
} 
in Section 3.2). ${ }^{54}$ As shown for both GD-Procurement and GD-Corrupt sectors, in columns 1 and 3 we find that sales per employee go up by 3.9\%-4.8\% in GD sectors, while there is no effect in other sectors. Moreover, we find that investment rates increase in GD sectors and decrease in non-GD sectors (columns 2 and 4). ${ }^{55}$ These findings are consistent with the overall increase in local economic activity reported in Section 5.2, and they suggest firms in GD sectors were suffering from the presence of a corruption tax before the audit, while other sectors may have been operating inefficiently in the presence of corruption. Ultimately, however, additional work with richer data on firm-level productivity and exogenous variation in corruption exposure across firms is needed to make conclusive statement regarding allocative efficiency.

We further enrich the analysis to explore more granular heterogeneity by identifying politically connected firms, which may be ex-ante more likely to benefit from the presence of corruption. To this end, we create multiple measures of political connections using data on the universe of political candidates (elected or not), party affiliations, and corporate donations in Brazil, as introduced in Section 3. We create the following indicator variables, which are equal to one if a firm has these characteristics at the time of the audit or at any time prior to that: (i) firm that donates to a political campaign; (ii) firm that has at least one manager who donates to a political campaign; (iii) firm that has at least one manager who is an elected politician; (iv) firm that has at least one manager who is a political candidate (elected or not); (v) firm that has at least one manager who is a registered member of a political party. As shown in columns 3-7 of Table 8, politically connected firms shrink considerably after the anti-corruption crackdown. ${ }^{56}$ The magnitudes of these differential effects are large across most measures, and particularly so for incumbent firms whose manager is an elected politician, arguably the strongest measure of political connection. As reported in Table A20, which shows various summary statistics on the prevalence of

\footnotetext{
${ }^{54} \mathrm{By}$ construction, since PAC and PAS only include firms above a certain size threshold, the vast majority of firms are incumbent firms. Because of this, we drop the Incumbent indicator from the analysis in Table A18.

${ }^{55}$ In Table A19, we re-estimate our firm-level analysis using employment as a dependent variable, but restricting the sample to firms that have at least 20 employees, so as to overlap with the PAC and PAS databases. We find that GD firms grow more even within that sample, thus alleviating the concern that firm dynamics in the administrative PAC and PAS data might be different than in our main sample.

${ }^{56}$ Unfortunately, we are not able to match the firm-level data on political connections to the measures of sales and investment in the PAC and PAS databases.
} 
politically connected firms across municipalities in our sample, we see that while few in numbers, these firms are large. ${ }^{57}$

In sum, our firm-level analysis shows that government-dependent firms interacting with the local government benefit the most from a business environment with lower levels of corruption. On the other hand, politically connected firms suffer conspicuously after the anti-corruption program. Consistent with our findings, Colonnelli et al. (2020b) find that the vast majority of firms involved in irregularities with the government are not the active perpetrators of corruption and in fact benefit from the anti-corruption crackdown. On the other hand, the small set of firms actively involved in the corruption suffers after the audits take place. All in all, our firm-level results are consistent with a large literature on the individual benefits that politically connected firms accrue through corruption, suggesting that a potential mechanism through which corruption affects local economic activity is by allowing connected but inefficient firms to operate and stifle competition (Akcigit et al., 2018).

\section{Conclusion}

We provide evidence that an anti-corruption crackdown on municipal governments positively affects local economic activity by making it easier for government-dependent firms to enter, survive, and grow in the market. We establish causality thanks to the unique features of Brazil's 2003-2014 randomized audit program, and we show that our effects are tightly linked to the specific channel of reduced corruption. Importantly, the real effects we observe are driven by a mix of direct detection effects and indirect deterrence power of audits. Suggestive back-of-the-envelope calculations indicate the presence of potentially large multipliers generated by government spending on anti-corruption efforts.

A key takeaway from our findings is that a model where corruption acts like a tax on government-dependent firms and sectors, and where corruption rents are extracted by public officials, politicians, and politically connected firms seems to best fit the patterns we document. This observation is certainly specific to the context we study, which primarily involves small and medium firms doing business with small

\footnotetext{
${ }^{57}$ For example, the least conservative measure is one where firms have at least one manager who is a registered member of a political party. These firms account for $5 \%$ of the total number of firms in the average municipality, but $20 \%$ of the total employment. On the other hand, our most restrictive measure of firms whose manager is a politician account for $0.03 \%$ and $0.2 \%$ of firms and employment, respectively. Interestingly, we find politically connected firms to be present in both GD and non-GD sectors.
} 
and medium municipalities. However, our findings may likely generalize to other contexts where firms deal with government agents that hold strong negotiating power and compete against large powerful corporations. Some argue one such case is that of multinationals doing business in unfamiliar, highly corrupt countries dominated by state-owned firms.

Other takeaways relate to the policy implications of our findings, as we highlight the importance of accounting for the role of the private sector when designing policies aimed at reducing corruption in the public sector, since the spillover effects on the former can be large. Additionally, in light of the severe costs they face because of corruption, our results show that firms may be valuable allies in the fight against corruption. Finally, crucial to anti-corruption policy is recognizing the central role played by public procurement, a key driver of the empirical findings we document. The emphasis the World Bank has placed on national and international policies focused on improving governance and best practices in public procurement in recent years represents a significant step in such direction.

There are several avenues of future research. For example, our finding that audits may backfire if they fail to detect corruption remains to be fully understood. More work is certainly needed to identify specific mechanisms through which corruption affects firms. Collecting panel data on bribes and firm choices in corrupt environments, for example through detailed firm surveys, is a promising way forward. Additionally, field experiments linking corruption and firm activity have the potential to overcome the challenges driven by the dearth of natural experiments in this context. There is also significant scope for new research that studies how corruption affects withinfirm resource allocation, a topic which remains largely unexplored. Relatedly, our analysis is limited by the lack of data on firm productivity, and future work is therefore required to quantify the role of corruption in explaining resource misallocation across firms and countries. Finally, while our design is limited to a partial equilibrium analysis, attempts to capture general equilibrium effects and macro-implications of anti-corruption programs deserve further attention. 


\section{REFERENCES}

Acconcia, A., G. Corsetti, And S. Simonelli (2014): "Mafia and public spending: Evidence on the fiscal multiplier from a quasi-experiment," American Economic Review, 104, 2185-2209. 5.4

Akcigit, U., S. Baslandze, And F. LotTi (2018): "Connecting to power: political connections, innovation, and firm dynamics," Tech. rep., National Bureau of Economic Research. 7, 6.3

Akey, P. (2015): "Valuing changes in political networks: Evidence from campaign contributions to close congressional elections," Review of Financial Studies, 28, 3188-3223. 7

Arias, E., H. Larreguy, J. Marshall, and P. Querubin (2018): "Priors rule: When do malfeasance revelations help or hurt incumbent parties?" Tech. rep., National Bureau of Economic Research. 43

Avis, E., C. Ferraz, And F. Finan (2018): "Do government audits reduce corruption? Estimating the impacts of exposing corrupt politicians," Journal of Political Economy, 126, 1912-1964. 1, 6, $2,5.1,26,5.3 .1,28,5.3 .2,5.4,32,6.1$

Bai, J., S. Jayachandran, E. J. Malesky, and B. A. Olken (2017): "Firm growth and corruption: empirical evidence from Vietnam," The Economic Journal, 129, 651-677. 6

Banerjee, A., S. Mullainathan, and R. Hanna (2012): "Corruption," Tech. rep., National Bureau of Economic Research. 2

Bardhan, P. (1997): "Corruption and development: A review of issues," Journal of Economic Literature, 35, 1320-1346. 2, 17, 52

Bartelsman, E., J. Haltiwanger, and S. Scarpetta (2009): "Measuring and analyzing crosscountry differences in firm dynamics," in Producer dynamics: New evidence from micro data, University of Chicago Press, 15-76. 1

Becker, G. S. (1968): "Crime and punishment: An economic approach," in The economic dimensions of crime, Springer, 13-68. 5.3

Becker, G. S. And G. J. Stigler (1974): "Law enforcement, malfeasance, and compensation of enforcers," The Journal of Legal Studies, 3, 1-18. 5.3

Bertrand, M., E. Duflo, and S. Mullainathan (2004): "How much should we trust differences-in-differences estimates?" The Quarterly Journal of Economics, 119, 249-275. 4.1

Besley, T. (2007): "The new political economy," The Economic Journal, 117, F570-F587. 5.3.1

Bliss, C. AND R. Di Tella (1997): "Does competition kill corruption?" Journal of Political Economy, 105, 1001-1023. 6

Bobonis, G. J., L. R. Cámara Fuertes, and R. Schwabe (2016): "Monitoring corruptible politicians," American Economic Review, 106, 2371-2405. 6, 26, 5.3 .2

Bologna, J. And A. Ross (2015): "Corruption and entrepreneurship: evidence from Brazilian municipalities," Public Choice, 165, 59-77. 6

Bologna Pavlik, J. And K. Harger (2018): "Political Corruption and Development in Brazil: Do Random Audits of Corruption Increase Economic Activity?" Available at SSRN 6.2.2

Brollo, F., T. Nannicini, R. Perotti, and G. Tabellini (2013): "The Political Resource Curse," American Economic Review, 103, 1759-96. 5.2.1, 6.2.3 
Burguet, R., J. J. Ganuza, And J. Garcia Montalvo (2016): "The microeconomics of corruption. a review of thirty years of research," . 17

Cavalcanti, F., G. Daniele, and S. Galletta (2018): "Popularity shocks and political selection," Journal of Public Economics, 165, 201-216. 5.3.1, 43

Chen, T. And J. K.-S. Kung (2018): "Busting the "Princelings": The campaign against corruption in China's primary land market," The Quarterly Journal of Economics, 134, 185-226. 6

Chodorow-Reich, G. (2019): "Geographic Cross-Sectional Fiscal Spending Multipliers: What Have We Learned?" American Economic Journal: Economic Policy, 11, 1-34. 31, 5.4, 7

Cingano, F. And P. Pinotti (2013): "Politicians at work: The private returns and social costs of political connections," Journal of the European Economic Association, 11, 433-465. 1

Clatessens, S., E. Feijen, And L. Laeven (2008): "Political connections and preferential access to finance: The role of campaign contributions," Journal of Financial Economics, 88, 554-580. 7

Cole, S. And A. TRAN (2011): "14 Evidence from the firm: a new approach to understanding corruption," International handbook on the economics of corruption, 408. 6

Colonnelli, E., J. A. Gallego, and M. Prem (2020a): "What predicts corruption?" Available at SSRN 3330651. 41

Colonnelli, E., S. Lagaras, J. Ponticelli, M. Prem, and M. Tsoutsoura (2020b): "Revealing Corruption: Firm and Worker Level Evidence From Brazil," Working paper. 5, 3.3, 5.2.1, $40,6.3$

Colonnelli, E., V. Pinho Neto, And E. Teso (2020c): "Politics At Work," Available at SSRN 371561\%. 3.3

Colonnelli, E., M. Prem, And E. Teso (2020d): "Patronage and selection in public sector organizations," American Economic Review, 110, 3071-99. 3.3

Cooper, M. J., H. Gulen, And A. V. Ovtchinnikov (2010): "Corporate political contributions and stock returns," The Journal of Finance, 65, 687-724. 7

Corbi, R., E. Papaioannou, And P. Surico (2019): "Regional transfer multipliers," The Review of Economic Studies, 86, 1901-1934. 1, 5.4, 38, 7

Decarolis, F., R. Fisman, P. Pinotti, and S. Vannutelli (2019): "Rules, Discretion, and Corruption in Procurement: Evidence from Italian Government Contracting," Working paper. 1, $6,5.4$

DiX-Carneiro, R. (2014): “Trade liberalization and labor market dynamics," Econometrica, 82, 825-885. 3.1

Duchin, R. And D. Sosyura (2012): "The politics of government investment," Journal of Financial Economics, 106, 24-48. 7

Dye, K. M. (2007): "Corruption and fraud detection by supreme audit institutions," Performance Accountability and Combating Corruption, Washington, DC: World Bank, 303-322. 5.3

Faccio, M. (2006): "Politically connected firms," The American Economic Review, 96, 369-386. 7

Faccio, M., R. W. Masulis, And J. MCConnell (2006): "Political connections and corporate bailouts," The Journal of Finance, 61, 2597-2635. 7

Fenizia, A. And R. SAggio (2020): "Can the Piovra's Tentacles Be Severed? The Economic Effects of the Removal of City Councils Infiltrated by the Mafia." . 39 
FerraZ, C. AND F. Finan (2008): "Exposing corrupt politicians: The effects of Brazil's publicly released audits on electoral outcomes," The Quarterly Journal of Economics, 123, 703-745. 6, $4.2,5.2 .1,5.3 .1$

(2011): "Electoral Accountability and Corruption: Evidence from the Audits of Local Governments," American Economic Review, 101, 1274-1311. 4.2, 5.2.1, 5.3.1

Fisman, R. (2001): "Estimating the value of political connections," American Economic Review, 1095-1102. 1, 7

Fisman, R. ANd M. A. Golden (2017): Corruption: What everyone needs to know, Oxford University Press. 2, 17, 52

Fisman, R. AND J. Svensson (2007): "Are corruption and taxation really harmful to growth? Firm level evidence," Journal of Development Economics, 83, 63-75. 6, 1

Fisman, R. AND Y. WANG (2015): "The mortality cost of political connections," The Review of Economic Studies, 82, 1346-1382. 7

Gerardino, M. P., S. Litschig, And D. Pomeranz (2017): "Can audits backfire? Evidence from public procurement in Chile," Tech. rep., National Bureau of Economic Research. 44

Giannetti, M., G. Liao, J. You, And X. Yu (2017): "The externalities of corruption: Evidence from entrepreneurial firms in China," European Corporate Governance Institute (ECGI)-Finance Working Paper, 17-6. 6

Goldman, E., J. Rocholl, And J. So (2008): "Do politically connected boards affect firm value?" The Review of Financial Studies, 22, 2331-2360. 7

González, F. And M. Prem (2020): "Losing your dictator: Firms during political transition," Journal of Economic Growth, 25, 227-257. 7

Hanna, R., S. Bishop, S. Nadel, G. Scheffler, and K. Durlacher (2011): "The effectiveness of anti-corruption policy: what has worked, what hasn't, and what we don't know - a systematic review," London. doi, 978-1. 2, 5.3

Helpman, E., O. Itskhoki, M.-A. Muendler, and S. J. Redding (2017): "Trade and inequality: From theory to estimation," The Review of Economic Studies, 84, 357-405. 3.1

Hsien, C.-T. And P. J. Klenow (2009): "Misallocation and Manufacturing TFP in China and India," The Quarterly Journal of Economics, 124, 1403-1448. 1, 5.1

- (2014): "The life cycle of plants in India and Mexico," The Quarterly Journal of Economics, 129, 1035-1084. 1

Huntington, S. (1968): "Political Order in Changing Societies, 1968," New Haven: Yeale Univ. Press, 25. 1, 5.1, 5.2.1

Jain, A. K. (2001): "Corruption: A review," Journal of Economic Surveys, 15, 71-121. 2, 52

Kaufmann, D. AND S.-J. Wei (1999): "Does grease money speed up the wheels of commerce?" . 6

Khwaja, A. I. And A. Mian (2005): "Do lenders favor politically connected firms? Rent provision in an emerging financial market," The Quarterly Journal of Economics, 120, 1371-1411. 7

LEFF, N. H. (1964): "Economic development through bureaucratic corruption," American Behavioral Scientist, 8, 8-14. 1, 5.1, 5.2.1 
Lichand, G. And G. Fernandes (2019): "The Dark Side of the Contract: Do Government Audits Reduce Corruption in the Presence of Displacement by Vendors?" Tech. rep., Working Paper. 5.3.2, 44

Lichand, G., M. F. Lopes, And M. C. Medeiros (2016): "Is corruption good for your health?" scholar. harvard. edu/glichand/publications/job-market-paper. Acessado em, 25, 2016. 6

Litschig, S. AND Y. ZAmbOni (2008): "Judicial presence and rent extraction," . 4.2

LuI, F. T. (1985): "An equilibrium queuing model of bribery," Journal of Political Economy, 93, 760-781. 5.1

Mauro, P. (1995): "Corruption and growth," The Quarterly Journal of Economics, 681-712. 6

Menezes-Filho, N. A., M.-A. Muendler, And G. Ramey (2008): "The structure of worker compensation in Brazil, with a comparison to France and the United States," The Review of Economics and Statistics, 90, 324-346. 3.1

Murphy, K. M., A. Shleifer, And R. W. Vishny (1991): "The allocation of talent: Implications for growth," The Quarterly Journal of Economics, 106, 503-530. 1, 5.1

Olken, B. A. (2007): "Monitoring corruption: evidence from a field experiment in Indonesia," Journal of Political Economy, 115, 200-249. 1, 6, 5.3, 5.4

Olken, B. A. And P. BARRon (2009): "The simple economics of extortion: evidence from trucking in Aceh," Journal of Political Economy, 117, 417-452. 1, 6, 5.4

Olken, B. A. And R. Pande (2012): "Corruption in developing countries," Annu. Rev. Econ., 4, 479-509. 2, 17, 5.3, 39, 52

Persson, T. and G. E. Tabellini (2002): Political economics: explaining economic policy, MIT press. 5.3.1

Restuccia, D. And R. Rogerson (2008): "Policy distortions and aggregate productivity with heterogeneous establishments," Review of Economic Dynamics, 11, 707-720. 1, 5.1

Romer, P. (1994): "New goods, old theory, and the welfare costs of trade restrictions," Journal of Development Economics, 43, 5-38. 5.1

Rose-Ackerman, S. And B. J. Palifka (2016): Corruption and government: Causes, consequences, and reform, Cambridge university press. 2, 52

SchoenherR, D. (2018): "Political connections and allocative distortions," Journal of Finance, forthcoming. 7

Sequeira, S. And S. DJankov (2014): "Corruption and firm behavior: Evidence from African ports," Journal of International Economics, 94, 277-294. 1, 6, 5.4

Shleifer, A. And R. W. Vishny (1993): "Corruption," The Quarterly Journal of Economics, 108, 599-617. 1, 6, 5.1

- (1994): "Politicians and firms," The Quarterly Journal of Economics, 995-1025. 6

Sмiтh, J. D. (2016): "US political corruption and firm financial policies," Journal of Financial Economics, 121, 350-367. 6

Svensson, J. (2003): "Who must pay bribes and how much? Evidence from a cross section of firms," The Quarterly Journal of Economics, 118, 207-230. 1, 6, 5.2.1, 5.4

- (2005): "Eight questions about corruption," The Journal of Economic Perspectives, 19, 19-42. 2,1 
Syverson, C. (2011): "What determines productivity?" Journal of Economic Literature, 49, 32665. 1

Timmer, M. P., E. Dietzenbacher, B. Los, R. Stehrer, and G. J. De Vries (2015): "An illustrated user guide to the world input-output database: the case of global automotive production," Review of International Economics, 23, 575-605. 33

TrAnSPARENCYINTERNATIONAL (2018): "The role of supreme audit institutions in fighting corruption," Transparency International U4 Helpdesk. 5.3

WADE, R. (1985): "The market for public office: Why the Indian state is not better at development," World Development, 13, 467-497. 6

Weaver, J. (2016): "Jobs for sale: Corruption and misallocation in hiring," Tech. rep., Tech. rep., Mimeo, Yale University. B. Treatment. 1. 6

Zamboni, Y. And S. Litschig (2018): "Audit risk and rent extraction: Evidence from a randomized evaluation in Brazil," Journal of Development Economics, 134, 133-149. 6, 5.3.2, 5.4

Zeume, S. (2017): "Bribes and firm value," The Review of Financial Studies, 30, 1457-1489. 6 


\section{Figure 1. The Anti-Corruption Program Over Time}

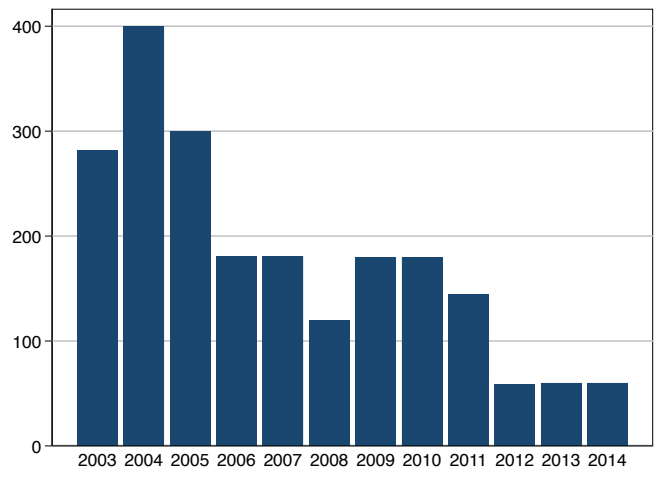

A. Audits

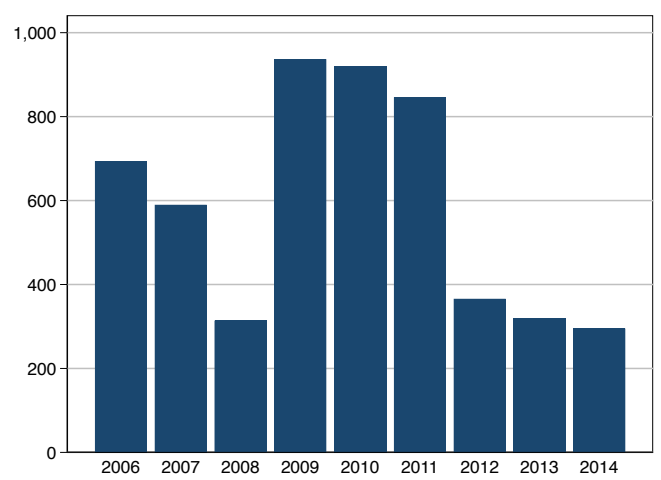

C. Mismanagement Irregularities

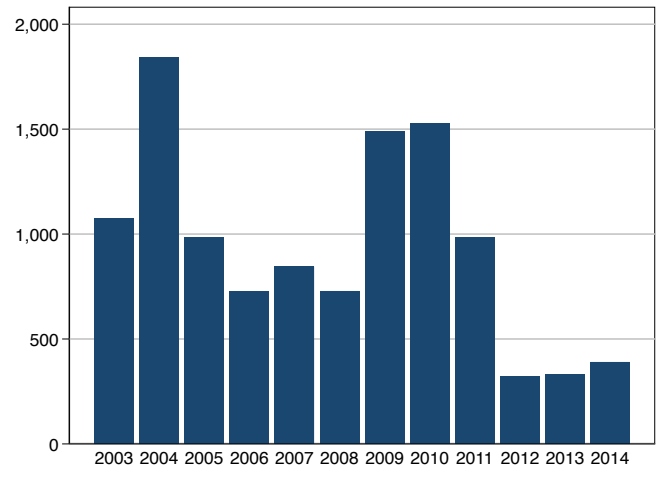

B. Audited Amount

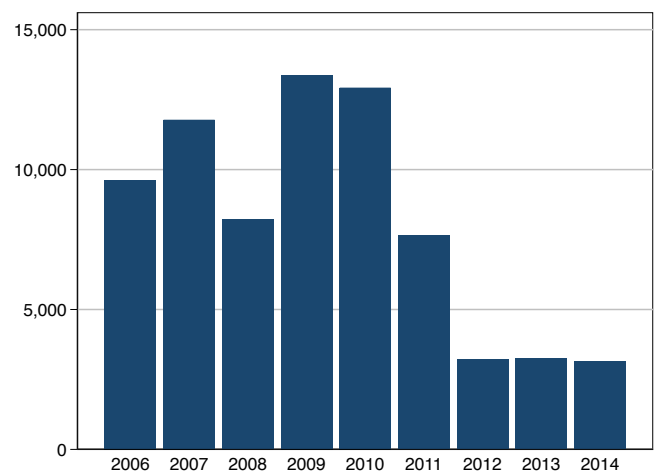

D. Corruption Irregularities

Notes: This figure illustrates the yearly variation in the anti-corruption program, using administrative data from CGU for 2006-2014. Panel A shows the total number of audits. Panel B shows the total amount of municipal resources audited, in real US millions of dollars. Panel C shows the total number of mismanagement irregularities. Panel D shows the total number of acts of corruption, which include cases of moderate and severe irregularities, as classified by CGU. 


\section{Figure 2. Corruption Across Brazilian Municipalities}

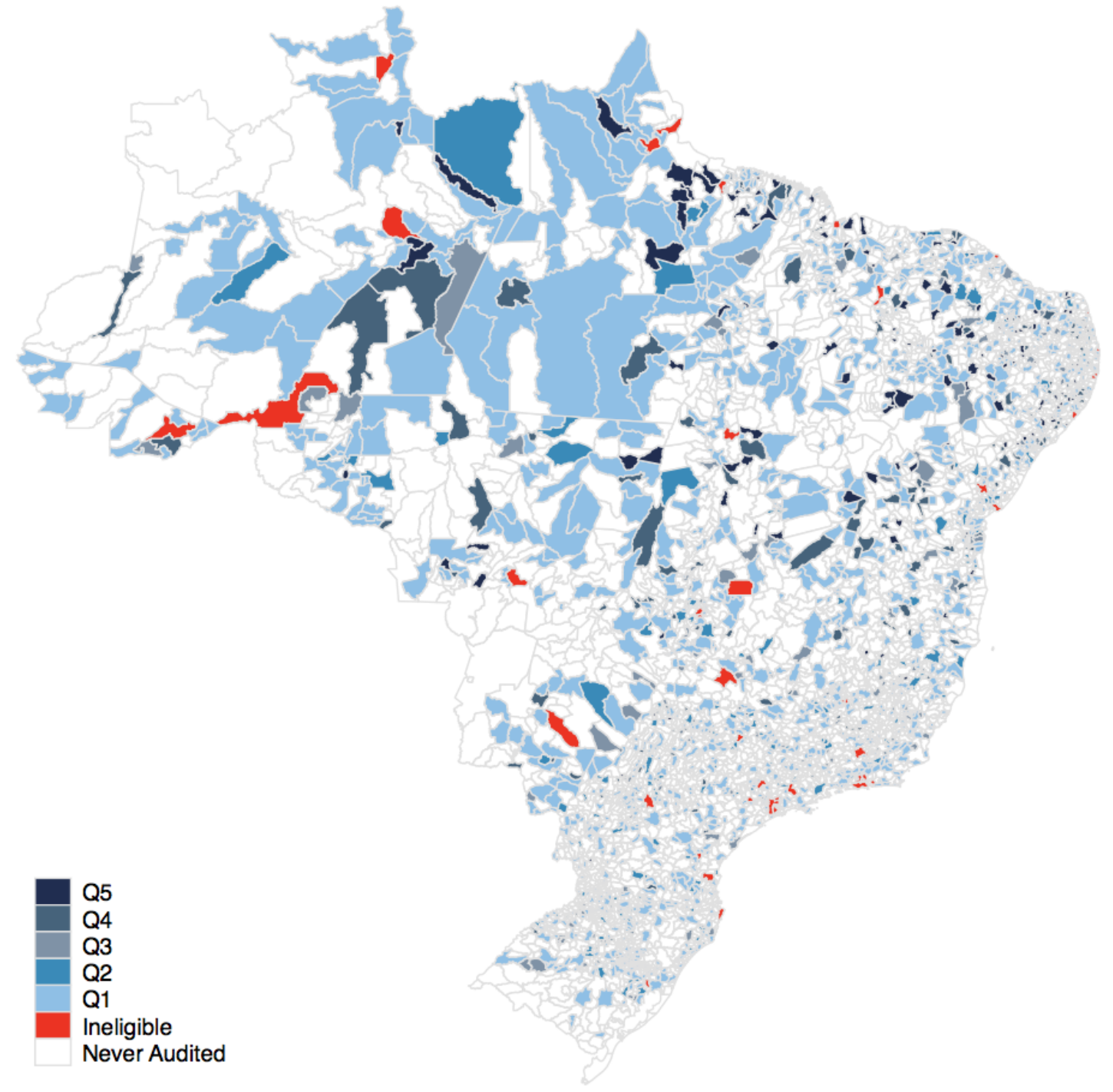

Notes: This figure shows a map of Brazilian municipalities to illustrate the spatial variation of audits and corruption intensity, using administrative data from CGU from 2006 to 2014. In red, we show the municipalities that are ineligible for the program. In white, we show the municipalities that are eligible for the program but have never been selected. In shades of blue, we highlight the municipalities that have been audited (for the first time) as part of the CGU program. A darker shade means the audit uncovered a higher share of corrupt irregularities in the audited funds, after scaling by municipality size using the number of establishments. 


\section{FiguRE 3. Audits and Firms: Raw Data and Point Estimates}

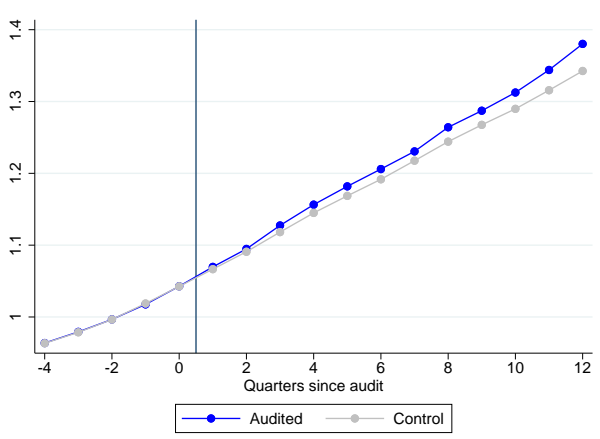

A. Establishments

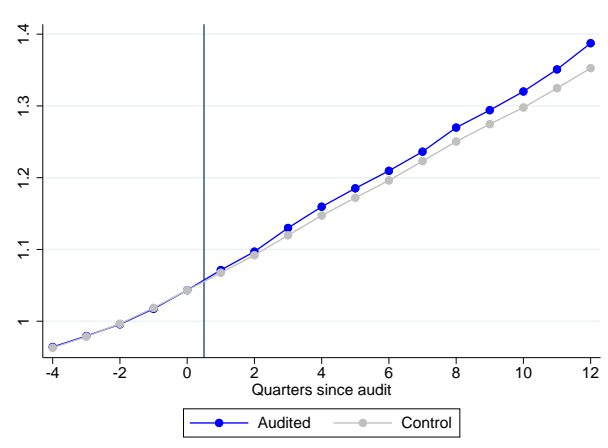

D. Firms

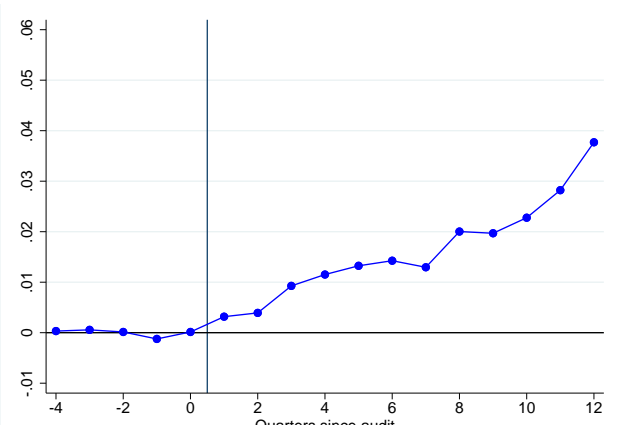

B. Establishments

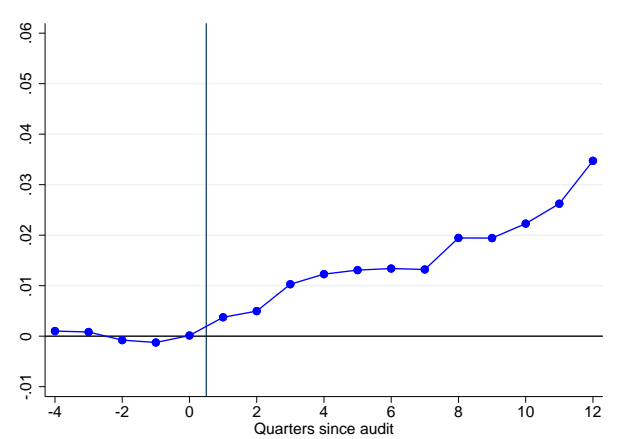

E. Firms

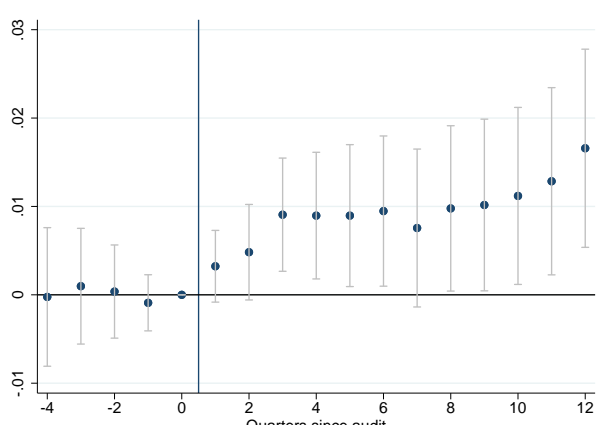

C. Establishments

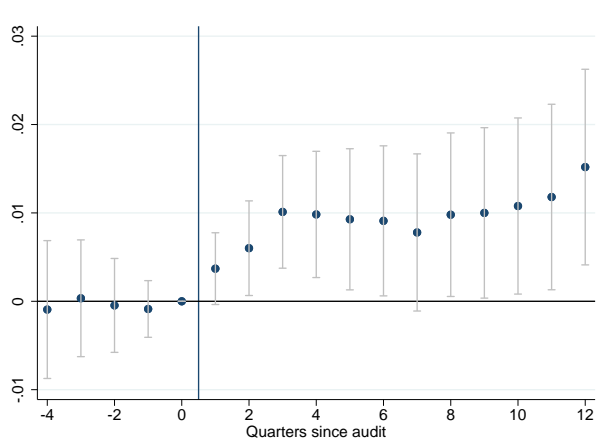

F. Firms

Notes: This figure reports the raw data and the dynamic coefficients obtained from the estimation of equation 4.1 together with $95 \%$ confidence intervals. The specification for Panels $\mathrm{C}$ and $\mathrm{F}$ is $y_{m t}=\alpha_{m}+\alpha_{t}+\sum_{k=-4}^{k=-1} \mu_{k}+\sum_{k=1}^{k=12} \mu_{k}+\epsilon_{m t}$, and is discussed in Section 4 . The sample includes all municipalities audited in the period 2003-2014 and all eligible non-audited municipalities, and covers the window [-4,+12] around the audit quarter. Panels A and D reports the raw data for total number of establishments and total number of firms in audited versus control municipalities, de-meaned using the average in the pre-audit period. Panels B and E report the difference in the de-meaned raw data between audited and control municipalities. Panels $\mathrm{C}$ and $\mathrm{F}$ presents the dynamic coefficients using as dependent variable, $y_{m t}$, the logarithm of the number of establishments and the logarithm of the number of firms. 
Figure 4. Audits and Firms: Government-Dependent Sectors

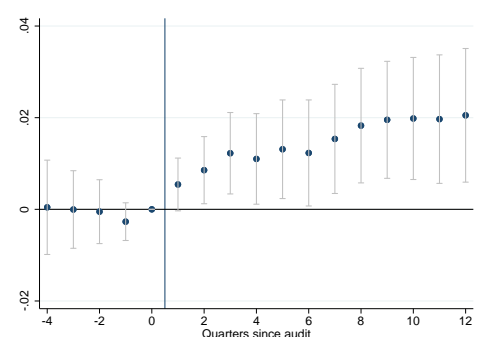

A. GD-Proc: Estab.

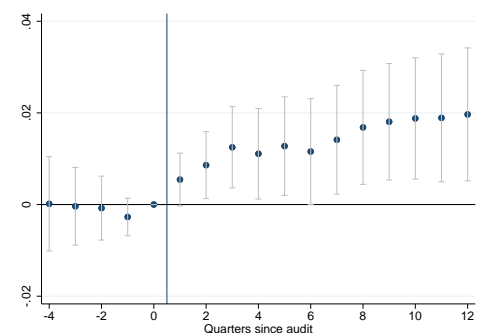

E. GD-Proc: Firms

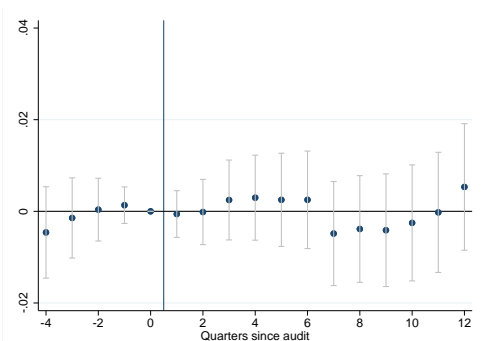

B. Non-GD-Proc: Estab.

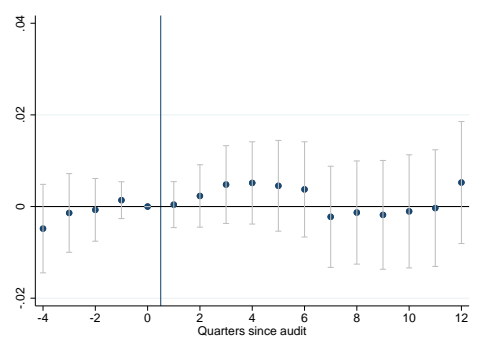

F. Non-GD-Proc: Firms

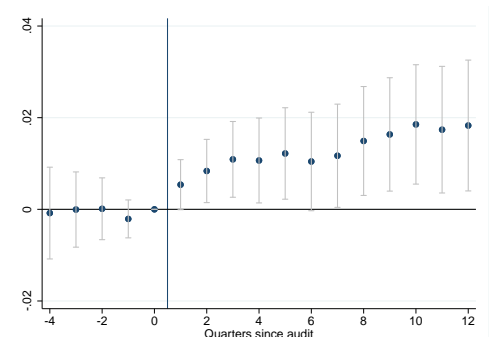

C. GD-Corrupt: Estab.

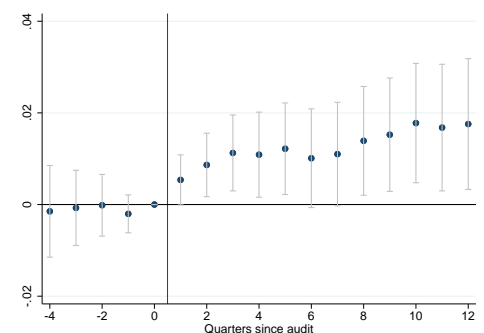

G. GD-Corrupt: Firms

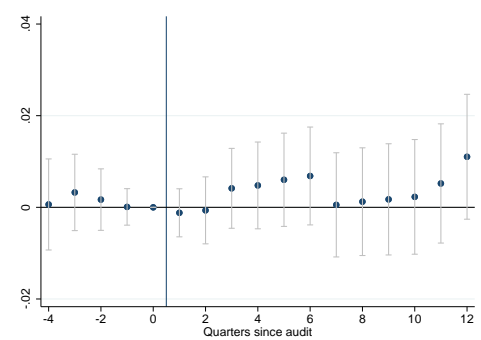

D. Non-GD-Corrupt: Estab.

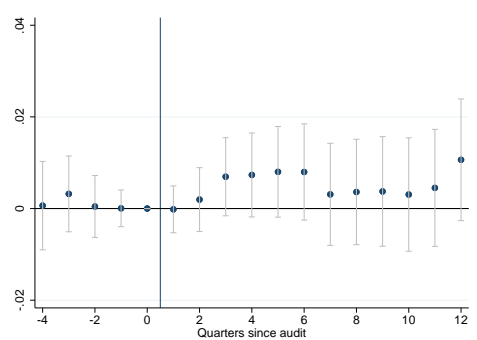

H. Non-GD-Corrupt: Firms

Notes: This figure reports the dynamic coefficients obtained from the estimation of equation 4.1 together with $95 \%$ confidence intervals. The specification is $y_{m t}=\alpha_{m}+\alpha_{t}+\sum_{k=-4}^{k=-1} \mu_{k}+\sum_{k=1}^{k=12} \mu_{k}+\epsilon_{m t}$, and is discussed in Section 4. The sample includes all municipalities audited in the period 2003-2014 and all eligible non-audited municipalities, and covers the window $[-4,+12]$ around the audit quarter. The dependent variables in each panel is the sum of the number of establishments (Panels A to D) and firms (Panels E to H) in each government-dependent sector, or its complement, as defined in section 5.2. 
TABLE 1. Summary Statistics: Local Economy

\begin{tabular}{|c|c|c|c|c|c|}
\hline & $\begin{array}{c}(1) \\
\text { Mean }\end{array}$ & $\begin{array}{l}(2) \\
\text { SD }\end{array}$ & $\begin{array}{l}(3) \\
\text { p10 }\end{array}$ & $\begin{array}{c}(4) \\
\text { Median }\end{array}$ & $\begin{array}{l}(5) \\
\text { p90 }\end{array}$ \\
\hline \multicolumn{6}{|c|}{ Panel A: Eligible municipalities } \\
\hline N Business Establishments & 251.11 & 710.67 & 6.00 & 53.00 & 555.00 \\
\hline N Firms & 239.38 & 672.00 & 6.00 & 51.00 & 532.00 \\
\hline Establishment Size & 11.21 & 74.63 & 1.00 & 3.00 & 17.00 \\
\hline Firm Size & 16.10 & 169.11 & 1.00 & 3.00 & 18.00 \\
\hline Private Sector Workers & $2,815.60$ & $9,688.85$ & 18.00 & 324.00 & $5,837.00$ \\
\hline Wage Private Sector & 460.66 & $1,137.98$ & 282.50 & 418.13 & 648.01 \\
\hline Public Sector Workers & 685.18 & $1,447.31$ & 122.00 & 335.00 & $1,382.00$ \\
\hline Wage Public Sector & 513.28 & $1,096.10$ & 232.22 & 466.16 & 759.66 \\
\hline Establishments GD-Proc & 141.42 & 400.83 & 3.00 & 30.00 & 309.00 \\
\hline Establishments GD-Corrupt & 156.23 & 420.21 & 4.00 & 35.00 & 355.00 \\
\hline Establishment Size GD-Proc & 10.53 & 67.37 & 1.00 & 3.00 & 17.00 \\
\hline Establishment Size GD-Corrupt & 10.11 & 65.57 & 1.00 & 3.00 & 16.00 \\
\hline Total Credit (M USD) & 49.03 & 195.45 & 0.65 & 11.56 & 99.02 \\
\hline GDP per capita & $4,686.43$ & $5,492.51$ & $1,411.96$ & $3,401.38$ & $8,798.00$ \\
\hline \multicolumn{6}{|c|}{ Panel B: Audited municipalities } \\
\hline N Business Establishments & 248.91 & 691.45 & 6.00 & 52.00 & 575.00 \\
\hline N Firms & 237.57 & 654.82 & 6.00 & 50.00 & 548.00 \\
\hline Establishment Size & 11.12 & 79.29 & 1.00 & 3.00 & 17.00 \\
\hline Firm Size & 15.78 & 135.36 & 1.00 & 3.00 & 19.00 \\
\hline Private Sector Workers & $2,768.95$ & $8,703.45$ & 17.00 & 326.00 & $5,961.00$ \\
\hline Wage Private Sector & 457.22 & 239.78 & 282.70 & 416.53 & 647.28 \\
\hline Public Sector Workers & 716.72 & $1,140.78$ & 125.00 & 383.00 & $1,496.00$ \\
\hline Wage Public Sector & 497.98 & 727.49 & 224.44 & 459.45 & 747.95 \\
\hline Establishments GD-Proc & 141.22 & 394.73 & 3.00 & 30.00 & 324.00 \\
\hline Establishments GD-Corrupt & 156.29 & 415.52 & 4.00 & 34.00 & 370.00 \\
\hline Establishment Size GD-Proc & 10.40 & 70.79 & 1.00 & 3.00 & 17.00 \\
\hline Establishment Size GD-Corrupt & 10.07 & 70.94 & 1.00 & 3.00 & 16.00 \\
\hline Total Credit (M USD) & 45.05 & 134.33 & 0.66 & 11.74 & 98.98 \\
\hline GDP per Capita & $4,675.53$ & $6,865.43$ & $1,381.61$ & $3,196.34$ & $8,401.58$ \\
\hline
\end{tabular}

Notes: This table reports summary statistics at the municipality level, using RAIS data for the period 2002-2017. The sample in Panel A includes all eligible municipalities, including those that are audited. The sample in Panel B includes only municipalities audited as part of the CGU anti-corruption program in 2003-2014. All variables are described in the text. $N$ Business Establishments (Firms) is the total number private sector establishments (firms) in the municipality, Establishment (Firm) Size is defined as the number of employees in the establishment (firm), Private (Public) Sector Workers is defined as the total number of workers in the private (public) sector, Wage Private Sector is the average wage in the private (public) sector, Establishments GD-Proc (Corrupt) is defined as the total number of establishment in GDProcurement (Corrupt) sectors (as defined in section 5.2), Establishments Size GD-Proc (Corrupt) is defined as the average number of employees in establishments in GD-Procurement (Corrupt) sectors (as defined in section 5.2), Total Credit (MUSD) is the total amount of credit by banks in 2014 USD, and GDP per Capita is the GDP per capita in 2014 USD. 
TABle 2. Are Audits Random?

\begin{tabular}{|c|c|c|c|c|c|}
\hline & \multirow[t]{2}{*}{$(1)$} & (2) & (3) & (4) & (5) \\
\hline & & \multicolumn{4}{|c|}{ Characteristics in (t-1) } \\
\hline & $\begin{array}{c}\text { Ever } \\
\text { Audited }\end{array}$ & 03-05 & $06-08$ & $09-11$ & $12-14$ \\
\hline Private Sector Workers & $\begin{array}{c}0.001 \\
(0.028)\end{array}$ & $\begin{array}{c}0.000 \\
(0.028)\end{array}$ & $\begin{array}{l}-0.002 \\
(0.026)\end{array}$ & $\begin{array}{c}0.002 \\
(0.029)\end{array}$ & $\begin{array}{l}-0.016 \\
(0.016)\end{array}$ \\
\hline N Business Establishments & $\begin{array}{l}-0.007 \\
(0.015)\end{array}$ & $\begin{array}{l}-0.010 \\
(0.014)\end{array}$ & $\begin{array}{c}0.010 \\
(0.014)\end{array}$ & $\begin{array}{l}-0.006 \\
(0.011)\end{array}$ & $\begin{array}{c}0.002 \\
(0.006)\end{array}$ \\
\hline Establishment Size & $\begin{array}{c}0.007 \\
(0.005)\end{array}$ & $\begin{array}{c}0.001 \\
(0.011)\end{array}$ & $\begin{array}{c}0.005 \\
(0.008)\end{array}$ & $\begin{array}{c}0.003 \\
(0.009)\end{array}$ & $\begin{array}{l}-0.004 \\
(0.002)\end{array}$ \\
\hline Share Employment in Small Establishments & $\begin{array}{l}-0.004 \\
(0.008)\end{array}$ & $\begin{array}{l}-0.010 \\
(0.007)\end{array}$ & $\begin{array}{c}0.001 \\
(0.008)\end{array}$ & $\begin{array}{c}0.000 \\
(0.007)\end{array}$ & $\begin{array}{c}0.003 \\
(0.004)\end{array}$ \\
\hline Share Employment in Medium Establishments & $\begin{array}{l}-0.006 \\
(0.008)\end{array}$ & $\begin{array}{l}-0.007 \\
(0.008)\end{array}$ & $\begin{array}{l}-0.004 \\
(0.008)\end{array}$ & $\begin{array}{l}-0.007 \\
(0.007)\end{array}$ & $\begin{array}{l}-0.002 \\
(0.004)\end{array}$ \\
\hline Share Manufacturing & $\begin{array}{c}0.003 \\
(0.008)\end{array}$ & $\begin{array}{c}0.000 \\
(0.007)\end{array}$ & $\begin{array}{c}0.001 \\
(0.005)\end{array}$ & $\begin{array}{c}0.010 \\
(0.006)\end{array}$ & $\begin{array}{c}0.001 \\
(0.004)\end{array}$ \\
\hline Share Services & $\begin{array}{l}-0.000 \\
(0.008)\end{array}$ & $\begin{array}{c}0.003 \\
(0.008)\end{array}$ & $\begin{array}{l}0.014^{*} \\
(0.007)\end{array}$ & $\begin{array}{l}-0.006 \\
(0.006)\end{array}$ & $\begin{array}{c}0.004 \\
(0.005)\end{array}$ \\
\hline Share Retail & $\begin{array}{c}0.006 \\
(0.009)\end{array}$ & $\begin{array}{c}0.017^{* *} \\
(0.008)\end{array}$ & $\begin{array}{c}0.002 \\
(0.007)\end{array}$ & $\begin{array}{l}0.006 \\
(0.007)\end{array}$ & $\begin{array}{c}0.003 \\
(0.005)\end{array}$ \\
\hline Share Construction & $\begin{array}{l}-0.002 \\
(0.007)\end{array}$ & $\begin{array}{c}0.007 \\
(0.007)\end{array}$ & $\begin{array}{l}-0.002 \\
(0.006)\end{array}$ & $\begin{array}{c}-0.009^{*} \\
(0.005)\end{array}$ & $\begin{array}{l}-0.003 \\
(0.003)\end{array}$ \\
\hline Public Sector Workers & $\begin{array}{l}-0.016 \\
(0.016)\end{array}$ & $\begin{array}{c}0.002 \\
(0.018)\end{array}$ & $\begin{array}{c}-0.019 \\
(0.016)\end{array}$ & $\begin{array}{l}-0.029 \\
(0.018)\end{array}$ & $\begin{array}{c}0.007 \\
(0.009)\end{array}$ \\
\hline Share Workers in Public Sector & $\begin{array}{c}0.002 \\
(0.022)\end{array}$ & $\begin{array}{l}-0.030 \\
(0.021)\end{array}$ & $\begin{array}{c}0.003 \\
(0.019)\end{array}$ & $\begin{array}{c}0.019 \\
(0.021)\end{array}$ & $\begin{array}{l}-0.012 \\
(0.013)\end{array}$ \\
\hline Population & $\begin{array}{c}0.003 \\
(0.015)\end{array}$ & $\begin{array}{l}-0.005 \\
(0.016)\end{array}$ & $\begin{array}{c}0.000 \\
(0.014)\end{array}$ & $\begin{array}{c}0.019 \\
(0.014)\end{array}$ & $\begin{array}{l}-0.005 \\
(0.008)\end{array}$ \\
\hline GDP & $\begin{array}{c}0.025 \\
(0.016)\end{array}$ & $\begin{array}{c}0.031 \\
(0.027)\end{array}$ & $\begin{array}{c}0.005 \\
(0.022)\end{array}$ & $\begin{array}{c}0.018 \\
(0.021)\end{array}$ & $\begin{array}{l}-0.001 \\
(0.013)\end{array}$ \\
\hline Share Informal Employment & $\begin{array}{l}-0.000 \\
(0.012)\end{array}$ & $\begin{array}{c}0.006 \\
(0.011)\end{array}$ & $\begin{array}{l}0.006 \\
(0.009)\end{array}$ & $\begin{array}{l}-0.007 \\
(0.008)\end{array}$ & $\begin{array}{l}-0.005 \\
(0.005)\end{array}$ \\
\hline Income Gini & $\begin{array}{c}0.009 \\
(0.007)\end{array}$ & $\begin{array}{c}0.015 \\
(0.009)\end{array}$ & $\begin{array}{l}-0.004 \\
(0.007)\end{array}$ & $\begin{array}{l}0.008 \\
(0.007)\end{array}$ & $\begin{array}{c}0.002 \\
(0.004)\end{array}$ \\
\hline Share Illiterate Population & $\begin{array}{c}0.009 \\
(0.014)\end{array}$ & $\begin{array}{c}0.016 \\
(0.014)\end{array}$ & $\begin{array}{c}0.012 \\
(0.011)\end{array}$ & $\begin{array}{l}-0.008 \\
(0.011)\end{array}$ & $\begin{array}{l}-0.006 \\
(0.006)\end{array}$ \\
\hline Share Population $>8$ Years Education & $\begin{array}{c}0.006 \\
(0.011)\end{array}$ & $\begin{array}{c}0.004 \\
(0.010)\end{array}$ & $\begin{array}{c}0.008 \\
(0.008)\end{array}$ & $\begin{array}{l}-0.002 \\
(0.008)\end{array}$ & $\begin{array}{l}-0.002 \\
(0.005)\end{array}$ \\
\hline Opposition Mayor & & $\begin{array}{c}0.005 \\
(0.014)\end{array}$ & $\begin{array}{l}-0.009 \\
(0.011)\end{array}$ & $\begin{array}{c}0.002 \\
(0.010)\end{array}$ & $\begin{array}{l}-0.001 \\
(0.006)\end{array}$ \\
\hline Observations & 5,505 & 4,574 & 4,039 & 3,984 & 3,740 \\
\hline R-squared & 0.037 & 0.051 & 0.019 & 0.022 & 0.011 \\
\hline State FE & Yes & Yes & Yes & Yes & Yes \\
\hline Mean DV & 0.340 & 0.209 & 0.106 & 0.0916 & 0.0316 \\
\hline
\end{tabular}

Notes: This table illustrates the randomness in the selection of municipalities to audit. All columns present the coefficients from cross-sectional regressions of the type Audited $_{m s}=\alpha_{s}+\gamma \times X_{m}+\epsilon_{m s}$. The outcome variable, Audited $_{m s}$, is an indicator for whether the municipality is audited in a given set of years as described in each column. All specifications include state fixed effects. The sample includes all eligible municipalities. We use as regressors variables measured in 2002 (Column 1), or in the year before the audit (Columns 2 to $5)$. We standardize each variable by their mean and standard deviation. The variables used come from the multiple data sources discussed in Section 3, and they are mostly discussed in the previous table and in the text. Small establishments have up to 3 employees, while medium establishments have more than 3 but no more than 10. Share Informal Employment, Income Gini, Share Illiterate Population, Share Population $>$ 8 Years Education come from the decennial census of 2000. Opposition Mayor is an indicator for whether the municipal mayor belongs to opposition party of the president's. Robust standard errors are presented in parenthesis. ${ }^{* * *} \mathrm{p}<0.01,{ }^{* *} \mathrm{p}<0.05,{ }^{*} \mathrm{p}<0.1$. 
TABle 3. The Impact of Anti-corruption Audits on Firms

\begin{tabular}{|c|c|c|c|c|c|c|c|c|c|c|}
\hline & \multirow[t]{2}{*}{$(1)$} & \multirow[t]{2}{*}{$(2)$} & $(3)$ & (4) & \multirow{2}{*}{\multicolumn{2}{|c|}{$\begin{array}{cc}(5) & (6) \\
\text { Non-GD-Procurement }\end{array}$}} & \multirow{2}{*}{\multicolumn{2}{|c|}{$\begin{array}{l}(7) \\
\text { GD-Corrupt }\end{array}$}} & \multirow{2}{*}{\multicolumn{2}{|c|}{$\begin{array}{c}(9) \quad(10) \\
\text { Non-GD-Corrupt }\end{array}$}} \\
\hline & & & GD-Procure & ment & & & & & & \\
\hline & Establishments & Firms & Establishments & Firms & Establishments & Firms & Establishments & Firms & Establishments & Firms \\
\hline PostAudit & $\begin{array}{c}0.009 * * \\
(0.004)\end{array}$ & $\begin{array}{c}0.009 * * \\
(0.004)\end{array}$ & $\begin{array}{c}0.014^{* * *} \\
(0.005)\end{array}$ & $\begin{array}{c}0.014^{* * *} \\
(0.005)\end{array}$ & $\begin{array}{c}0.001 \\
(0.005)\end{array}$ & $\begin{array}{c}0.003 \\
(0.005)\end{array}$ & $\begin{array}{c}0.012^{* * *} \\
(0.005)\end{array}$ & $\begin{array}{c}0.013^{* * *} \\
(0.005)\end{array}$ & $\begin{array}{c}0.002 \\
(0.005)\end{array}$ & $\begin{array}{c}0.004 \\
(0.005)\end{array}$ \\
\hline Observations & 277,392 & 277,392 & 277,392 & 277,392 & 277,392 & 277,392 & 277,392 & 277,392 & 277,392 & 277,392 \\
\hline R-squared & 0.984 & 0.985 & 0.977 & 0.977 & 0.979 & 0.980 & 0.975 & 0.975 & 0.980 & 0.981 \\
\hline Municipality FE & Yes & Yes & Yes & Yes & Yes & Yes & Yes & Yes & Yes & Yes \\
\hline Year-quarter FE & Yes & Yes & Yes & Yes & Yes & Yes & Yes & Yes & Yes & Yes \\
\hline Avg Dep Var & 4.179 & 4.138 & 3.607 & 3.593 & 3.370 & 3.309 & 3.552 & 3.538 & 3.428 & 3.367 \\
\hline SD Dep Var & 1.611 & 1.607 & 1.606 & 1.598 & 1.602 & 1.595 & 1.535 & 1.527 & 1.675 & 1.671 \\
\hline p-value GD vs Non-GD & & & 0.049 & 0.095 & 0.049 & 0.095 & 0.093 & 0.153 & 0.093 & 0.153 \\
\hline
\end{tabular}

Notes: This table illustrates the main effects of the audits on firms. The table reports the coefficients obtained from the estimation of equation 4.2 The specification is $y_{m t}=\alpha_{m}+\alpha_{t}+\beta \times$ PostAudit $_{m t}+\epsilon_{m t}$, and is discussed in Section 4. The sample includes all municipalities audited in the period 2003-2014 and all eligible non-audited municipalities, and covers the window $[-4,+12]$ quarters around the audit quarter. PostAudit $t_{m t}$ is an indicator variable taking value 1 for all quarter-years after the audit in the audited municipality, and 0 otherwise. PostAuditmt is always 0 for never treated municipalities. All specifications include municipality and year-quarter fixed effects. Establishments is the log of the total number of private sector establishments in the municipality. Firms is the log of the total number of private sector firms in the municipality. Dependent variables in columns 1 and 2 refer to all sectors in the municipality, columns 3 and 4 to GD-Procurement sectors, columns 5 and 6 to Non-GD-Procurement sectors, columns 7 and 8 to GD-Corrupt sectors, and columns 9 ad 10 to Non-GD-Corrupt sectors. These classifications are defined in Section 5.2. The $p$-value GD vs Non-GD presents the p-value for the difference between PostAudit coefficients in GD vs Non-GD sectors. Avg Dep Var and SD Dep Var are computed using eligible non-audited municipalities and audited municipalities in the 4 quarters before the audit. Robust standard errors are clustered at the municipality level. $* * * \mathrm{p}<0.01,{ }^{*} \mathrm{p}<0.05, * \mathrm{p}<0.1$. 
TABLE 4. The Impact of Audits on Other Measures of Economic Activity

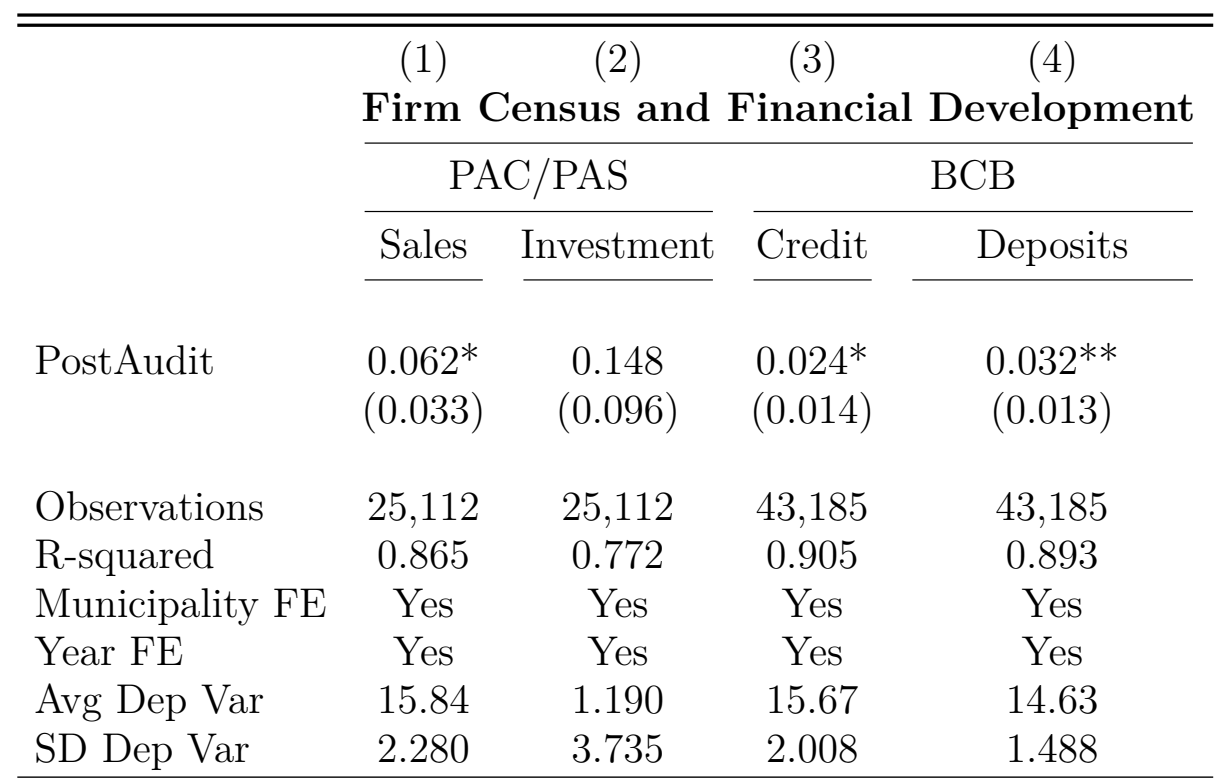

Notes: This table illustrates the main effects of the audit on other measures of local economic activity. The table mostly reports the coefficients obtained from the estimation of equation 4.2. The specification is $y_{m t}=\alpha_{m}+\alpha_{t}+\beta \times$ PostAudit $_{m t}+\epsilon_{m t}$ and is discussed in Section 4. The sample includes all municipalities audited in the period 2003-2014 and all eligible non-audited municipalities, and covers the window [-1,+3] years around the audit year. PostAudit $m$ is an indicator variable taking value 1 for all years after the audit in the audited municipality, and 0 otherwise. PostAudit $t_{m}$ is always 0 for never treated municipalities. All specifications include municipality and year fixed effects. Sales is the logarithm of (the sum of) total sales by local firms in the PAC and PAS datasets. Investment is defined as the (sum of) total capital expenditure over total assets by local firms in the PAC and PAS datasets. Credit and Deposits use municipality-level data from the Central Bank and are defined in section 3. Avg Dep Var and SD Dep Var are computed using eligible non-audited municipalities and audited municipalities in the year before the audit. Robust standard errors are clustered at the municipality level. *** $\mathrm{p}<0.01,{ }^{* *} \mathrm{p}<0.05,{ }^{*} \mathrm{p}<0.1$. 
TABLE 5. Direct Effects and Political Incentives

\begin{tabular}{|c|c|c|c|c|c|c|c|c|c|c|}
\hline & $\begin{array}{l}\text { (1) } \\
\text { All }\end{array}$ & $\begin{array}{c}(2) \\
\text { GD } \\
\text { Procurement }\end{array}$ & $\begin{array}{c}(3) \\
\text { Non-GD } \\
\text { Procurement }\end{array}$ & $\begin{array}{c}(4) \\
\text { GD } \\
\text { Corrupt } \\
\end{array}$ & $\begin{array}{c}(5) \\
\text { Non-GD } \\
\text { Corrupt } \\
\end{array}$ & $\begin{array}{l}(6) \\
\text { All }\end{array}$ & $\begin{array}{c}(7) \\
\text { GD } \\
\text { Procurement } \\
\end{array}$ & $\begin{array}{c}(8) \\
\text { Non-GD } \\
\text { Procurement }\end{array}$ & $\begin{array}{c}(9) \\
\text { GD } \\
\text { Corrupt } \\
\end{array}$ & $\begin{array}{c}(10) \\
\text { Non-GD } \\
\text { Corrupt } \\
\end{array}$ \\
\hline & \multicolumn{5}{|c|}{ Panel A: Early years } & \multicolumn{5}{|c|}{ Panel B: Final years } \\
\hline PostAudit & $\begin{array}{c}0.006 \\
(0.005)\end{array}$ & $\begin{array}{l}0.012^{*} \\
(0.006)\end{array}$ & $\begin{array}{c}-0.000 \\
(0.006)\end{array}$ & $\begin{array}{c}0.008 \\
(0.006)\end{array}$ & $\begin{array}{c}0.001 \\
(0.006)\end{array}$ & $\begin{array}{c}0.013 * * \\
(0.006)\end{array}$ & $\begin{array}{c}0.016^{* *} \\
(0.008)\end{array}$ & $\begin{array}{c}0.006 \\
(0.007)\end{array}$ & $\begin{array}{c}0.017^{* *} \\
(0.007)\end{array}$ & $\begin{array}{c}0.007 \\
(0.007)\end{array}$ \\
\hline Observations & 263,353 & 263,353 & 263,353 & 263,353 & 263,353 & 259,706 & 259,706 & 259,706 & 259,706 & 259,706 \\
\hline R-squared & 0.984 & 0.976 & 0.979 & 0.974 & 0.981 & 0.984 & 0.976 & 0.979 & 0.974 & 0.980 \\
\hline Avg Dep Var & 4.143 & 3.598 & 3.313 & 3.542 & 3.373 & 4.140 & 3.595 & 3.311 & 3.540 & 3.370 \\
\hline SD Dep Var & 1.606 & 1.597 & 1.595 & 1.526 & 1.671 & 1.606 & 1.597 & 1.595 & 1.525 & 1.671 \\
\hline p-value GD vs Non-GD & & 0.160 & 0.160 & 0.370 & 0.370 & & 0.325 & 0.325 & 0.267 & 0.267 \\
\hline \multirow[t]{2}{*}{ p-value Panel A vs B } & 0.375 & 0.636 & 0.444 & 0.316 & 0.498 & 0.375 & 0.636 & 0.444 & 0.316 & 0.498 \\
\hline & \multicolumn{5}{|c|}{ Panel C: First term } & \multicolumn{5}{|c|}{ Panel D: Second term } \\
\hline PostAudit & $\begin{array}{c}0.010^{* *} \\
(0.004)\end{array}$ & $\begin{array}{c}0.013^{* *} \\
(0.006)\end{array}$ & $\begin{array}{c}0.005 \\
(0.006)\end{array}$ & $\begin{array}{c}0.013^{* *} \\
(0.005)\end{array}$ & $\begin{array}{c}0.003 \\
(0.006)\end{array}$ & $\begin{array}{c}0.005 \\
(0.007)\end{array}$ & $\begin{array}{c}0.015 \\
(0.010)\end{array}$ & $\begin{array}{c}-0.004 \\
(0.008)\end{array}$ & $\begin{array}{c}0.009 \\
(0.009)\end{array}$ & $\begin{array}{c}0.002 \\
(0.009)\end{array}$ \\
\hline Observations & 269,624 & 269,624 & 269,624 & 269,624 & 269,624 & 253,380 & 253,380 & 253,380 & 253,380 & 253,380 \\
\hline R-squared & 0.985 & 0.976 & 0.980 & 0.974 & 0.981 & 0.984 & 0.976 & 0.979 & 0.973 & 0.980 \\
\hline Avg Dep Var & 4.139 & 3.594 & 3.310 & 3.539 & 3.369 & 4.144 & 3.599 & 3.315 & 3.543 & 3.375 \\
\hline SD Dep Var & 1.606 & 1.598 & 1.595 & 1.526 & 1.671 & 1.605 & 1.596 & 1.595 & 1.525 & 1.671 \\
\hline p-value GD vs Non-GD & & 0.257 & 0.257 & 0.165 & 0.165 & & 0.095 & 0.095 & 0.533 & 0.533 \\
\hline p-value Panel C vs D & 0.578 & 0.900 & 0.358 & 0.657 & 0.882 & 0.578 & 0.900 & 0.358 & 0.657 & 0.882 \\
\hline Municipality FE & Yes & Yes & Yes & Yes & Yes & Yes & Yes & Yes & Yes & Yes \\
\hline Year-quarter FE & Yes & Yes & Yes & Yes & Yes & Yes & Yes & Yes & Yes & Yes \\
\hline
\end{tabular}

Notes: This table illustrates the main effects of the audits on firms for different subsamples, depending on when the audit was conducted. Panel A presents the results for municipalities that were audited in the first two years of a mayor's term, while Panel B presents results for audits that occur in in the last two years of a mayor's term. Panel C presents the results for municipalities that were audited during the mayor's first term, while Panel D presents results for municipalities audited during the mayor's second term. The table reports the coefficients obtained from the estimation of equation 4.2. The specification is $y_{m t}=\alpha_{m}+\alpha_{t}+\beta \times$ PostAudit $_{m t}+\epsilon_{m t}$, and is discussed in Section 4 . The sample includes all municipalities audited in the period 2003-2014 and all eligible non-audited municipalities, and covers the window $[-4,+12]$ quarters around the audit quarter. PostAudit ${ }_{m t}$ is an indicator variable taking value 1 for all quarter-years after the audit in the audited municipality, and 0 otherwise. PostAudit ${ }_{m t}$ is always 0 for never treated municipalities. All specifications include municipality and year-quarter fixed effects. The dependent variable is the log of the total number of private sector firms in the municipality. Dependent variables in columns 1 and 6 refer to all sectors in the municipality, columns 2 and 7 to GD-Procurement sectors, columns 3 and 8 to Non-GD-Procurement sectors, columns 4 and 9 to GD-Corrupt sectors, and columns 5 and 10 to Non-GD-Corrupt sectors. These classifications are defined in Section 5.2. The p-value GD vs Non-GD presents the p-value for the difference between PostAudit coefficients in GD vs Non-GD sectors. The $p$-value Panel $A$ vs $B$ ( $C$ vs $D)$ presents the p-value for the difference between PostAudit coefficients in the same column across panels. Avg Dep Var and SD Dep Var are computed using eligible non-audited municipalities and audited municipalities in the 4 quarters before the audit. Robust standard errors are clustered at the municipality level. ${ }^{* * *} \mathrm{p}<0.01,{ }^{* *} \mathrm{p}<0.05,{ }^{*} \mathrm{p}<0.1$. 
TABLE 6. Indirect Effects: Estimating Deterrence via Spillovers

\begin{tabular}{|c|c|c|c|c|c|}
\hline & $\begin{array}{l}(1) \\
\text { All }\end{array}$ & $\begin{array}{c}(2) \\
\text { GD } \\
\text { Procurement }\end{array}$ & $\begin{array}{c}(3) \\
\text { Non-GD } \\
\text { Procurement }\end{array}$ & $\begin{array}{c}(4) \\
\text { GD } \\
\text { Corrupt }\end{array}$ & $\begin{array}{c}(5) \\
\text { Non-GD } \\
\text { Corrupt }\end{array}$ \\
\hline \multicolumn{6}{|c|}{ Panel A: Spillover effects } \\
\hline PostAudit & $\begin{array}{c}0.012^{* *} \\
(0.005)\end{array}$ & $\begin{array}{c}0.021^{* * *} \\
(0.006)\end{array}$ & $\begin{array}{l}-0.004 \\
(0.005)\end{array}$ & $\begin{array}{l}0.012^{*} \\
(0.006)\end{array}$ & $\begin{array}{c}0.007 \\
(0.006)\end{array}$ \\
\hline Observations & 69,866 & 69,866 & 69,866 & 69,866 & 69,866 \\
\hline R-squared & 0.993 & 0.989 & 0.989 & 0.988 & 0.990 \\
\hline Avg Dep Var & 4.025 & 3.475 & 3.213 & 3.440 & 3.251 \\
\hline SD Dep Var & 1.677 & 1.691 & 1.626 & 1.621 & 1.706 \\
\hline p-value GD vs Non-GD & & 0.001 & 0.001 & 0.565 & 0.565 \\
\hline \multicolumn{6}{|c|}{ Panel B: Excluding spillover effects } \\
\hline PostAudit & $\begin{array}{c}0.022^{* * *} \\
(0.006)\end{array}$ & $\begin{array}{c}0.030^{* * *} \\
(0.007)\end{array}$ & $\begin{array}{c}0.004 \\
(0.006)\end{array}$ & $\begin{array}{c}0.025^{* * *} \\
(0.007)\end{array}$ & $\begin{array}{c}0.010 \\
(0.007)\end{array}$ \\
\hline Observations & 44,075 & 44,075 & 44,075 & 44,075 & 44,075 \\
\hline R-squared & 0.992 & 0.988 & 0.989 & 0.987 & 0.990 \\
\hline Municipality FE & Yes & Yes & Yes & Yes & Yes \\
\hline Year-quarter FE & Yes & Yes & Yes & Yes & Yes \\
\hline Avg Dep Var & 4.484 & 3.918 & 3.672 & 3.844 & 3.754 \\
\hline SD Dep Var & 1.734 & 1.740 & 1.705 & 1.671 & 1.780 \\
\hline p-value GD vs Non-GD & & 0.002 & 0.002 & 0.076 & 0.076 \\
\hline
\end{tabular}

Notes: This table illustrates the deterrence effects of the audits through the analysis of geographic spillovers. Panel A reports the coefficients obtained from the estimation of a specification similar to $y_{m t}=\alpha_{m}+\alpha_{t}+$ $\beta \times$ PostAudit $_{m t}+\epsilon_{m t}$, but for the impact of the audits on nearby municipalities, and is discussed in Section 5. That is, we define as nearby those municipalities in the same micro-region of an audited one, and exclude

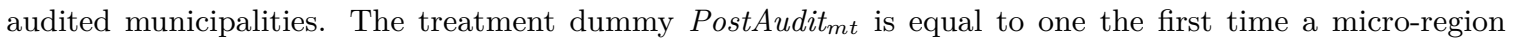
has one of its municipalities that is audited. Panel B reports the results for the main specification, but where we exclude from the sample all never-audited municipalities in a micro-region where there was at least one municipality that was audited. The sample covers municipalities audited in the period 2003-2014 and the window $[-4,+12]$ quarters around the audit quarter. All specifications include municipality and year-quarter fixed effects. The dependent variable is the log of the total number of private sector firms in the municipality. Dependent variables in column 1 refers to all sectors in the municipality, column 2 to GD-Procurement sectors, column 3 to Non-GD-Procurement sectors, column 4 to GD-Corrupt sectors, and column 5 to Non-GD-Corrupt sectors. These classifications are defined in section 5.2. The $p$-value $G D$ vs Non-GD presents the p-value for the difference between PostAudit coefficients in GD vs Non-GD sectors. Avg Dep Var and SD Dep Var are computed using eligible non-audited municipalities and audited municipalities in the 4 quarters before the audit. Robust standard errors are clustered at the municipality level. ${ }^{* * *} \mathrm{p}<0.01,{ }^{* *} \mathrm{p}<0.05,{ }^{*} \mathrm{p}<0.1$. 
TABLE 7. Anti-corruption Multipliers and Cost-Benefit Analysis

\begin{tabular}{lcc}
\hline \hline \multicolumn{1}{c}{ Measures } & $\begin{array}{c}\text { Multiplier } \\
(\mathbf{1})\end{array}$ & $\begin{array}{c}\text { Cost-Benefit } \\
(\mathbf{2})\end{array}$ \\
\hline Overall & & \\
Value Added - WOID & 1.97 & 4.33 \\
Value Added - IBGE & 1.46 & 3.21 \\
Formula from CR-CPS & 2.09 & 4.60 \\
& & \\
Accounting for Spillovers & & \\
Value Added - WOID & 4.82 & 10.61 \\
Value Added - IBGE & 3.57 & 7.84 \\
Formula from CR-CPS & 5.11 & 11.25 \\
\hline \hline
\end{tabular}

Notes: This table reports local multipliers of the audits as outlined in Section 5.4. The multipliers are computed using three different approaches. The first relies on firm-level estimates of value added constructed from the Brazil's socio-economic accounts of the World Input-Output Database (WIOD). The second relies on firm-level estimates of value added constructed from $I B G E$. The third $(C R-C P S)$ relies on the formula by Corbi et al. (2019) and Chodorow-Reich (2019). 
TABLE 8. Heterogeneity Across Local Firms

\begin{tabular}{|c|c|c|c|c|c|c|c|}
\hline & (1) & $(2)$ & $(3)$ & (4) & $(5)$ & $(6)$ & $(7)$ \\
\hline & \multicolumn{2}{|c|}{ Government-Dependent } & \multicolumn{5}{|c|}{ Politically Connected } \\
\hline & $\begin{array}{c}\text { GD } \\
\text { Procurement }\end{array}$ & $\begin{array}{l}\text { GD } \\
\text { Corrupt }\end{array}$ & $\begin{array}{l}\text { Firm } \\
\text { Donor }\end{array}$ & $\begin{array}{l}\text { Manager } \\
\text { Donor }\end{array}$ & Politician & Candidate & $\begin{array}{l}\text { Party } \\
\text { Member }\end{array}$ \\
\hline PostAudit $\times$ Incumbent $\times \mathrm{Z}$ & $\begin{array}{c}0.014^{* * *} \\
(0.003)\end{array}$ & $\begin{array}{c}0.011^{* * *} \\
(0.003)\end{array}$ & $\begin{array}{c}0.000 \\
(0.015)\end{array}$ & $\begin{array}{c}-0.067^{* *} \\
(0.033)\end{array}$ & $\begin{array}{c}-0.250^{* *} \\
(0.123)\end{array}$ & $\begin{array}{c}-0.092^{*} \\
(0.047)\end{array}$ & $\begin{array}{c}-0.024^{* * *} \\
(0.007)\end{array}$ \\
\hline PostAudit $\times$ Z & $\begin{array}{c}0.009^{* * *} \\
(0.002)\end{array}$ & $\begin{array}{c}0.009^{* * *} \\
(0.002)\end{array}$ & $\begin{array}{c}-0.050^{* * *} \\
(0.008)\end{array}$ & $\begin{array}{c}-0.098^{* * *} \\
(0.017)\end{array}$ & $\begin{array}{l}-0.061 \\
(0.065)\end{array}$ & $\begin{array}{c}-0.095^{* * *} \\
(0.027)\end{array}$ & $\begin{array}{c}-0.084^{* * *} \\
(0.004)\end{array}$ \\
\hline PostAudit $\times$ Incumbent & $\begin{array}{c}0.047^{* * *} \\
(0.004)\end{array}$ & $\begin{array}{c}0.050^{* * *} \\
(0.004)\end{array}$ & $\begin{array}{c}0.055^{* * *} \\
(0.003)\end{array}$ & $\begin{array}{c}0.055^{* * *} \\
(0.003)\end{array}$ & $\begin{array}{c}0.055^{* * *} \\
(0.003)\end{array}$ & $\begin{array}{c}0.055^{* * *} \\
(0.003)\end{array}$ & $\begin{array}{c}0.055^{* * *} \\
(0.003)\end{array}$ \\
\hline PostAudit & $\begin{array}{c}-0.032^{* * *} \\
(0.002)\end{array}$ & $\begin{array}{c}-0.032^{* * *} \\
(0.003)\end{array}$ & $\begin{array}{c}-0.026^{* * *} \\
(0.002)\end{array}$ & $\begin{array}{c}-0.027^{* * *} \\
(0.002)\end{array}$ & $\begin{array}{c}-0.027^{* * *} \\
(0.002)\end{array}$ & $\begin{array}{c}-0.027 * * * \\
(0.002)\end{array}$ & $\begin{array}{c}-0.018^{* * *} \\
(0.002)\end{array}$ \\
\hline Observations & $73,461,266$ & $73,461,266$ & $73,461,266$ & $73,461,266$ & $73,461,266$ & $73,461,266$ & $73,461,266$ \\
\hline R-squared & 0.831 & 0.831 & 0.831 & 0.831 & 0.831 & 0.831 & 0.831 \\
\hline Plant FE & Yes & Yes & Yes & Yes & Yes & Yes & Yes \\
\hline Year-quarter FE & Yes & Yes & Yes & Yes & Yes & Yes & Yes \\
\hline Avg Dep Var & 1.286 & 1.286 & 1.286 & 1.286 & 1.286 & 1.286 & 1.286 \\
\hline SD Dep Var & 1.163 & 1.163 & 1.163 & 1.163 & 1.163 & 1.163 & 1.163 \\
\hline p-value sum of coefficients & 0.000 & 0.000 & 0.152 & 0.000 & 0.007 & 0.000 & 0.000 \\
\hline
\end{tabular}

Notes: This table illustrates the heterogeneous effects of the audit across local firms. The table reports the coefficients obtained from the estimation of equation 6.1. The specification is $y_{f m t}=\alpha_{f}+\alpha_{t}+\gamma_{1} \times Z_{f} \times$ Incumbent $_{f} \times$ PostAudit $_{m t}+\gamma_{2} \times$ Incumbent $_{f} \times$ PostAudit $_{m t}+\gamma_{3} \times Z_{f} \times$ PostAudit $_{m t}+$ $\beta \times$ PostAudit $_{m t}+\epsilon_{f m t}$, and is discussed in Section 6.3. The sample includes all establishments in municipalities audited in the period 2003-2014 and all establishments in eligible non-audited municipalities, and covers the window $[-4,+12]$ quarters around the audit quarter. The dependent variable is the log of total employment in the establishment. PostAudit $t_{m t}$ is an indicator variable taking value 1 for all quarter-years after the audit in the audited municipality, and 0 otherwise. PostAudit $t_{m t}$ is always 0 for never treated municipalities. Incumbent $f_{f}$ is an indicator variable equal to one for firms that are alive at the time of the audit and in the previous two quarters. $Z_{f}$ are establishment characteristics based on government-dependent sectors and political connections. In the case of the sector-based measures: GD-Procurement is an indicator for belonging to a GD-Procurement sector and $G D$-Corrupt is an indicator for belonging to a GD-Corrupt sector. The variables that capture a firm's political connection status, measured at any time up to the audit, are: Firm Donor for firm that donated to a political campaign, Manager Donor for firms whose manager donated to a political campaign, Politician for firms whose manager was an elected politician, Candidate for firms whose manager was a political candidate (elected or not), and Party Member for firms whose manager was a registered member of a political party. All specifications include establishment and year-quarter fixed effects. Avg Dep Var and SD Dep Var are computed using establishments in eligible non-audited municipalities and audited municipalities in the year before the audit. Robust standard errors are clustered at the municipality level. ${ }^{* * *} \mathrm{p}<0.01,{ }^{* *} \mathrm{p}<0.05,{ }^{*} \mathrm{p}<0.1$. 


\title{
APPENDIX
}

\author{
Appendix A.1. Figures and TABles
}

\section{FiguRE A1. Informality/Formality: Validating Imputation from State- to Municipality- Level}

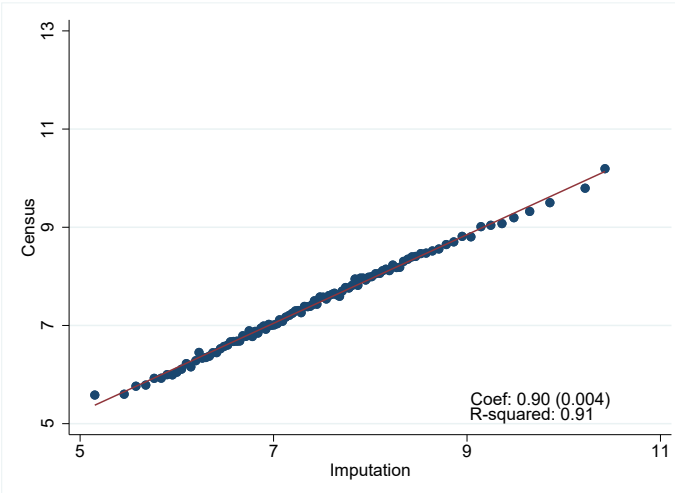

A. Informal (population shares)

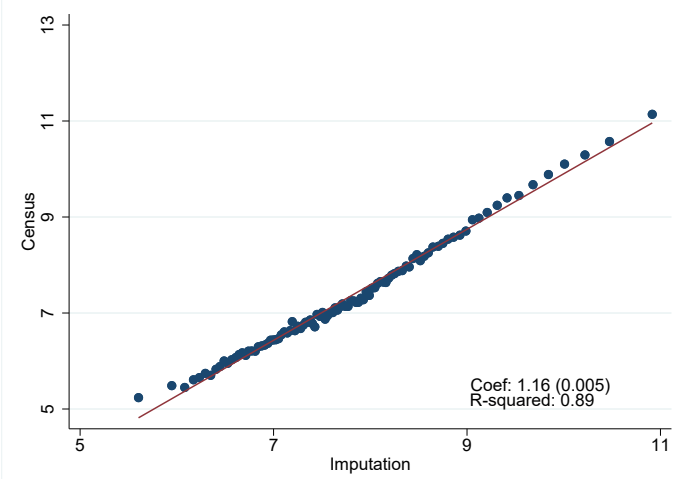

C. Formal (population shares)

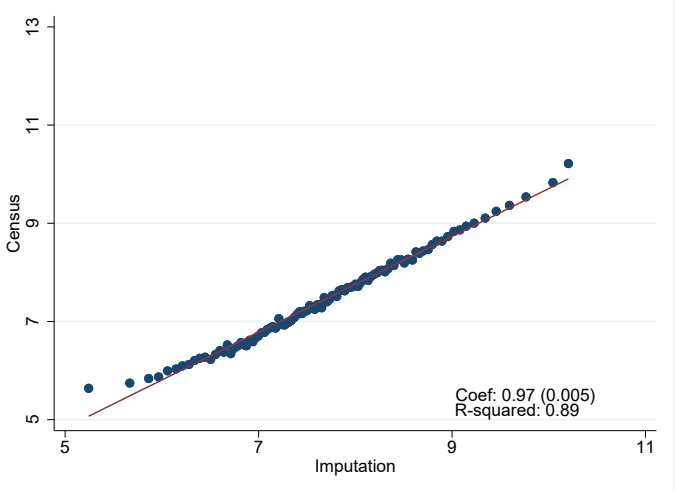

B. Informal (informality shares)

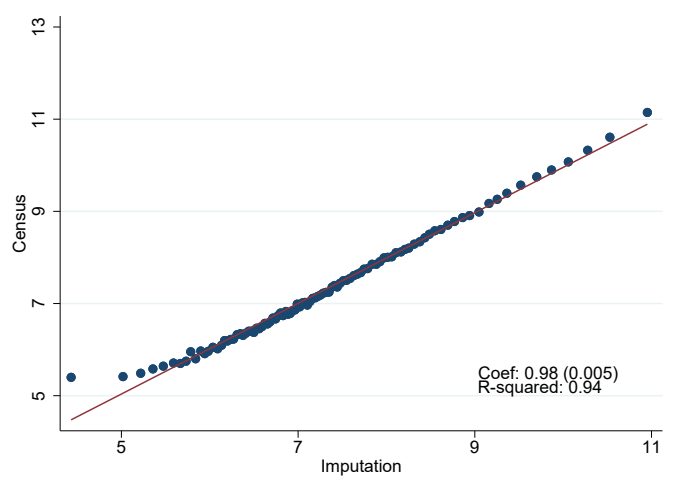

D. Formal (informality shares)

Notes: This figure reports both the estimated coefficients and the R-squared of the linear regression of the 2010 Decennial Census municipal measures of informal and formal employment (in logarithmic terms) on our imputations of those same measures in the PNAD dataset from state to municipality level. The imputations in Panels A and C are based on population shares, constructed from the annual IBGE data. The imputations in Panels B and D are based on informality shares, constructed from the 2000 Decennial Census. Since PNAD surveys are not conducted in 2010, we conduct this test using the average of the PNAD imputations for 2009 and 2011. 


\section{Figure A2. Government Dependence Sectors (Establish- ments): Alternative Measures}

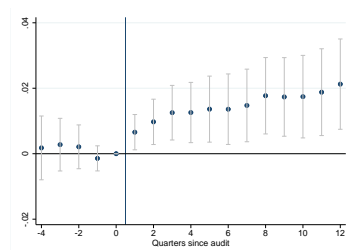

A. GD-Proc-NS

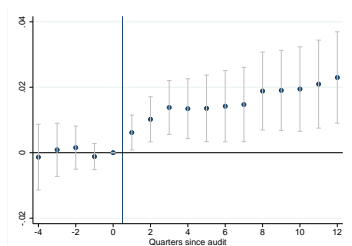

E NS

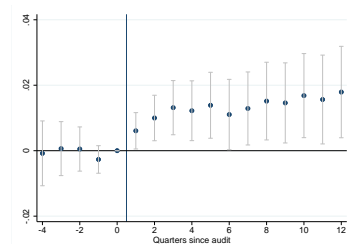

I. GD-Corr-Firms-NS J
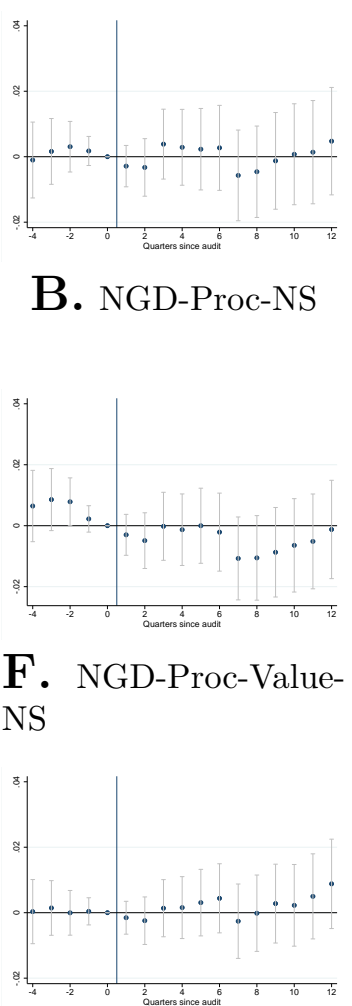

B. NGD-Proc-NS

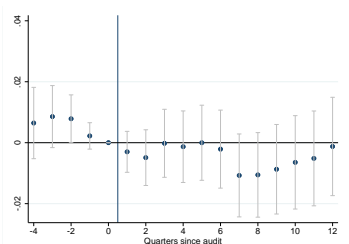

F. NGD-Proc-ValueNS NS
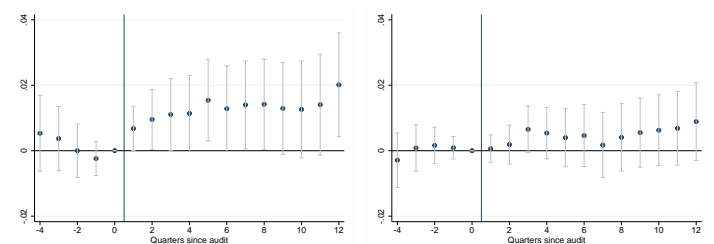

C. GD-Proc-Value-S

D. NGD-Proc-Value$\mathrm{S}$

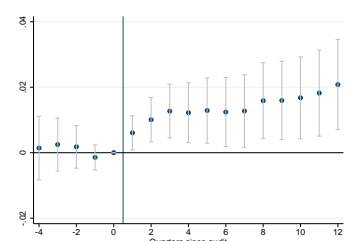

G. GD-Corr-NS
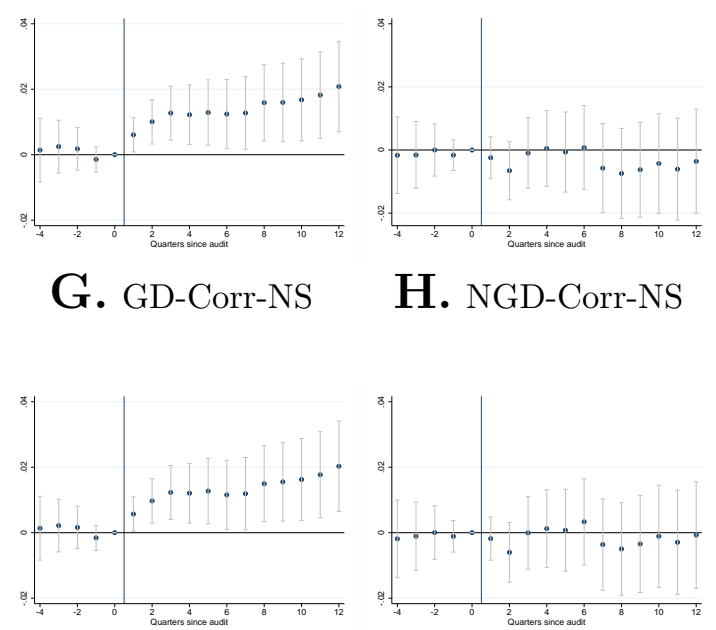

H. NGD-Corr-NS K NS

Notes: This figure reports the dynamic coefficients obtained from the estimation of equation 4.1 together with $95 \%$ confidence intervals, for different measures of government-dependent sectors (and their complement). The specification is $y_{m t}=\alpha_{m}+\alpha_{t}+\sum_{k=-4}^{k=-1} \mu_{k}+\sum_{k=1}^{k=12} \mu_{k}+\epsilon_{m t}$, and is discussed in Section 4. The sample includes all municipalities audited in the period 2003-2014 and all eligible non-audited municipalities, and covers the window $[-4,+12]$ quarters around the audit quarter. The dependent variable is the logarithm of private sector establishments. $G D$ and $N G D$ stand for government-dependent and non-government-dependent, respectively, and all alternative measures based on them are described in section 5.2. The other abbreviations in the figure are $S$ and $N S$, which stand for "scaled" and "not scaled," respectively. "Value" ("Firms") indicates that the sectoral classification comes from the distribution based on total value of contracts (total number of firms) in an industry. 


\section{Figure A3. Government-Dependent Sectors (Firms): Alter- native Measures}

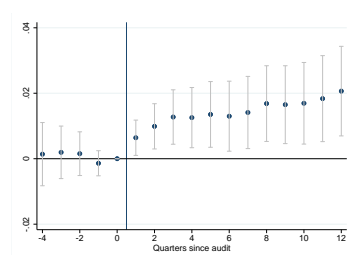

A. GD-Proc-NS

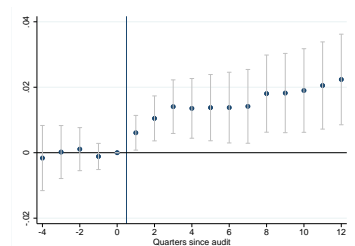

E. NS

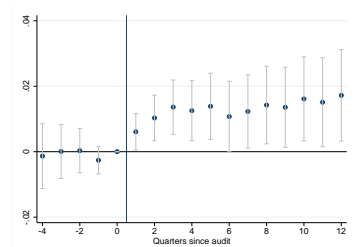

I. GD-Corr-Firms-NS J
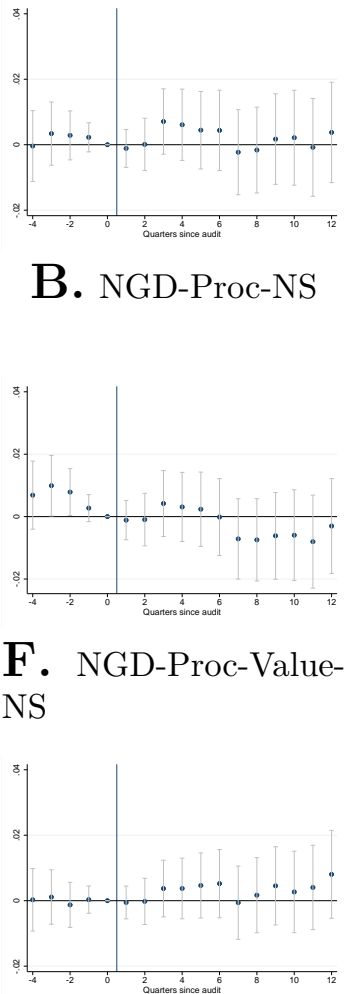

B. NGD-Proc-NS

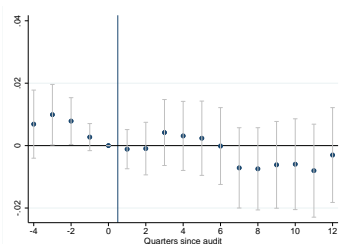

F. NGD-Proc-ValueNS

\section{NS}
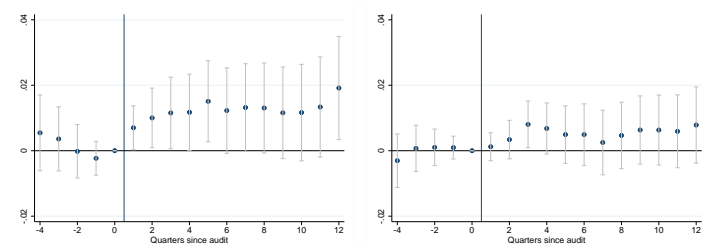

C. GD-Proc-Value-S

D. NGD-Proc-Value$\mathrm{S}$

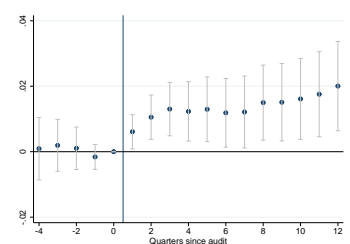

G. GD-Corr-NS
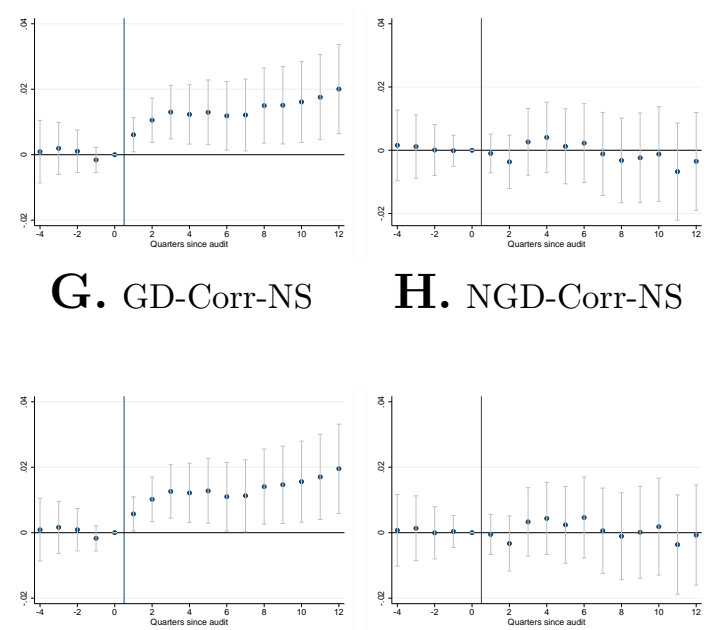

H. NGD-Corr-NS

L. NGD-Corr-FirmsNS

Notes: This figure reports the dynamic coefficients obtained from the estimation of equation 4.1 together with $95 \%$ confidence intervals, for different measures of government-dependent sectors (and their complement). The specification is $y_{m t}=\alpha_{m}+\alpha_{t}+\sum_{k=-4}^{k=-1} \mu_{k}+\sum_{k=1}^{k=12} \mu_{k}+\epsilon_{m t}$, and is discussed in Section 4 . The sample includes all municipalities audited in the period 2003-2014 and all eligible non-audited municipalities, and covers the window $[-4,+12]$ quarters around the audit quarter. The dependent variable is the logarithm of private sector firms. GD and $N G D$ stand for government-dependent and non-governmentdependent, respectively, and all alternative measures based on them are described in section 5.2. The other abbreviations in the figure are $S$ and $N S$, which stand for "scaled" and "not scaled," respectively. "Value" ("Firms") indicates that the sectoral classification comes from the distribution based on total value of contracts (total number of firms) in an industry. 
Figure A4. Direct Effects and Political Incentives: Early vs Late

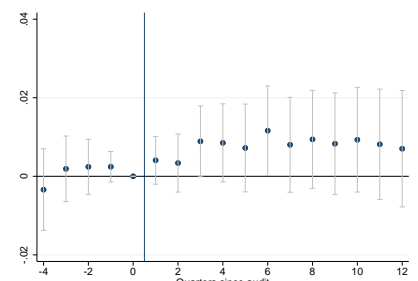

A. Early: All

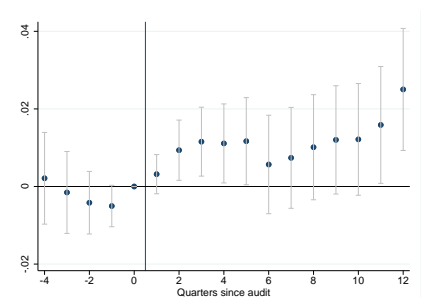

F. Final: All

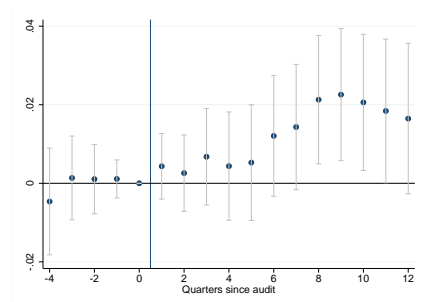

B. Early: GD-Proc

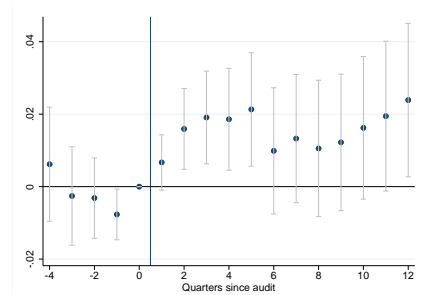

G. Final: GD-Proc

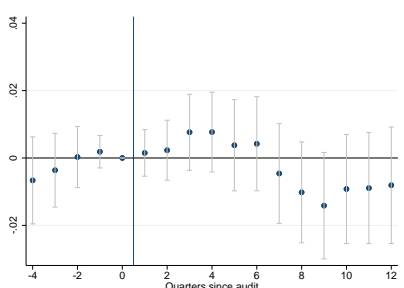

C. Early: Non-GD-Proc

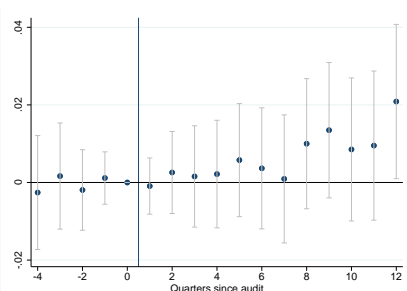

H. Final: Non-GD-Proc

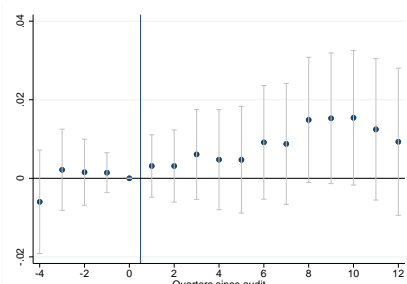

D. Early: GD-Corr

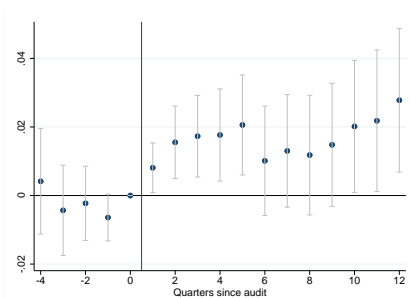

I. Final: GD-Corr

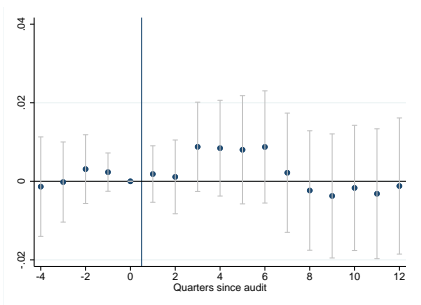

E. Early: Non-GD-Corr

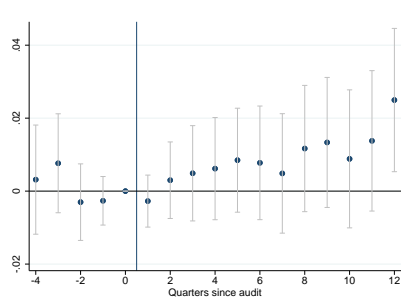

J. Final: Non-GD-Corr

Notes: This figure reports the dynamic coefficients obtained from the estimation of equation 4.1 together with $95 \%$ confidence intervals. The specification is $y_{m t}=\alpha_{m}+\alpha_{t}+\sum_{k=-4}^{k=-1} \mu_{k}+\sum_{k=1}^{k=12} \mu_{k}+\epsilon_{m t}$, and is discussed in Section 4. The sample includes all municipalities audited in the period 2003-2014 and all eligible non-audited municipalities, and covers the window $[-4,+12]$ around the audit quarter. The dependent variables is the log of the number of firms, and in each government-dependent sector, or its complement, as defined in section 5.2. Panels A to E show the results for municipalities that were audited in the first two years of the mayor's term, while Panels F to J present them for those audited in the last two years. 
Figure A5. Direct Effects and Political Incentives: First vs Second Term

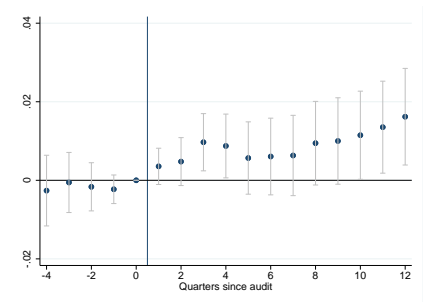

A. 1st term: All

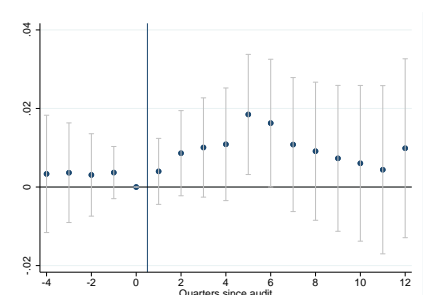

F. 2nd term: All

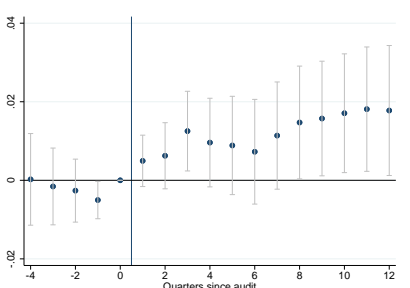

B. 1st term: GD-Proc

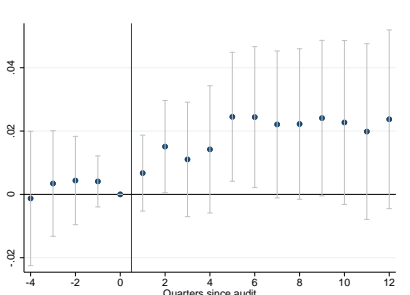

G. 2nd term: GD-Proc

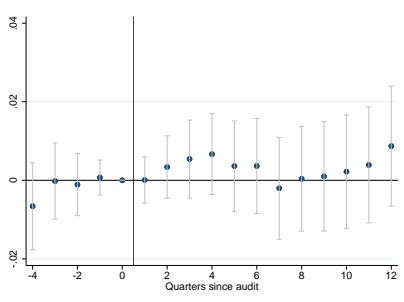

C. 1st term: Non-GD Proc

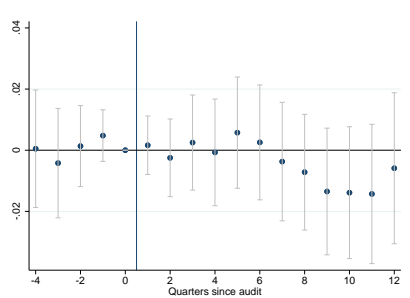

$\underset{\text { Proc }}{\mathbf{H}}$

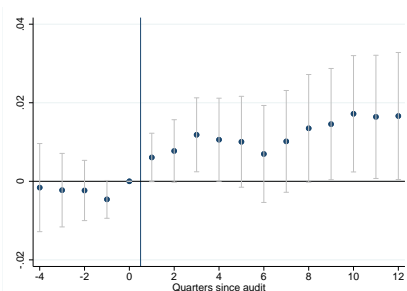

D. 1st term: GD-Corrup

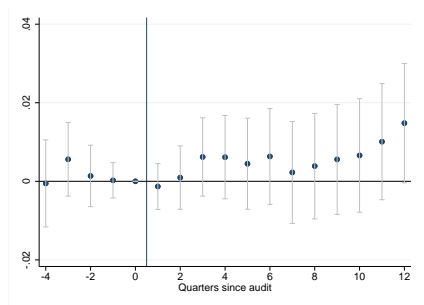

E. 1st term: Non-GDCorrupt
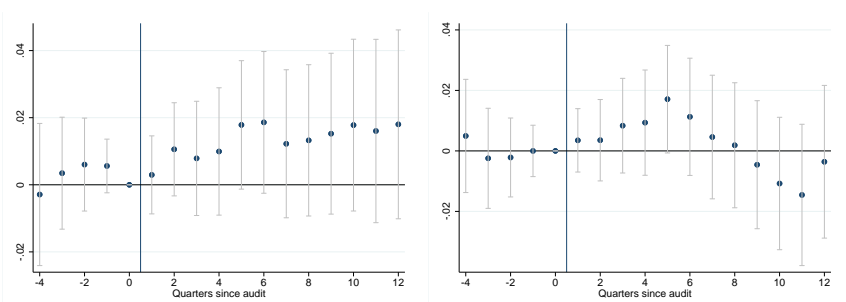

J. 2nd term: Non-GDCorrupt

Notes: This figure reports the dynamic coefficients obtained from the estimation of equation 4.1 together with $95 \%$ confidence intervals. The specification is $y_{m t}=\alpha_{m}+\alpha_{t}+\sum_{k=-4}^{k=-1} \mu_{k}+\sum_{k=1}^{k=12} \mu_{k}+\epsilon_{m t}$, and is discussed in Section 4. The sample includes all municipalities audited in the period 2003-2014 and all eligible non-audited municipalities, and covers the window [-4,+12] around the audit quarter. The dependent variables is the log of the number of firms, and in each government-dependent sector, or its complement, as defined in section 5.2. Panels A to E present the results for municipalities that were audited during the mayor's first term, while Panels F to J present them for those audited during the mayor's second term. 
TABle A1. Correlation Across Government Dependence Measures

\begin{tabular}{|c|c|c|c|c|c|c|c|c|}
\hline & \multicolumn{4}{|c|}{ GD-Procurement } & \multicolumn{4}{|c|}{ GD-Corrupt } \\
\hline & $\begin{array}{c}\text { Contracts } \\
\text { scaled }\end{array}$ & $\begin{array}{c}\text { Contracts } \\
\text { unscaled }\end{array}$ & $\begin{array}{r}\text { Value } \\
\text { scaled }\end{array}$ & $\begin{array}{c}\text { Value } \\
\text { unscaled }\end{array}$ & $\begin{array}{c}\text { Contracts } \\
\text { scaled }\end{array}$ & $\begin{array}{c}\text { Contracts } \\
\text { unscaled }\end{array}$ & $\begin{array}{l}\text { Firms } \\
\text { scaled }\end{array}$ & $\begin{array}{c}\text { Firms } \\
\text { unscaled }\end{array}$ \\
\hline GD-Proc-Contracts scaled & 1 & & & & & & & \\
\hline GD-Proc-Contracts unscaled & 0.588 & 1 & & & & & & \\
\hline GD-Proc-Value scaled & 0.556 & 0.338 & 1 & & & & & \\
\hline GD-Proc-Value unscaled & 0.453 & 0.633 & 0.582 & 1 & & & & \\
\hline GD-Corr-Contracts scaled & 0.267 & 0.274 & 0.225 & 0.274 & 1 & & & \\
\hline GD-Corr-Contracts unscaled & 0.238 & 0.528 & 0.122 & 0.464 & 0.548 & 1 & & \\
\hline GD-Corr-Firms scaled & 0.246 & 0.260 & 0.246 & 0.274 & 0.850 & 0.505 & 1 & \\
\hline GD-Corr-Firms unscaled & 0.227 & 0.512 & 0.136 & 0.466 & 0.510 & 0.931 & 0.524 & 1 \\
\hline
\end{tabular}

Notes: This table reports the correlation matrix for all measures of government dependence we create, as discussed in section 5.2. 


\section{Table A2. Most and Least Common Government-Dependent Sectors: Procurement}

\begin{tabular}{|c|c|}
\hline Ranked list of TOP 50 GD sectors & Ranked list of LEAST 50 GD sectors \\
\hline Wholesale of instruments and materials for medical, surgical, orthopedic and dental & Soy cultivation \\
\hline Wholesale of office and stationery goods, books, newspapers and other publications & Cattle breeding \\
\hline Wholesale of machinery, apparatus and equipment for dental and medical purposes & Coffee cultivation \\
\hline Manufacture of pharmaceutical preparations & Orange cultivation \\
\hline Wholesale of pharmaceutical products for human and veterinary use & Cultivation of permanent fruit crops (except orange and grape) \\
\hline Manufacture of medicines & Activities of religious organizations \\
\hline Retail of medical and orthopedic supplies & Raising of large animals \\
\hline Manufacture of organic chemicals & Assistance activities for elderly and disabled \\
\hline Wholesale of computers and computer supplies & Pig breeding \\
\hline Industrial gas manufacturing & Activities of unions \\
\hline Wholesale of electrical material & Savings banks \\
\hline Computer equipment manufacturing & Commercial banks \\
\hline Manufacture of chemicals & Cultivation of temporary tillage plants \\
\hline Manufacture of electromedical, electrotherapeutic and irradiation apparatus & Sugarcane cultivation \\
\hline Pharmaceutical manufacturing & Poultry farming \\
\hline Manufacture of instruments and materials for medical, dental or optical purposes & Early childhood education - preschool \\
\hline Wholesale of liquefied petroleum gas (LPG) & Hairdressers and other beauty treatment activities \\
\hline Retail of books, newspapers, magazines and stationery & Courier activities \\
\hline Manufacture of cars, vans and utilities & Saltwater fishing \\
\hline Manufacture of computer peripheral equipment & Livestock support activities \\
\hline Manufacture of clocks and stopwatches & Credit, financing and investment companies \\
\hline Retail of electrical material & Notaries \\
\hline Wholesale (specialized) of other intermediate products & Early childhood education and day care \\
\hline Wholesale of hardware and tools & Social assistance activities in private residences \\
\hline Manufacture of optical, photographic and cinematographic instruments & Social, sports and similar clubs \\
\hline Wholesale of chemicals and petrochemicals & Art and culture education \\
\hline Wholesale of general merchandise, excluding agriculture & Housekeeper services \\
\hline Wholesale of food products & Compulsory social security \\
\hline Wholesale of construction materials & Manufacture of sneakers \\
\hline Retail of computer equipment and supplies & Banks with commercial portfolio \\
\hline Wholesale of general merchandise (mainly food) & Saltwater and brackish aquaculture \\
\hline Wholesale trade of machinery and equipment for industrial use & Justice \\
\hline Wholesale of cement & Manufacture of tobacco products \\
\hline Wholesale of general machinery, apparatus and equipment & Manufacture of raw sugar \\
\hline Wired telecommunications & Vehicle parking \\
\hline Retail of lubricants & Activities of organizations for culture and art \\
\hline Wholesale of equipment for personal and household use & Manufacture of wine \\
\hline Manufacture of heavy military equipment and firearms & Real estate activities \\
\hline Wholesale of machinery and equipment for commercial use & Extraction of iron ore \\
\hline Manufacture of paper, cardboard, paperboard & Rental of videotapes and DVDs \\
\hline Retail of hardware, wood and construction materials & Manufacture of iron \\
\hline Manufacture of pipes and plastic material for construction & Veterinary activities \\
\hline Maintenance and repair of electronic and optical equipment & Rental of clothing, jewelry and accessories \\
\hline Manufacture of measuring, testing and control equipment & Freshwater aquaculture \\
\hline Retail of paints and materials & Other financial services activities \\
\hline Manufacture of insulated wires, cables and electrical condu & Radio activities \\
\hline Manufacture of environ & Activities of employer associations \\
\hline Manufacture of glass packaging & Insurance \\
\hline Retail of musical instruments and accessories & Health care for mental disorders \\
\hline Manufacture of oil refining products & Highways, bridges, tunnels and related structures \\
\hline
\end{tabular}

Notes: This table reports the most and least common 4-digit sectors we classify as government-dependent measured by GD-Procurement, as discussed in section 5 . We select the top/least 50 sectors. 
TABlE A3. Most and Least Common Government-Dependent Sectors: Corruption

\begin{tabular}{|c|c|}
\hline Ranked list of TOP 50 GD sectors & Ranked list of LEAST 50 GD sectors \\
\hline Wholesale of pharmaceutical products & Horticulture \\
\hline Maintenance and repair of railway vehicles & Manufacture of cement \\
\hline Construction of road and railroad & Forest production \\
\hline Railway passenger transport & Manufacture of footwear of synthetic material \\
\hline Manufacture of cars and trucks & Wholesale of pesticides and fertilizers \\
\hline Wholesale of materials for medical, surgical, orthopedic and dental use & Manufacture of machinery and equipment for the plastics industry \\
\hline Treatment and disposal of non-hazardous waste & Extraction of radioactive minerals \\
\hline Passenger air transport & Compulsory social security \\
\hline Road passenger transport & Housekeeper services \\
\hline Wholesale of general merchandise (mainly food) & Saltwater fishing \\
\hline Retail of automotive fuel & Extraction of iron ore \\
\hline Patient removal services (except mobile emergency care) & Cultivation of flowers and ornamental plants \\
\hline Retail of general merchandise (mainly supermarkets) & Manufacture of iron \\
\hline Civil engineering works & Rental of clothing, jewelry and accessories \\
\hline Construction of buildings & Manufacture of metal packaging \\
\hline Manufacture of juices from fruits and vegetables & Orange growing \\
\hline Earthworks & Manufacture of cosmetics, perfumery and toiletries \\
\hline Wholesale of processed flour and starch & Coffee cultivation \\
\hline Construction of oundations & Social, sports and similar clubs \\
\hline Urbanization works: streets, squares and sidewalks & Cultivation of permanent fruit crops \\
\hline Road passenger transport & Library and archive activities \\
\hline Electricity and telecommunications works & Insurance \\
\hline Retail of books, newspapers, magazines and stationery & Manufacture of artificial and synthetic fibers \\
\hline Construction of water supply, sewage systems and related & Freshwater aquaculture \\
\hline Wholesale of office and stationery supplies & Manufacture of sneakers (any material) \\
\hline Manufacture of medicines & Raising of large animals \\
\hline Wholesale of machinery and equipment for dental and medical purposes & Pig breeding \\
\hline Manufacture of steam generating boilers & Interior design and decoration \\
\hline Manufacture of milk & Hairdressers and other beauty treatment activities \\
\hline Manufacture of construction machinery (except tractors) & Savings banks \\
\hline Retail of medical and orthopedic supplies & Sugarcane cultivation \\
\hline Manufacture of electromedical, electrotherapeutic and irradiation apparatus & Manufacture of paper \\
\hline Road passenger transport by freight & Saltwater and brackish aquaculture \\
\hline Integrated edition of cadastre and other graphic products & Credit, financing and investment companies \\
\hline Rental of office machinery and equipment & Manufacture of refined sugar \\
\hline School transportation & Veterinary activities \\
\hline Demolition and preparation of construction sites & Manufacture of wine \\
\hline Wholesale of food products & Call center activities \\
\hline Manufacture of meat products & Commercial Banks \\
\hline Milling of wheat & Grape growing \\
\hline Construction of special artworks & Other financial services activities \\
\hline Printing of materials for other uses & Livestock support activities \\
\hline Credit card management & Banks with commercial portfolio \\
\hline Services of land preparation & Soy cultivation \\
\hline Manufacture of clocks and stopwatches & Poultry farming \\
\hline Retail of general merchandise (mainly food) & Early childhood education \\
\hline Wholesale of food products & Activities of religious organizations \\
\hline Car rental & Activities of employer associations \\
\hline Hospital care activities & Highways, bridges, tunnels and related structures \\
\hline Manufacture of metal furniture & Iron and steel foundry \\
\hline
\end{tabular}

Notes: This table reports the most and least common 4-digit sectors we classify as government-dependent measured by GD-Corrupt, as discussed in section 5 . We select the top/least 50 sectors. 
Table A4. Sao Paulo Municipal Public Procurement

\begin{tabular}{|c|c|c|c|}
\hline & $\begin{array}{c}(1) \\
\text { Establishments }\end{array}$ & $\begin{array}{c}\text { Establishments } \\
\text { First Time in Municipality }\end{array}$ & $\begin{array}{c}(3) \\
\text { Establishments } \\
\text { First Time Ever }\end{array}$ \\
\hline PostAudit & $\begin{array}{c}0.014 \\
(0.012)\end{array}$ & $\begin{array}{c}0.057^{* *} \\
(0.028)\end{array}$ & $\begin{array}{c}0.086^{* *} \\
(0.037)\end{array}$ \\
\hline Observations & 4,846 & 4,846 & 4,846 \\
\hline R-squared & 0.942 & 0.983 & 0.959 \\
\hline Municipality FE & Yes & Yes & Yes \\
\hline Year FE & Yes & Yes & Yes \\
\hline Avg Dep Var & 6.302 & 3.776 & 2.961 \\
\hline SD Dep Var & 0.359 & 2.470 & 1.976 \\
\hline
\end{tabular}

Notes: This table illustrates the main effects of the audits on local public procurement outcomes in the state of Sao Paulo. The table reports the coefficients obtained from the estimation of equation 4.2. The specification is $y_{m t}=\alpha_{m}+\alpha_{t}+\beta \times$ PostAudit $_{m t}+\epsilon_{m t}$, and is discussed in Section 4. The regression uses data from Sao Paulo public procurement from 2008. The sample includes all SP municipalities audited in the period 2007-2014 and all eligible non-audited SP municipalities, and covers the window $[-1,+3]$ years around the audit year. PostAudit $t_{m t}$ is an indicator variable taking value 1 for all years after the audit in the audited municipality, and 0 otherwise. PostAudit ${ }_{m t}$ is always 0 for never treated municipalities. All specifications include municipality and year fixed effects. Establishments is the log of the total number of private sector establishments who obtain at least one contract from the municipality. Establishments First Time in Municipality is the log of the total number of private sector establishments that obtain at least one contract from the municipality, and that never obtained any contract from that municipality prior to the audit. Establishments First Time Ever is the log of the total number of private sector establishments that obtain at least one contract from the municipality, and that never obtained any contract from any municipality prior to the audit. Avg Dep Var and SD Dep Var are computed using eligible non-audited municipalities and audited municipalities in the year before the audit. Robust standard errors are clustered at the municipality level. ${ }^{* * *} \mathrm{p}<0.01,{ }^{* *} \mathrm{p}<0.05,{ }^{*} \mathrm{p}<0.1$. 
TABle A5. Main Effect: PAC/PAS Sample

\begin{tabular}{|c|c|c|}
\hline & $\begin{array}{c}(1) \\
\text { Establishments }\end{array}$ & $\begin{array}{l}(2) \\
\text { Firms }\end{array}$ \\
\hline PostAudit & $\begin{array}{c}0.018^{* *} \\
(0.008)\end{array}$ & $\begin{array}{c}0.018^{* *} \\
(0.008)\end{array}$ \\
\hline Observations & 199,480 & 199,480 \\
\hline R-squared & 0.947 & 0.946 \\
\hline Municipality FE & Yes & Yes \\
\hline Year-quarter FE & Yes & Yes \\
\hline Avg Dep Var & 1.377 & 1.356 \\
\hline SD Dep Var & 1.397 & 1.376 \\
\hline
\end{tabular}

Notes: This table illustrates the main effects of the audits on firms restricting the analysis to the samples that overlap with the PAC and PAS databases. The table reports the coefficients obtained from the estimation of equation 4.2. The specification is $y_{m t}=\alpha_{m}+\alpha_{t}+\beta \times$ PostAudit $_{m t}+\epsilon_{m t}$, and is discussed in Section 4. The sample includes all municipalities audited in the period 2003-2014 and all eligible nonaudited municipalities, and covers the window $[-4,+12]$ quarters around the audit quarter. PostAudit Pt $_{\text {is }}$ an indicator variable taking value 1 for all quarter-years after the audit in the audited municipality, and 0 otherwise. PostAudit ${ }_{m t}$ is always 0 for never treated municipalities. All specifications include municipality and year-quarter fixed effects. Establishments is the log of the total number of private sector establishments in the municipality. Firms is the log of the total number of private sector firms in the municipality. Results are based on the RAIS dataset but focusing on the sectors and firms covered by the PAC and PAS surveys and for establishments and firms with more than 20 employees. Avg Dep Var and SD Dep Var are computed using eligible non-audited municipalities and audited municipalities in the 4 quarters before the audit. Robust standard errors are clustered at the municipality level. ${ }^{* * *} \mathrm{p}<0.01,{ }^{* *} \mathrm{p}<0.05,{ }^{*} \mathrm{p}<0.1$. 
TABle A6. The Impact of Audits on Firms: Robustness

\begin{tabular}{|c|c|c|c|c|c|c|c|c|}
\hline \multirow[b]{3}{*}{ Panel A } & \multicolumn{2}{|c|}{$\begin{array}{cc}(1) & (2) \\
\text { No Window Restriction }\end{array}$} & \multicolumn{2}{|c|}{$\begin{array}{c}(3) \\
\text { Drop Audited Twice }\end{array}$} & \multicolumn{2}{|c|}{$\begin{array}{c}(5) \\
\text { Audited Post-2004 }\end{array}$} & \multicolumn{2}{|c|}{$\begin{array}{c}(7) \\
\text { Audited Pre-2012 }\end{array}$} \\
\hline & Establishments & Firms & Establishments & Firms & Establishments & Firms & Establishments & Firms \\
\hline & & & & & & & & \\
\hline PostAudit & $\begin{array}{c}0.034^{* * *} \\
(0.008)\end{array}$ & $\begin{array}{c}0.034^{* * *} \\
(0.008)\end{array}$ & $\begin{array}{r}0.009^{* *} \\
(0.004)\end{array}$ & $\begin{array}{r}0.010^{* *} \\
(0.004)\end{array}$ & $\begin{array}{r}0.011^{* *} \\
(0.005)\end{array}$ & $\begin{array}{c}0.012^{* *} \\
(0.005)\end{array}$ & $\begin{array}{c}0.010^{* *} \\
(0.004)\end{array}$ & $\begin{array}{c}0.011^{* * *} \\
(0.004)\end{array}$ \\
\hline Observations & 372,513 & 372,513 & 273,293 & 273,293 & 266,054 & 266,054 & 275,369 & 275,369 \\
\hline R-squared & 0.983 & 0.984 & 0.984 & 0.985 & 0.984 & 0.984 & 0.984 & 0.985 \\
\hline Municipality FE & Yes & Yes & Yes & Yes & Yes & Yes & Yes & Yes \\
\hline Year-quarter FE & Yes & Yes & Yes & Yes & Yes & Yes & Yes & Yes \\
\hline Avg Dep Var & 4.127 & 4.086 & 4.180 & 4.139 & 4.181 & 4.141 & 4.178 & 4.137 \\
\hline SD Dep Var & 1.624 & 1.619 & 1.611 & 1.606 & 1.611 & 1.606 & 1.612 & 1.607 \\
\hline \multicolumn{9}{|l|}{ Panel B } \\
\hline & \multicolumn{2}{|c|}{ Ever Audited } & \multicolumn{2}{|c|}{$\begin{array}{c}\text { Control for } \\
\text { Audit Probability }\end{array}$} & \multicolumn{2}{|c|}{ No Winsorization } & \multicolumn{2}{|c|}{$5 \%$ Winsorization } \\
\hline & Establishments & Firms & Establishments & Firms & Establishments & Firms & Establishments & Firms \\
\hline PostAudit & $\begin{array}{c}0.024^{* * *} \\
(0.003)\end{array}$ & $\begin{array}{c}0.026^{* * *} \\
(0.003)\end{array}$ & $\begin{array}{c}0.009^{* *} \\
(0.004)\end{array}$ & $\begin{array}{c}0.009^{* *} \\
(0.004)\end{array}$ & $\begin{array}{c}0.008^{* *} \\
(0.004)\end{array}$ & $\begin{array}{c}0.009^{* *} \\
(0.004)\end{array}$ & $\begin{array}{l}0.006^{*} \\
(0.004)\end{array}$ & $\begin{array}{l}0.007^{*} \\
(0.004)\end{array}$ \\
\hline Observations & 31,725 & 31,725 & 277,392 & 277,392 & 277,392 & 277,392 & 277,392 & 277,392 \\
\hline R-squared & 0.994 & 0.994 & 0.984 & 0.985 & 0.985 & 0.985 & 0.983 & 0.984 \\
\hline Municipality FE & Yes & Yes & Yes & Yes & Yes & Yes & Yes & Yes \\
\hline Year-quarter FE & Yes & Yes & Yes & Yes & Yes & Yes & Yes & Yes \\
\hline Avg Dep Var & 3.991 & 3.944 & 4.179 & 4.138 & 4.180 & 4.140 & 4.159 & 4.119 \\
\hline SD Dep Var & 1.642 & 1.635 & 1.611 & 1.607 & 1.616 & 1.611 & 1.517 & 1.512 \\
\hline
\end{tabular}

Notes: This table illustrates the robustness of the main effects of the audit on the local economy. The table reports the coefficients obtained from the estimation of equation 4.2. The baseline specification is $y_{m t}=\alpha_{m}+\alpha_{t}+\beta \times$ PostAudit $_{m t}+\epsilon_{m t}$, and is discussed in Section 4. Unless otherwise specified and discussed in Section 5.2, the sample includes all municipalities audited in the period 2003-2014 and all eligible non-audited municipalities, and covers the window $[-4,+12]$ quarters around the audit quarter. PostAudit Pt $_{\text {t }}$ is an indicator variable taking value 1 for all quarter-years after the audit in the audited municipality, and 0 otherwise. PostAudit ${ }_{m t}$ is always 0 for never treated municipalities. Establishments (Firms) is the log of the total number of private sector establishments (firms) in the municipality. The various robustness tests are discussed in section 5.2. Notice that in the specification where we drop the never-audited municipalities (i.e., columns 1 and 2 of Panel B, we include year rather than year-quarter fixed effects; all other specifications include municipality and year-quarter fixed effects. Avg Dep Var and SD Dep Var are computed using data in the 4 quarters before the audit. Robust standard errors are clustered at the municipality level. *** $\mathrm{p}<0.01,{ }^{* *} \mathrm{p}<0.05,{ }^{*} \mathrm{p}<0.1$. 
TABle A7. The Impact of Audits on Firms: Robustness to Alternative Measures of GovernmentDependent Sectors

\begin{tabular}{|c|c|c|c|c|c|c|c|c|c|c|c|c|}
\hline & (1) & (2) & $\begin{array}{l}(3) \\
\text { GD-Pro }\end{array}$ & $\begin{array}{c}(4) \\
\text { urement }\end{array}$ & (5) & (6) & (7) & (8) & $\begin{array}{l}(9) \\
\text { GD-Co }\end{array}$ & $\begin{array}{l}(10) \\
\text { rrupt }\end{array}$ & (11) & (12) \\
\hline & Contract: & unscaled & Value & scaled & Value $\mathrm{u}$ & nscaled & Contract & 5 unscaled & Firms & scaled & Firms & unscaled \\
\hline & GD & Non-GD & GD & Non-GD & GD & Non-GD & GD & Non-GD & GD & Non-GD & GD & Non-GD \\
\hline \multicolumn{13}{|c|}{ Panel A: Establishments } \\
\hline PostAudit & $\begin{array}{l}0.012^{* *} \\
(0.005)\end{array}$ & $\begin{array}{l}-0.001 \\
(0.006)\end{array}$ & $\begin{array}{l}0.010^{*} \\
(0.006)\end{array}$ & $\begin{array}{c}0.004 \\
(0.004)\end{array}$ & $\begin{array}{c}0.014^{* * *} \\
(0.005)\end{array}$ & $\begin{array}{l}-0.010^{*} \\
(0.005)\end{array}$ & $\begin{array}{l}0.012^{* *} \\
(0.005)\end{array}$ & $\begin{array}{l}-0.002 \\
(0.006)\end{array}$ & $\begin{array}{c}0.013^{* * * *} \\
(0.005)\end{array}$ & $\begin{array}{c}0.001 \\
(0.005)\end{array}$ & $\begin{array}{l}0.011^{* *} \\
(0.005)\end{array}$ & $\begin{array}{l}-0.000 \\
(0.006)\end{array}$ \\
\hline Observations & 277,392 & 277,392 & 277,392 & 277,392 & 277,392 & 277,392 & 277,392 & 277,392 & 277,392 & 277,392 & 277,392 & 277,392 \\
\hline R-squared & 0.981 & 0.960 & 0.975 & 0.983 & 0.981 & 0.961 & 0.981 & 0.956 & 0.975 & 0.981 & 0.981 & 0.958 \\
\hline Avg Dep Var & 3.960 & 2.501 & 3.118 & 3.786 & 3.945 & 2.565 & 3.995 & 2.362 & 3.514 & 3.470 & 3.988 & 2.407 \\
\hline SD Dep Var & 1.692 & 1.301 & 1.647 & 1.551 & 1.691 & 1.332 & 1.678 & 1.295 & 1.514 & 1.687 & 1.675 & 1.320 \\
\hline p-value GD vs Non-GD & 0.062 & 0.062 & 0.344 & 0.344 & 0.001 & 0.001 & 0.072 & 0.072 & 0.067 & 0.067 & 0.116 & 0.116 \\
\hline \multicolumn{13}{|l|}{ Panel B: Firms } \\
\hline PostAudit & $\begin{array}{c}0.012 \text { *** } \\
(0.005)\end{array}$ & $\begin{array}{l}-0.000 \\
(0.005)\end{array}$ & $\begin{array}{l}0.010^{*} \\
(0.005)\end{array}$ & $\begin{array}{c}0.005 \\
(0.004)\end{array}$ & $\begin{array}{c}0.014^{* * *} \\
(0.005)\end{array}$ & $\begin{array}{l}-0.009^{*} \\
(0.005)\end{array}$ & $\begin{array}{l}0.012^{* *} \\
(0.005)\end{array}$ & $\begin{array}{l}-0.002 \\
(0.005)\end{array}$ & $\begin{array}{c}0.013^{* * *} \\
(0.005)\end{array}$ & $\begin{array}{c}0.003 \\
(0.005)\end{array}$ & $\begin{array}{l}0.011^{* *} \\
(0.005)\end{array}$ & $\begin{array}{c}0.000 \\
(0.005)\end{array}$ \\
\hline Observations & 277,392 & 277,392 & 277,392 & 277,392 & 277,392 & 277,392 & 277,392 & 277,392 & 277,392 & 277,392 & 277,392 & 277,392 \\
\hline R-squared & 0.981 & 0.963 & 0.975 & 0.983 & 0.981 & 0.964 & 0.981 & 0.959 & 0.975 & 0.982 & 0.981 & 0.961 \\
\hline Avg Dep Var & 3.943 & 2.405 & 3.107 & 3.738 & 3.929 & 2.469 & 3.977 & 2.259 & 3.500 & 3.412 & 3.970 & 2.308 \\
\hline SD Dep Var & 1.683 & 1.267 & 1.640 & 1.544 & 1.682 & 1.306 & 1.669 & 1.258 & 1.505 & 1.684 & 1.667 & 1.287 \\
\hline p-value GD vs Non-GD & 0.071 & 0.071 & 0.438 & 0.438 & 0.001 & 0.001 & 0.062 & 0.062 & 0.108 & 0.108 & 0.108 & 0.108 \\
\hline Municipality FE & Yes & Yes & Yes & Yes & Yes & Yes & Yes & Yes & Yes & Yes & Yes & Yes \\
\hline Year-quarter FE & Yes & Yes & Yes & Yes & Yes & Yes & Yes & Yes & Yes & Yes & Yes & Yes \\
\hline
\end{tabular}

Notes: This table illustrates the robustness of the main effects of the audit on the local economy, using various alternative definitions of governmentdependent sectors. The table reports the coefficients obtained from the estimation of equation 4.2 . The specification is $y_{m t}=\alpha_{m}+\alpha_{t}+\beta \times P_{o s t A u d i t} t+$ $\epsilon_{m t}$, and is discussed in Section 4. The sample includes all municipalities audited in the period 2003-2014 and all eligible non-audited municipalities, and covers the window [-4,+12] quarters around the audit quarter. PostAudit ${ }_{m t}$ is an indicator variable taking value 1 for all quarter-years after the audit in the audited municipality, and 0 otherwise. PostAudit ${ }_{m t}$ is always 0 for never treated municipalities. All specifications include municipality and year-quarter fixed effects. Establishments (Firms) is the log of the total number of private sector establishments (firms) in the municipality. The various definitions of government dependence are discussed in section 5.2. The p-value GD vs Non-GD presents the p-value for the difference between PostAudit coefficients in GD vs Non-GD sectors. Avg Dep Var and SD Dep Var are computed using eligible non-audited municipalities and audited municipalities in the 4 quarters before the audit. Robust standard errors are clustered at the municipality level. ${ }^{* * *} \mathrm{p}<0.01,{ }^{* *} \mathrm{p}<0.05,{ }^{*} \mathrm{p}<0.1$. 
TABLE A8. Direct Effects: Discipline and Selection

\begin{tabular}{|c|c|c|c|c|c|c|c|c|c|c|}
\hline & $\begin{array}{l}\text { (1) } \\
\text { All }\end{array}$ & $\begin{array}{c}(2) \\
\text { GD } \\
\text { Procurement }\end{array}$ & $\begin{array}{c}(3) \\
\text { Non-GD } \\
\text { Procurement }\end{array}$ & $\begin{array}{c}(4) \\
\text { GD } \\
\text { Corrupt }\end{array}$ & $\begin{array}{c}(5) \\
\text { Non-GD } \\
\text { Corrupt }\end{array}$ & $\begin{array}{l}\text { (6) } \\
\text { All }\end{array}$ & $\begin{array}{c}(7) \\
\text { GD } \\
\text { Procurement }\end{array}$ & $\begin{array}{c}(8) \\
\text { Non-GD } \\
\text { Procurement }\end{array}$ & $\begin{array}{c}(9) \\
\text { GD } \\
\text { Corrupt }\end{array}$ & $\begin{array}{c}(10) \\
\text { Non-GD } \\
\text { Corrupt }\end{array}$ \\
\hline & \multicolumn{5}{|c|}{ Panel A: New mayor $[0,3]$} & \multicolumn{5}{|c|}{ Panel B: No change in mayor $[0,3]$} \\
\hline PostAudit & $\begin{array}{c}0.006 \\
(0.004)\end{array}$ & $\begin{array}{c}0.011^{* *} \\
(0.006)\end{array}$ & $\begin{array}{l}-0.000 \\
(0.006)\end{array}$ & $\begin{array}{c}0.013^{* *} \\
(0.006)\end{array}$ & $\begin{array}{c}-0.003 \\
(0.006)\end{array}$ & $\begin{array}{c}0.016^{* *} \\
(0.007)\end{array}$ & $\begin{array}{c}0.019^{* *} \\
(0.009)\end{array}$ & $\begin{array}{c}0.009 \\
(0.008)\end{array}$ & $\begin{array}{c}0.012 \\
(0.008)\end{array}$ & $\begin{array}{c}0.017^{* *} \\
(0.008)\end{array}$ \\
\hline Observations & 267,311 & 267,311 & 267,311 & 267,311 & 267,311 & 255,748 & 255,748 & 255,748 & 255,748 & 255,748 \\
\hline R-squared & 0.984 & 0.976 & 0.979 & 0.974 & 0.981 & 0.984 & 0.976 & 0.979 & 0.974 & 0.980 \\
\hline Avg Dep Var & 4.139 & 3.594 & 3.310 & 3.539 & 3.369 & 4.144 & 3.598 & 3.314 & 3.543 & 3.374 \\
\hline SD Dep Var & 1.606 & 1.597 & 1.594 & 1.526 & 1.670 & 1.606 & 1.597 & 1.596 & 1.526 & 1.672 \\
\hline \multirow{2}{*}{ p-value Panel A vs B } & 0.185 & 0.491 & 0.337 & 0.929 & 0.050 & 0.185 & 0.491 & 0.337 & 0.929 & 0.050 \\
\hline & \multicolumn{5}{|c|}{ Panel C: New party $[0,3]$} & \multicolumn{5}{|c|}{ Panel D: No change in party $[0,3]$} \\
\hline PostAudit & $\begin{array}{c}0.006 \\
(0.004)\end{array}$ & $\begin{array}{l}0.010^{*} \\
(0.006)\end{array}$ & $\begin{array}{c}0.003 \\
(0.005)\end{array}$ & $\begin{array}{l}0.009^{*} \\
(0.006)\end{array}$ & $\begin{array}{c}0.004 \\
(0.005)\end{array}$ & $\begin{array}{c}0.016^{* *} \\
(0.007)\end{array}$ & $\begin{array}{c}0.024^{* *} \\
(0.009)\end{array}$ & $\begin{array}{c}0.002 \\
(0.009)\end{array}$ & $\begin{array}{c}0.020^{* *} \\
(0.009)\end{array}$ & $\begin{array}{c}0.002 \\
(0.009)\end{array}$ \\
\hline Observations & 267,949 & 267,949 & 267,949 & 267,949 & 267,949 & 255,110 & 255,110 & 255,110 & 255,110 & 255,110 \\
\hline R-squared & 0.985 & 0.976 & 0.980 & 0.974 & 0.981 & 0.984 & 0.976 & 0.979 & 0.974 & 0.980 \\
\hline Avg Dep Var & 4.140 & 3.595 & 3.311 & 3.540 & 3.370 & 4.143 & 3.598 & 3.314 & 3.542 & 3.373 \\
\hline SD Dep Var & 1.605 & 1.597 & 1.594 & 1.526 & 1.670 & 1.606 & 1.597 & 1.596 & 1.526 & 1.672 \\
\hline p-value Panel C vs D & 0.207 & 0.184 & 0.897 & 0.262 & 0.846 & 0.207 & 0.184 & 0.897 & 0.262 & 0.846 \\
\hline Municipality FE & Yes & Yes & Yes & Yes & Yes & Yes & Yes & Yes & Yes & Yes \\
\hline Year-quarter FE & Yes & Yes & Yes & Yes & Yes & Yes & Yes & Yes & Yes & Yes \\
\hline
\end{tabular}

Notes: This table illustrates the main effects of the audits on firms for different subsamples, depending on when the audit was conducted. Panel A presents the results for municipalities that faced a change in mayor in the three years after the audit, while Panel B presents results for municipalities that did not face any change in mayor in the same period. Panel $\mathrm{C}$ presents the results for municipalities that faced a change in the ruling party in the three years after the audit, while Panel D presents results for municipalities that did not face any change in the ruling party in the same period. The table reports the coefficients obtained from the estimation of equation 4.2. The specification is $y_{m t}=\alpha_{m}+\alpha_{t}+\beta \times P_{o s t A u d i t} t+\epsilon_{m t}$, and is discussed in Section 4. The sample includes all municipalities audited in the period 2003-2014 and all eligible non-audited municipalities, and covers the window $[-4,+12]$ quarters around the audit quarter. PostAudit $t_{m t}$ is an indicator variable taking value 1 for all quarter-years after the audit in the audited municipality, and 0 otherwise. PostAudit ${ }_{m t}$ is always 0 for never treated municipalities. All specifications include municipality and year-quarter fixed effects. The dependent variable is the log of the total number of private sector firms in the municipality. Dependent variables in columns 1 and 6 refer to all sectors in the municipality, columns 2 and 6 to GD-Procurement sectors, columns 3 and 7 to Non-GD-Procurement sectors, columns 4 and 9 to GD-Corrupt sectors, and columns 5 and 10 to Non-GD-Corrupt sectors. These classifications are defined in Section 5.2. The p-value Panel A vs $B$ (C vs D) presents the p-value for the difference between PostAudit coefficients in the same column across panels. Avg Dep Var and SD Dep Var are computed using eligible non-audited municipalities and audited municipalities in the 4 quarters before the audit. Robust standard errors are clustered at the municipality level. ${ }^{* * *} \mathrm{p}<0.01,{ }^{* *} \mathrm{p}<0.05,{ }^{*} \mathrm{p}<0.1$. 
TABle A9. Heterogeneity by Corruption Detected: Main

\begin{tabular}{|c|c|c|c|c|c|}
\hline & $\begin{array}{l}\text { (1) } \\
\text { All }\end{array}$ & $\begin{array}{c}(2) \\
\text { GD } \\
\text { Procurement }\end{array}$ & $\begin{array}{c}(3) \\
\text { Non-GD } \\
\text { Procurement }\end{array}$ & $\begin{array}{c}(4) \\
\text { GD } \\
\text { Corrupt }\end{array}$ & $\begin{array}{c}(5) \\
\text { Non-GD } \\
\text { Corrupt }\end{array}$ \\
\hline \multicolumn{6}{|c|}{ Panel A: High Corruption } \\
\hline PostAudit $\times \mathrm{Z}$ & $\begin{array}{c}0.052^{* * *} \\
(0.007)\end{array}$ & $\begin{array}{c}0.071^{* * * *} \\
(0.008)\end{array}$ & $\begin{array}{c}0.007 \\
(0.008)\end{array}$ & $\begin{array}{c}0.076^{* * *} \\
(0.008)\end{array}$ & $\begin{array}{c}0.003 \\
(0.009)\end{array}$ \\
\hline PostAudit & $\begin{array}{c}-0.023^{* * *} \\
(0.004)\end{array}$ & $\begin{array}{c}-0.030 * * * \\
(0.005)\end{array}$ & $\begin{array}{l}-0.001 \\
(0.005)\end{array}$ & $\begin{array}{c}-0.034^{* * *} \\
(0.004)\end{array}$ & $\begin{array}{c}0.002 \\
(0.006)\end{array}$ \\
\hline Observations & 277,392 & 277,392 & 277,392 & 277,392 & 277,392 \\
\hline R-squared & 0.985 & 0.977 & 0.980 & 0.975 & 0.981 \\
\hline Avg Dep Var & 4.138 & 3.593 & 3.309 & 3.538 & 3.367 \\
\hline SD Dep Var & 1.607 & 1.598 & 1.595 & 1.527 & 1.671 \\
\hline
\end{tabular}

\section{Panel B: Predicted High Corruption}

\begin{tabular}{lccccc} 
PostAudit $\times \mathrm{Z}$ & $0.041^{* * *}$ & $0.059^{* * *}$ & 0.001 & $0.062^{* * *}$ & -0.003 \\
& $(0.004)$ & $(0.005)$ & $(0.005)$ & $(0.005)$ & $(0.005)$ \\
PostAudit & $0.008^{* *}$ & $0.012^{* *}$ & 0.003 & $0.011^{* *}$ & 0.004 \\
& $(0.004)$ & $(0.005)$ & $(0.005)$ & $(0.004)$ & $(0.005)$ \\
Observations & 277,392 & 277,392 & 277,392 & 277,392 & 277,392 \\
R-squared & 0.985 & 0.977 & 0.980 & 0.975 & 0.981 \\
Municipality FE & Yes & Yes & Yes & Yes & Yes \\
Year-quarter FE & Yes & Yes & Yes & Yes & Yes \\
Avg Dep Var & 4.138 & 3.593 & 3.309 & 3.538 & 3.367 \\
SD Dep Var & 1.607 & 1.598 & 1.595 & 1.527 & 1.671 \\
\hline
\end{tabular}

Notes: This table illustrates the heterogeneous effects of the audit on firms, with an heterogeneity aimed at capturing the importance of detecting high levels of corruption. The table reports the coefficients obtained from the estimation of equation 4.3. The specification is $y_{m t}=\alpha_{m}+\alpha_{t}+\beta_{1} \times$ PostAudit $_{m t}+\beta_{2} \times Z_{m} \times$ PostAudit ${ }_{m t}+\epsilon_{m t}$ and is discussed in Section 4. The sample includes all municipalities audited in the period 2003-2014 and all eligible non-audited municipalities, and covers the window $[-4,+12]$ quarters around the audit quarter. PostAudit Pt $_{\text {is }}$ an indicator variable taking value 1 for all quarter-years after the audit in the audited municipality, and 0 otherwise. PostAudit $t_{m t}$ is always 0 for never treated municipalities. All specifications include municipality and year-quarter fixed effects. $Z_{m}$ are fixed municipality characteristics. In Panel A, $Z_{m}$ is an indicator for municipalities where the audit uncovers above-median irregularities (scaled by municipality size), while in Panel $\mathrm{B}, Z_{m}$ is based on the predicted probability that a municipality has high levels of corruption detected (using LASSO). Notice that the latter probability is standardized by its mean and standard deviation (see Section 6 for more details). The dependent variable is the log of the total number of private sector firms in the municipality. Column 1 refers to all firms in the municipality, column 2 to GD-Procurement sectors, column 3 to Non-GD-Procurement sectors, column 4 to GD-Corrupt sectors, and column 5 to Non-GD-Corrupt sectors. These classifications are defined in section 5.2. Avg Dep Var and $S D$ Dep Var are computed using eligible non-audited municipalities and audited municipalities in the year before the audit. Robust standard errors are clustered at the municipality level. $* * * \mathrm{p}<0.01, * * \mathrm{p}<0.05, *$ $\mathrm{p}<0.1$. 
TABLE A10. Heterogeneity by Corruption Detected: Excluding Spillovers

\begin{tabular}{llcccc}
\hline \hline$(1)$ & $(2)$ & $(3)$ & $(4)$ & $(5)$ \\
& All & GD & Non-GD & GD & Non-GD \\
& & Procurement & Procurement & Corrupt & Corrupt \\
\hline
\end{tabular}

Panel A: High Corruption

$\begin{array}{lccccc}\text { PostAudit } \times \mathrm{Z} & 0.053^{* * *} & 0.073^{* * *} & 0.007 & 0.077^{* * *} & 0.003 \\ & (0.007) & (0.008) & (0.008) & (0.008) & (0.009) \\ \text { PostAudit } & -0.010^{*} & -0.013^{*} & 0.000 & -0.021^{* * *} & 0.008 \\ & (0.006) & (0.007) & (0.007) & (0.007) & (0.007) \\ & & & & & \\ \text { Observations } & 44,075 & 44,075 & 44,075 & 44,075 & 44,075 \\ \text { R-squared } & 0.992 & 0.988 & 0.989 & 0.987 & 0.990 \\ \text { Avg Dep Var } & 4.484 & 3.918 & 3.672 & 3.844 & 3.754 \\ \text { SD Dep Var } & 1.734 & 1.740 & 1.705 & 1.671 & 1.780\end{array}$

Panel B: Predicted High Corruption

\begin{tabular}{lccccc} 
PostAudit $\times \mathrm{Z}$ & $0.041^{* * *}$ & $0.058^{* * *}$ & 0.001 & $0.062^{* * *}$ & -0.003 \\
& $(0.004)$ & $(0.005)$ & $(0.005)$ & $(0.005)$ & $(0.005)$ \\
PostAudit & $0.019^{* * *}$ & $0.027^{* * *}$ & 0.004 & $0.022^{* * *}$ & 0.010 \\
& $(0.006)$ & $(0.007)$ & $(0.006)$ & $(0.007)$ & $(0.006)$ \\
& & & & & \\
Observations & 44,075 & 44,075 & 44,075 & 44,075 & 44,075 \\
R-squared & 0.992 & 0.988 & 0.989 & 0.987 & 0.990 \\
Municipality FE & Yes & Yes & Yes & Yes & Yes \\
Year-quarter FE & Yes & Yes & Yes & Yes & Yes \\
Avg Dep Var & 4.484 & 3.918 & 3.672 & 3.844 & 3.754 \\
SD Dep Var & 1.734 & 1.740 & 1.705 & 1.671 & 1.780 \\
\hline
\end{tabular}

Notes: This table illustrates the heterogeneous effects of the audit on on firms, with an heterogeneity aimed at capturing the importance of detecting high levels of corruption. The table reports the coefficients obtained from the estimation of equation 4.3. The specification is $y_{m t}=\alpha_{m}+\alpha_{t}+\beta_{1} \times$ PostAudit $_{m t}+$ $\beta_{2} \times Z_{m} \times$ PostAudit $_{m t}+\epsilon_{m t}$ and is discussed in Section 4. The sample includes all municipalities audited in the period 2003-2014 and all eligible non-audited municipalities, excluding from the sample any neveraudited municipality in a micro-region where there was at least one municipality audited, and covers the window $[-4,+12]$ quarters around the audit quarter. PostAudit $t_{m t}$ is an indicator variable taking value 1 for all quarter-years after the audit in the audited municipality, and 0 otherwise. PostAudit mt $_{\text {is always } 0}$ for never treated municipalities. All specifications include municipality and year-quarter fixed effects. $Z_{m}$ are fixed municipality characteristics. In Panel $\mathrm{A}, Z_{m}$ is an indicator for municipalities where the audit uncovers above-median irregularities (scaled by municipality size), while in Panel $\mathrm{B}, Z_{m}$ is based on the predicted probability that a municipality has high levels of corruption detected (using LASSO). Notice that the latter probability is standardized by its mean and standard deviation (see Section 6 for more details). The dependent variable is the $\log$ of the total number of private sector firms in the municipality. Column 1 refers to all firms in the municipality, column 2 to GD-Procurement sectors, column 3 to Non-GDProcurement sectors, column 4 to GD-Corrupt sectors, and column 5 to Non-GD-Corrupt sectors. These classifications are defined in section 5.2. Avg Dep Var and SD Dep Var are computed using eligible nonaudited municipalities and audited municipalities in the year before the audit. Robust standard errors are clustered at the municipality level. ${ }^{* * *} \mathrm{p}<0.01,{ }^{* *} \mathrm{p}<0.05,{ }^{*} \mathrm{p}<0.1$. 
TABLE A11. Heterogeneity by Corruption Detected: Spillovers

\begin{tabular}{|c|c|c|c|c|c|}
\hline & $\begin{array}{l}\text { (1) } \\
\text { All }\end{array}$ & $\begin{array}{c}(2) \\
\text { GD } \\
\text { Procurement }\end{array}$ & $\begin{array}{c}(3) \\
\text { Non-GD } \\
\text { Procurement }\end{array}$ & $\begin{array}{c}(4) \\
\text { GD } \\
\text { Corrupt }\end{array}$ & $\begin{array}{c}(5) \\
\text { Non-GD } \\
\text { Corrupt }\end{array}$ \\
\hline \multicolumn{6}{|c|}{ Panel A: Share of Audited Municipalities } \\
\hline PostAudit $\times \mathrm{Z}$ & $\begin{array}{c}0.018^{* * *} * \\
(0.005)\end{array}$ & $\begin{array}{c}0.020 * * * \\
(0.006)\end{array}$ & $\begin{array}{c}0.011^{* *} \\
(0.005)\end{array}$ & $\begin{array}{c}0.013^{* *} \\
(0.006)\end{array}$ & $\begin{array}{c}0.018^{* * *} * \\
(0.006)\end{array}$ \\
\hline PostAudit & $\begin{array}{c}0.020^{* * * *} \\
(0.006)\end{array}$ & $\begin{array}{c}0.029^{* * *} \\
(0.007)\end{array}$ & $\begin{array}{c}0.001 \\
(0.006)\end{array}$ & $\begin{array}{c}0.018^{* *} \\
(0.007)\end{array}$ & $\begin{array}{c}0.015^{* *} \\
(0.007)\end{array}$ \\
\hline Observations & 69,866 & 69,866 & 69,866 & 69,866 & 69,866 \\
\hline R-squared & 0.993 & 0.989 & 0.989 & 0.988 & 0.990 \\
\hline Avg Dep Var & 4.025 & 3.475 & 3.213 & 3.440 & 3.251 \\
\hline SD Dep Var & 1.677 & 1.691 & 1.626 & 1.621 & 1.706 \\
\hline
\end{tabular}

Panel B: Share of High Corruption Cases

\begin{tabular}{lccccc} 
PostAudit $\times \mathrm{Z}$ & $0.016^{* * *}$ & $0.024^{* * *}$ & -0.001 & $0.026^{* * *}$ & -0.005 \\
& $(0.004)$ & $(0.007)$ & $(0.004)$ & $(0.006)$ & $(0.005)$ \\
PostAudit & $0.014^{* * *}$ & $0.023^{* * *}$ & -0.004 & $0.015^{* *}$ & 0.007 \\
& $(0.005)$ & $(0.006)$ & $(0.005)$ & $(0.006)$ & $(0.006)$ \\
Observations & 69,866 & 69,866 & 69,866 & 69,866 & 69,866 \\
R-squared & 0.993 & 0.989 & 0.989 & 0.988 & 0.990 \\
Municipality FE & Yes & Yes & Yes & Yes & Yes \\
Year FE & Yes & Yes & Yes & Yes & Yes \\
Avg Dep Var & 4.025 & 3.475 & 3.213 & 3.440 & 3.251 \\
SD Dep Var & 1.677 & 1.691 & 1.626 & 1.621 & 1.706 \\
\hline
\end{tabular}

Notes: This table illustrates the heterogeneous effects for the geographic spillover effects of the audits, which aim to capture the importance of detecting high levels of corruption. The table reports the coefficients obtained from the estimation of a specification similar to $y_{m t}=\alpha_{m}+\alpha_{t}+\beta_{1} \times$ PostAudit $_{m t}+\beta_{2} \times Z_{m} \times$ PostAudit ${ }_{m t}+\epsilon_{m t}$, but for the impact of the audits on nearby municipalities, as discussed in Section 5 . That is, we define as nearby those municipalities in the same micro-region of an audited one, and exclude audited municipalities. The treatment dummy PostAudit $t_{m t}$ is equal to one the first time a micro-region has one of its municipality that is audited. The sample covers the period 2003-2014 and the window [-4,+12] quarters around the audit quarter. All specifications include municipality and year-quarter fixed effects. $Z_{m}$ are fixed municipality characteristics. In Panel $\mathrm{A}, Z_{m}$ is the standardized share of audited municipalities over the total number of municipalities in the micro-region. In Panel $\mathrm{B}, Z_{m}$ is the total number of irregularity cases uncovered by the audits over the total number of establishments in the micro-region, standardized by its mean and standard deviation. The dependent variable is the log of the total number of private sector firms in the municipality. Column 1 refers to all firms in the municipality, column 2 to GD-Procurement sectors, column 3 to Non-GD-Procurement sectors, column 4 to GD-Corrupt sectors, and column 5 to NonGD-Corrupt sectors. These classifications are defined in section 5.2. The p-value GD vs Non-GD presents the p-value for the difference between PostAudit coefficients in GD vs Non-GD sectors. Avg Dep Var and $S D$ Dep Var are computed using eligible non-audited municipalities and audited municipalities in the 4 quarters before the audit. Robust standard errors are clustered at the municipality level. ${ }^{* * *} \mathrm{p}<0.01,{ }^{* *} \mathrm{p}<0.05, *$ $\mathrm{p}<0.1$. 
TABLE A12. Robustness to Excluding Litigation-Related Sectors

\begin{tabular}{|c|c|c|c|c|c|c|c|c|c|c|}
\hline & \multirow[t]{2}{*}{$(1)$} & \multirow[t]{2}{*}{$(2)$} & \multirow{2}{*}{\multicolumn{2}{|c|}{$\begin{array}{c}(3) \quad(4) \\
\text { GD-Procurement }\end{array}$}} & \multirow{2}{*}{\multicolumn{2}{|c|}{$\begin{array}{cc}(5) & (6) \\
\text { Non-GD-Procurement }\end{array}$}} & \multirow{2}{*}{\multicolumn{2}{|c|}{${ }_{\text {GD-Corrupt }}^{(7)}$}} & \multirow{2}{*}{\multicolumn{2}{|c|}{$\begin{array}{c}(9) \quad(10) \\
\text { Non-GD-Corrupt }\end{array}$}} \\
\hline & & & & & & & & & & \\
\hline & Establishments & Firms & Establishments & Firms & Establishments & Firms & Establishments & Firms & Establishments & Firms \\
\hline \multicolumn{11}{|c|}{ Panel A: Excluding Legal Activities (CNAE 69117) } \\
\hline PostAudit & $\begin{array}{r}0.008^{* *} \\
(0.004)\end{array}$ & $\begin{array}{c}0.008^{* *} \\
(0.004)\end{array}$ & $\begin{array}{c}0.014^{* * *} \\
(0.005)\end{array}$ & $\begin{array}{c}0.014^{* * *} \\
(0.005)\end{array}$ & $\begin{array}{c}0.001 \\
(0.005)\end{array}$ & $\begin{array}{c}0.002 \\
(0.005)\end{array}$ & $\begin{array}{c}0.012^{* * * *} \\
(0.005)\end{array}$ & $\begin{array}{c}0.013^{* * *} \\
(0.005)\end{array}$ & $\begin{array}{c}0.002 \\
(0.005)\end{array}$ & $\begin{array}{c}0.002 \\
(0.005)\end{array}$ \\
\hline Observations & 277,392 & 277,392 & 277,392 & 277,392 & 277,392 & 277,392 & 277,392 & 277,392 & 277,392 & 277,392 \\
\hline R-squared & 0.984 & 0.985 & 0.977 & 0.977 & 0.979 & 0.980 & 0.975 & 0.975 & 0.980 & 0.981 \\
\hline Avg Dep Var & 4.178 & 4.148 & 3.607 & 3.593 & 3.368 & 3.329 & 3.552 & 3.538 & 3.426 & 3.388 \\
\hline SD Dep Var & 1.611 & 1.602 & 1.606 & 1.599 & 1.601 & 1.587 & 1.535 & 1.527 & 1.674 & 1.663 \\
\hline \multicolumn{11}{|c|}{ Panel B: Excluding Legal, Accounting, and Auditing Activities (CNAE 69) } \\
\hline PostAudit & $\begin{array}{c}0.008^{* *} \\
(0.004)\end{array}$ & $\begin{array}{c}0.008^{* *} \\
(0.004)\end{array}$ & $\begin{array}{c}0.014^{* * *} \\
(0.005)\end{array}$ & $\begin{array}{c}0.014^{* * *} \\
(0.005)\end{array}$ & $\begin{array}{c}0.000 \\
(0.005)\end{array}$ & $\begin{array}{l}0.001 \\
(0.005)\end{array}$ & $\begin{array}{c}0.012^{* * *} \\
(0.005)\end{array}$ & $\begin{array}{c}0.013^{* * *} \\
(0.005)\end{array}$ & $\begin{array}{c}0.001 \\
(0.005)\end{array}$ & $\begin{array}{c}0.002 \\
(0.005)\end{array}$ \\
\hline Observations & 277,392 & 277,392 & 277,392 & 277,392 & 277,392 & 277,392 & 277,392 & 277,392 & 277,392 & 277,392 \\
\hline R-squared & 0.984 & 0.985 & 0.977 & 0.977 & 0.979 & 0.980 & 0.975 & 0.975 & 0.980 & 0.981 \\
\hline Avg Dep Var & 4.172 & 4.142 & 3.607 & 3.593 & 3.354 & 3.315 & 3.552 & 3.538 & 3.413 & 3.375 \\
\hline SD Dep Var & 1.608 & 1.599 & 1.606 & 1.599 & 1.595 & 1.581 & 1.535 & 1.527 & 1.669 & 1.658 \\
\hline \multicolumn{11}{|c|}{ Panel C: Excluding Legal, Accounting, Auditing, and Consulting Activities (CNAE 69 and 70) } \\
\hline PostAudit & $\begin{array}{c}0.008^{* *} \\
(0.004)\end{array}$ & $\begin{array}{c}0.008^{* *} \\
(0.004)\end{array}$ & $\begin{array}{c}0.014^{* * *} \\
(0.005)\end{array}$ & $\begin{array}{c}0.014^{* * *} \\
(0.005)\end{array}$ & $\begin{array}{c}0.000 \\
(0.005)\end{array}$ & $\begin{array}{c}0.001 \\
(0.005)\end{array}$ & $\begin{array}{c}0.012^{* * *} \\
(0.005)\end{array}$ & $\begin{array}{c}0.013^{* * *} \\
(0.005)\end{array}$ & $\begin{array}{c}0.001 \\
(0.005)\end{array}$ & $\begin{array}{c}0.002 \\
(0.005)\end{array}$ \\
\hline Observations & 277,391 & 277,391 & 277,391 & 277,391 & 277,391 & 277,391 & 277,391 & 277,391 & 277,391 & 277,391 \\
\hline R-squared & 0.984 & 0.985 & 0.977 & 0.977 & 0.979 & 0.980 & 0.975 & 0.975 & 0.980 & 0.981 \\
\hline Avg Dep Var & 4.171 & 4.142 & 3.607 & 3.593 & 3.353 & 3.314 & 3.552 & 3.538 & 3.412 & 3.374 \\
\hline SD Dep Var & 1.608 & 1.599 & 1.606 & 1.599 & 1.594 & 1.581 & 1.535 & 1.527 & 1.669 & 1.658 \\
\hline \multicolumn{11}{|c|}{ Panel D: Exclude Full Service Sector } \\
\hline PostAudit & $\begin{array}{c}0.008^{* *} \\
(0.004)\end{array}$ & $\begin{array}{c}0.008^{* *} * \\
(0.004)\end{array}$ & $\begin{array}{c}0.013^{* * *} \\
(0.005)\end{array}$ & $\begin{array}{c}0.013^{* * *} \\
(0.005)\end{array}$ & $\begin{array}{c}0.001 \\
(0.005)\end{array}$ & $\begin{array}{c}0.002 \\
(0.005)\end{array}$ & $\begin{array}{c}0.013^{\text {*** }} \text { * } \\
(0.005)\end{array}$ & $\begin{array}{c}0.013^{* * *} \\
(0.005)\end{array}$ & $\begin{array}{c}0.002 \\
(0.005)\end{array}$ & $\begin{array}{c}0.003 \\
(0.005)\end{array}$ \\
\hline Observations & 277,273 & 277,273 & 277,273 & 277,273 & 277,273 & 277,273 & 277,273 & 277,273 & 277,273 & 277,273 \\
\hline R-squared & 0.983 & 0.983 & 0.977 & 0.977 & 0.972 & 0.974 & 0.975 & 0.974 & 0.975 & 0.976 \\
\hline Avg Dep Var & 4.032 & 4.001 & 3.568 & 3.554 & 3.053 & 3.007 & 3.528 & 3.515 & 3.118 & 3.073 \\
\hline SD Dep Var & 1.553 & 1.544 & 1.593 & 1.585 & 1.476 & 1.459 & 1.522 & 1.514 & 1.584 & 1.571 \\
\hline Municipality FE & Yes & Yes & Yes & Yes & Yes & Yes & Yes & Yes & Yes & Yes \\
\hline Year-quarter FE & Yes & Yes & Yes & Yes & Yes & Yes & Yes & Yes & Yes & Yes \\
\hline
\end{tabular}

Notes: This table illustrates the main effects of firms, excluding litigation-related sectors. The table reports the coefficients obtained from the estimation of equation 4.2. The specification is $y_{m t}=\alpha_{m}+\alpha_{t}+\beta \times$ PostAudit $t_{m t}+\epsilon_{m t}$, and is discussed in Section 4. The sample includes all municipalities audited in the period 2003-2014 and all eligible non-audited municipalities, and covers the window $[-4,+12]$ quarters around the audit quarter. PostAudit $t_{m}$ is an indicator variable taking value 1 for all quarter-years after the audit in the audited municipality, and 0 otherwise. PostAudit $t_{m}$ is always 0 for never treated municipalities. All specifications include municipality and year-quarter fixed effects. Establishments is the log of the total number of private sector establishments in the municipality in the specific sector highlighted in each panel. Firms is the log of the total number of private sector firms in the municipality in the specific sector highlighted in each panel. Avg Dep Var and SD Dep Var are computed using eligible non-audited municipalities and audited municipalities in the 4 quarters before the audit. Robust standard errors are clustered at the municipality level. ${ }^{* * *} \mathrm{p}<0.01,{ }^{* *} \mathrm{p}<0.05,{ }^{*} \mathrm{p}<0.1$. 
TABLE A13. Long-Run Effects on Firms

\begin{tabular}{|c|c|c|c|c|c|c|}
\hline & $(1)$ & $(2)$ & $(3)$ & $(4)$ & $(5)$ & $(6)$ \\
\hline & \multicolumn{2}{|c|}{ 3-year window (baseline) } & \multicolumn{2}{|c|}{ 6-year window } & \multicolumn{2}{|c|}{ 10-year window } \\
\hline & Establishments & Firms & Establishments & Firms & Establishments & Firms \\
\hline PostAudit & $\begin{array}{c}0.009^{* *} \\
(0.004)\end{array}$ & $\begin{array}{c}0.009 * * \\
(0.004)\end{array}$ & $\begin{array}{c}0.015^{* * *} \\
(0.005)\end{array}$ & $\begin{array}{c}0.015^{* * *} \\
(0.005)\end{array}$ & $\begin{array}{c}0.018^{* * *} \\
(0.006)\end{array}$ & $\begin{array}{c}0.018^{* * *} \\
(0.006)\end{array}$ \\
\hline Observations & 277,392 & 277,392 & 299,199 & 299,199 & 323,179 & 323,179 \\
\hline R-squared & 0.984 & 0.985 & 0.985 & 0.985 & 0.985 & 0.985 \\
\hline Municipality FE & Yes & Yes & Yes & Yes & Yes & Yes \\
\hline Year-quarter FE & Yes & Yes & Yes & Yes & Yes & Yes \\
\hline Avg Dep Var & 4.179 & 4.138 & 4.179 & 4.138 & 4.179 & 4.138 \\
\hline SD Dep Var & 1.611 & 1.607 & 1.611 & 1.607 & 1.611 & 1.607 \\
\hline
\end{tabular}

Notes: This table illustrates the main effects of the audits on firms. The table reports the coefficients obtained from the estimation of equation 4.2 . The specification is $y_{m t}=\alpha_{m}+\alpha_{t}+\beta \times$ PostAudit $_{m t}+\epsilon_{m t}$, and is discussed in Section 4. The sample includes all municipalities audited in the period 2003-2014 and all eligible non-audited municipalities. Columns 1 and 2 cover the window [-4,+12] quarters around the audit quarter, columns 3 and 4 cover the window $[-4,24]$, and columns 5 and 6 cover the window $[-4,40]$. PostAuditmt is an indicator variable taking value 1 for all quarter-years after the audit in the audited municipality, and 0 otherwise. PostAudit $t_{m t}$ is always 0 for never treated municipalities. All specifications include municipality and year-quarter fixed effects. Establishments is the log of the total number of private sector establishments in the municipality. Firms is the log of the total number of private sector firms in the municipality. Avg Dep Var and SD Dep Var are computed using eligible non-audited municipalities and audited municipalities in the 4 quarters before the audit. Robust standard errors are clustered at the municipality level. $* * * \mathrm{p}<0.01, * * \mathrm{p}<0.05, * \mathrm{p}<0.1$. 
TABLE A14. Heterogeneous Effects Depending on Extent of Informality

\begin{tabular}{|c|c|c|c|c|c|c|c|c|c|c|}
\hline & \multirow[t]{2}{*}{ (1) } & \multirow[t]{2}{*}{$(2)$} & \multirow{2}{*}{\multicolumn{2}{|c|}{$\begin{array}{c}(3) \quad(4) \\
\text { GD-Procurement }\end{array}$}} & \multirow{2}{*}{\multicolumn{2}{|c|}{$\begin{array}{cc}(5) & (6) \\
\text { Non-GD-Procurement }\end{array}$}} & \multirow{2}{*}{\multicolumn{2}{|c|}{$\stackrel{(7)}{\text { GD-Corrupt }}$}} & \multirow{2}{*}{\multicolumn{2}{|c|}{$\begin{array}{l}(9) \quad(10) \\
\text { Non-GD-Corrupt }\end{array}$}} \\
\hline & & & & & & & & & & \\
\hline & Establishments & Firms & Establishments & Firms & Establishments & Firms & Establishments & Firms & Establishments & Firms \\
\hline PostAudit $\times \mathrm{Z}$ & $\begin{array}{c}0.034^{* * *} \\
(0.006)\end{array}$ & $\begin{array}{c}0.033^{* * *} \\
(0.006)\end{array}$ & $\begin{array}{c}0.043^{* * *} \\
(0.008)\end{array}$ & $\begin{array}{c}0.043^{* * *} \\
(0.008)\end{array}$ & $\begin{array}{l}0.010^{*} \\
(0.005)\end{array}$ & $\begin{array}{c}0.008 \\
(0.005)\end{array}$ & $\begin{array}{c}0.042^{* * *} \\
(0.008)\end{array}$ & $\begin{array}{c}0.042^{* * *} \\
(0.008)\end{array}$ & $\begin{array}{l}0.009^{*} \\
(0.005)\end{array}$ & $\begin{array}{c}0.008 \\
(0.005)\end{array}$ \\
\hline PostAudit & $\begin{array}{c}0.009^{* *} \\
(0.004)\end{array}$ & $\begin{array}{c}0.009^{* *} \\
(0.004)\end{array}$ & $\begin{array}{c}0.014^{* * *} \\
(0.005)\end{array}$ & $\begin{array}{c}0.014^{* * * *} \\
(0.005)\end{array}$ & $\begin{array}{c}0.001 \\
(0.005)\end{array}$ & $\begin{array}{c}0.003 \\
(0.005)\end{array}$ & $\begin{array}{c}0.013^{* * * *} \\
(0.005)\end{array}$ & $\begin{array}{c}0.013^{* * *} \\
(0.005)\end{array}$ & $\begin{array}{c}0.002 \\
(0.005)\end{array}$ & $\begin{array}{c}0.004 \\
(0.005)\end{array}$ \\
\hline Observations & 277,392 & 277,392 & 277,392 & 277,392 & 277,392 & 277,392 & 277,392 & 277,392 & 277,392 & 277,392 \\
\hline R-squared & 0.984 & 0.985 & 0.977 & 0.977 & 0.979 & 0.980 & 0.975 & 0.975 & 0.980 & 0.981 \\
\hline Municipality FE & Yes & Yes & Yes & Yes & Yes & Yes & Yes & Yes & Yes & Yes \\
\hline Year-quarter FE & Yes & Yes & Yes & Yes & Yes & Yes & Yes & Yes & Yes & Yes \\
\hline Avg Dep Var & 4.179 & 4.138 & 3.607 & 3.593 & 3.370 & 3.309 & 3.552 & 3.538 & 3.428 & 3.367 \\
\hline SD Dep Var & 1.611 & 1.607 & 1.606 & 1.598 & 1.602 & 1.595 & 1.535 & 1.527 & 1.675 & 1.671 \\
\hline
\end{tabular}

Notes: This table illustrates the heterogeneous effects of the audits depending on the pre-existing shares of informal employment in the municipality. The table reports the coefficients obtained from the following specification $y_{m t}=\alpha_{m}+\alpha_{t}+\gamma \times Z_{m} \times$ PostAudit $_{m t}+\beta \times$ PostAudit $_{m t}+\epsilon_{m t}$. The sample includes all municipalities audited in the period 2003-2014 and all eligible non-audited municipalities, and covers the window [-4,+12] quarters around the audit quarter. PostAudit $t_{m t}$ is an indicator variable taking value 1 for all quarter-years after the audit in the audited municipality, and 0 otherwise. PostAudit $t_{m}$ is always 0 for never treated municipalities. All specifications include municipality and year-quarter fixed effects. $Z_{m}$ is the share of informal over formal workers in the 2000 Census, standardized by the mean and standard deviation. Establishments is the log of the total number of private sector establishments in the municipality. Firms is the log of the total number of private sector firms in the municipality. Dependent variables in columns 1 and 2 refer to all sectors in the municipality, columns 3 and 4 to GD-Procurement sectors, columns 5 and 6 to Non-GD-Procurement sectors, columns 7 and 8 to GD-Corrupt sectors, and columns 9 ad 10 to Non-GD-Corrupt sectors. These classifications are defined in Section 5.2 . Avg Dep Var and SD Dep Var are computed using eligible non-audited municipalities and audited municipalities in the 4 quarters before the audit. Robust standard errors are clustered at the municipality level. $* * * \mathrm{p}<0.01, * * \mathrm{p}<0.05, * \mathrm{p}<0.1$. 
TABLE A15. Informality

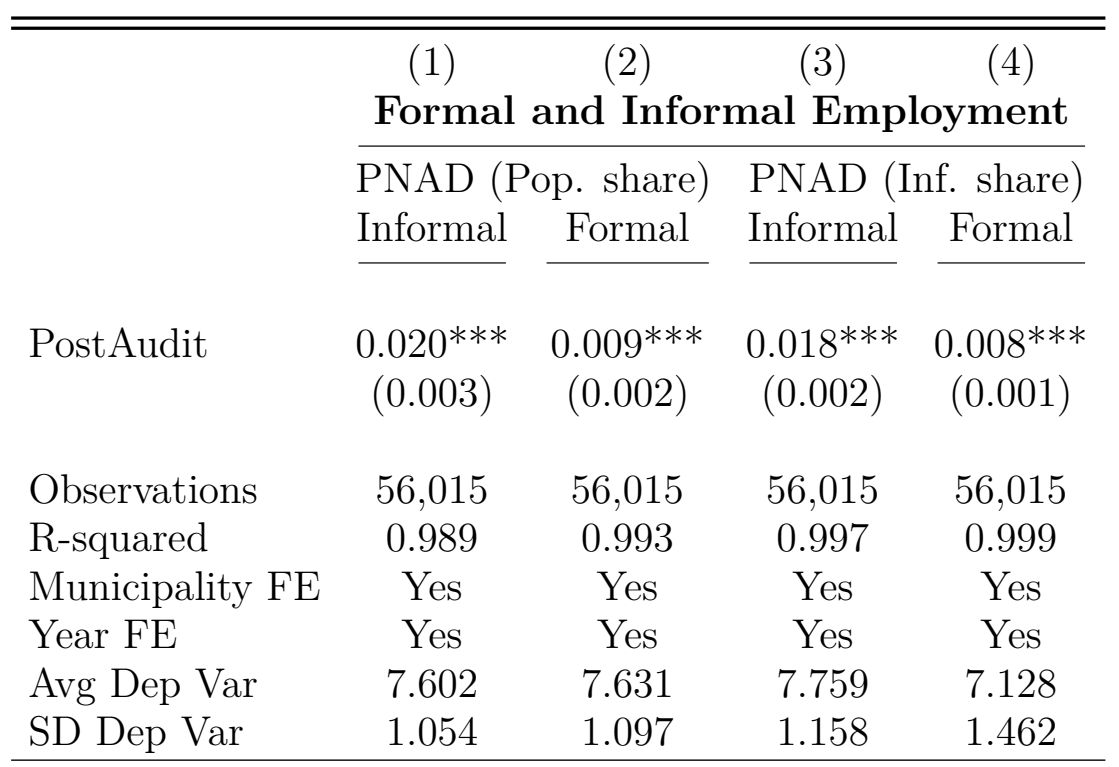

Notes: This table illustrates the main effects of the audit on other measures of local economic activity, specifically informal versus formal employment. The table mostly reports the coefficients obtained from the estimation of equation 4.2. The specification is $y_{m t}=\alpha_{m}+\alpha_{t}+\beta \times$ PostAudit $_{m t}+\epsilon_{m t}$ and is discussed in Section 4. The sample includes all municipalities audited in the period 2003-2014 and all eligible non-audited municipalities, and covers the window $[-1,+3]$ years around the audit year. PostAudit mt $_{\text {is }}$ an indicator variable taking value 1 for all years after the audit in the audited municipality, and 0 otherwise. PostAudit Pt $_{\text {s }}$ is always 0 for never treated municipalities. All specifications include municipality and year fixed effects. The construction of dependent variables, which measure informal and formal employment, is discussed in Section 3. Avg Dep Var and SD Dep Var are computed using eligible non-audited municipalities and audited municipalities in the year before the audit. Robust standard errors are clustered at the municipality level. $* * * \mathrm{p}<0.01, * * \mathrm{p}<0.05, * \mathrm{p}<0.1$. 
TABLE A16. Employment, Hiring, and Firing

\begin{tabular}{|c|c|c|c|c|c|c|c|c|c|}
\hline & $(1)$ & (2) & (3) & (4) & (5) & (6) & $(7)$ & $(8)$ & $(9)$ \\
\hline & \multicolumn{3}{|c|}{ 3-year window (baseline) } & \multicolumn{3}{|c|}{ 6-year window } & \multicolumn{3}{|c|}{ 10-year window } \\
\hline & Employment & Hiring & Firing & Employment & Hiring & Firing & Employment & Hiring & Firing \\
\hline PostAudit & $\begin{array}{c}0.007 \\
(0.007)\end{array}$ & $\begin{array}{c}0.006 \\
(0.011)\end{array}$ & $\begin{array}{c}0.003 \\
(0.010)\end{array}$ & $\begin{array}{l}0.013^{*} \\
(0.008)\end{array}$ & $\begin{array}{c}0.013 \\
(0.012)\end{array}$ & $\begin{array}{c}0.009 \\
(0.011)\end{array}$ & $\begin{array}{c}0.017^{* *} \\
(0.008)\end{array}$ & $\begin{array}{l}0.022^{*} \\
(0.012)\end{array}$ & $\begin{array}{c}0.016 \\
(0.012)\end{array}$ \\
\hline Observations & 277,392 & 277,392 & 277,392 & 299,199 & 299,199 & 299,199 & 323,179 & 323,179 & 323,179 \\
\hline R-squared & 0.961 & 0.895 & 0.914 & 0.961 & 0.896 & 0.914 & 0.961 & 0.896 & 0.914 \\
\hline Municipality FE & Yes & Yes & Yes & Yes & Yes & Yes & Yes & Yes & Yes \\
\hline Year-quarter FE & Yes & Yes & Yes & Yes & Yes & Yes & Yes & Yes & Yes \\
\hline Avg Dep Var & 6.999 & 4.329 & 3.639 & 6.999 & 4.329 & 3.639 & 6.999 & 4.329 & 3.639 \\
\hline SD Dep Var & 1.452 & 1.957 & 1.960 & 1.452 & 1.957 & 1.960 & 1.452 & 1.957 & 1.960 \\
\hline
\end{tabular}

Notes: This table illustrates the main effects of the audits on employment. The table reports the coefficients obtained from the estimation of equation 4.2. The specification is $y_{m t}=\alpha_{m}+\alpha_{t}+\beta \times$ PostAudit $_{m t}+\epsilon_{m t}$, and is discussed in Section 4 . The sample includes all municipalities audited in the period 2003-2014 and all eligible non-audited municipalities. Columns 1 to 3 cover the window [-4,+12] quarters around the audit quarter, columns 4 to 6 cover the window $[-4,24]$, and columns 7 to 9 covers the window $[-4,40]$. PostAudit $t_{m t}$ is an indicator variable taking value 1 for all quarter-years after the audit in the audited municipality, and 0 otherwise. PostAudit $t_{m}$ is always 0 for never treated municipalities. All specifications include municipality and year-quarter fixed effects. Employment is the log of the total number of employees in the municipality. Hiring is the log of the total number of employees hired in the municipality. Firing is the log of the total number of employees fired in the municipality. Avg Dep Var and SD Dep Var are computed using eligible non-audited municipalities and audited municipalities in the 4 quarters before the audit. Robust standard errors are clustered at the municipality level. ${ }^{* * *} \mathrm{p}<0.01,{ }^{* *} \mathrm{p}<0.05,{ }^{*} \mathrm{p}<0.1$. 
TABle A17. Does the Federal Government Channel More Resources to Audited Municipalities?

\begin{tabular}{|c|c|c|c|c|c|c|}
\hline & $(1)$ & $\begin{array}{c}(2) \\
\text { Transfers }\end{array}$ & $(3)$ & (4) & Grants $^{(5)}$ & $(6)$ \\
\hline & $\begin{array}{c}\text { Federal Capital } \\
\text { Transfers }\end{array}$ & $\begin{array}{c}\text { Federal Revenue } \\
\text { Transfers }\end{array}$ & $\begin{array}{c}\text { Municipal } \\
\text { Participation } \\
\text { Fund }\end{array}$ & $\begin{array}{l}\text { Total } \\
\text { Value }\end{array}$ & $\begin{array}{l}\text { Share of Funds } \\
\text { Disbursed }\end{array}$ & $\begin{array}{c}\text { Total Value of } \\
\text { Federal } \\
\text { Procurement }\end{array}$ \\
\hline PostAudit & $\begin{array}{l}-0.135 \\
(0.101)\end{array}$ & $\begin{array}{c}0.002 \\
(0.063)\end{array}$ & $\begin{array}{c}0.021 \\
(0.063)\end{array}$ & $\begin{array}{l}-0.052 \\
(0.097)\end{array}$ & $\begin{array}{l}-0.001 \\
(0.008)\end{array}$ & $\begin{array}{c}0.045 \\
(0.061)\end{array}$ \\
\hline Observations & 71,332 & 71,332 & 71,332 & 71,332 & 71,332 & 71,332 \\
\hline R-squared & 0.282 & 0.259 & 0.237 & 0.322 & 0.248 & 0.604 \\
\hline Municipality FE & Yes & Yes & Yes & Yes & Yes & Yes \\
\hline Year FE & Yes & Yes & Yes & Yes & Yes & Yes \\
\hline Avg Dep Var & 2.864 & 14.69 & 14.37 & 10.40 & 0.621 & 1.869 \\
\hline SD Dep Var & 5.029 & 2.765 & 2.762 & 4.888 & 0.390 & 4.429 \\
\hline
\end{tabular}


TABLE A18. Firm-Level Sales and Investment

\begin{tabular}{|c|c|c|c|c|}
\hline & $(1)$ & $(2)$ & $(3)$ & (4) \\
\hline & \multicolumn{2}{|c|}{ GD-Procurement } & \multicolumn{2}{|c|}{ GD-Corrupt } \\
\hline & $\begin{array}{c}\text { Sales } \\
\text { per Emp }\end{array}$ & Investment & $\begin{array}{c}\text { Sales } \\
\text { per Emp }\end{array}$ & Investment \\
\hline PostAudit $\times Z$ & $\begin{array}{c}0.048^{* * *} \\
(0.014)\end{array}$ & $\begin{array}{c}0.020^{* *} \\
(0.008)\end{array}$ & $\begin{array}{c}0.039^{* * *} \\
(0.015)\end{array}$ & $\begin{array}{c}0.015^{* *} \\
(0.007)\end{array}$ \\
\hline PostAudit & $\begin{array}{c}0.006 \\
(0.016)\end{array}$ & $\begin{array}{c}-0.024^{* * *} \\
(0.008)\end{array}$ & $\begin{array}{c}0.010 \\
(0.013)\end{array}$ & $\begin{array}{c}-0.021^{* *} \\
(0.009)\end{array}$ \\
\hline Observations & 312,430 & 134,713 & 312,430 & 134,713 \\
\hline R-squared & 0.927 & 0.429 & 0.918 & 0.429 \\
\hline Avg Dep Var & 10.09 & 0.176 & 10.09 & 0.176 \\
\hline SD Dep Var & 1.669 & 0.280 & 1.669 & 0.280 \\
\hline Establishment FE & Yes & Yes & Yes & Yes \\
\hline Year FE & Yes & Yes & Yes & Yes \\
\hline
\end{tabular}

Notes: This table illustrates the heterogeneous effects of the audit across local firms. The table reports the coefficients obtained from the estimation of equation 6.1. The specification is $y_{f m t}=\alpha_{f}+\gamma_{1} \times Z_{f} \times$ PostAudit $_{m t}+\beta \times$ PostAudit $_{m t}+\epsilon_{f m t}$, and is discussed in Section 6.3. The sample includes all firms in PAC and PAS surveys located in municipalities audited in the period 2003-2014 and in eligible non-audited municipalities, and covers the window [-1,3] years around the audit year. Sales per Emp is the logarithm of total sales over total employment; Investment is defined as total capital expenditure over total assets. PostAudit $_{m t}$ is an indicator variable taking value 1 for all years after the audit in the audited municipality, and 0 otherwise. PostAudit $t_{m}$ is always 0 for never treated municipalities. $Z_{f}$ are two firm characteristics, as indicated in the top labels: GD-Procurement is an indicator for belonging to a GD-Procurement sector; $G D$ Corrupt is an indicator for belonging to a GD-Corrupt sector. All specifications include firm and year fixed effects. Avg Dep Var and SD Dep Var are computed using firms in eligible non-audited municipalities and audited municipalities in the year before the audit. Robust standard errors are clustered at the municipality level. *** $\mathrm{p}<0.01,{ }^{* *} \mathrm{p}<0.05,{ }^{*} \mathrm{p}<0.1$. 
TABLE A19. Heterogeneity Across Local Firms: PAC/PAS Sample

\begin{tabular}{lccc}
\hline \hline & $(1)$ & & $(2)$ \\
& GD & & GD \\
& Procurement & & Corrupt \\
\cline { 2 - 2 } PostAudit $\times \mathrm{Z}$ & $0.015^{* * *}$ & & $0.011^{* * *}$ \\
& $(0.004)$ & & $(0.004)$ \\
PostAudit & 0.000 & & 0.004 \\
& $(0.004)$ & & $(0.004)$ \\
& & & \\
Observations & $2,994,238$ & & $2,994,238$ \\
R-squared & 0.851 & & 0.851 \\
Plant FE & Yes & & Yes \\
Year-quarter FE & Yes & & Yes \\
Avg Dep Var & 3.746 & & 3.746 \\
SD Dep Var & 0.624 & & 0.624 \\
\hline
\end{tabular}

Notes: This table illustrates the heterogeneous effects of the audit across local firms restricting the analysis to the samples that overlap with the PAC and PAS databases. The table reports the coefficients obtained from the estimation of equation 6.1. The specification is $y_{f m t}=\alpha_{f}+\alpha_{t}+\gamma_{3} \times Z_{f} \times$ PostAudit $_{m t}+\beta \times$ PostAudit ${ }_{m t}+\epsilon_{f m t}$, and is discussed in Section 6.3. The sample includes all establishments in municipalities audited in the period 2003-2014 and all establishments in eligible non-audited municipalities, and covers the window $[-4,+12]$ quarters around the audit quarter. The dependent variable is the log of total employment in the establishment. PostAudit $t_{m t}$ is an indicator variable taking value 1 for all quarter-years after the audit in the audited municipality, and 0 otherwise. PostAudit $m_{m t}$ is always 0 for never treated municipalities. $Z_{f}$ are establishment characteristics based on sectors and political connections. In the case of the sector-based measures: GD-Procurement is an indicator for belonging to a GD-Procurement sector and GD-Corrupt is an indicator for belonging to a GD-Corrupt sector. Results are based on the RAIS dataset but focusing on the sectors and firms covered by the PAC and PAS surveys and for establishments and firms with more than 20 employees. All specifications include establishment and year-quarter fixed effects. Avg Dep Var and SD Dep Var are computed using establishments in eligible non-audited municipalities and audited municipalities in the year before the audit. Robust standard errors are clustered at the municipality level. ${ }^{* * *} \mathrm{p}<0.01, * *$ $\mathrm{p}<0.05, * \mathrm{p}<0.1$. 
TABLE A20. Politically Connected Firms

\begin{tabular}{|c|c|c|c|c|c|c|c|c|c|c|c|c|c|c|c|}
\hline & $\begin{array}{c}(1) \\
\text { Average }\end{array}$ & $\begin{array}{c}(2) \\
\text { Median }\end{array}$ & $\begin{array}{c}(3) \\
\text { Standard } \\
\text { deviation } \\
\end{array}$ & $\begin{array}{c}(4) \\
\text { 90th perc }\end{array}$ & $\begin{array}{c}(5) \\
\text { 10th perc }\end{array}$ & $\begin{array}{c}(6) \\
\text { Average }\end{array}$ & $\begin{array}{c}(7) \\
\text { Median }\end{array}$ & $\begin{array}{c}(8) \\
\text { Standard } \\
\text { deviation } \\
\end{array}$ & $\begin{array}{c}\text { (9) } \\
\text { 90th perc }\end{array}$ & $\begin{array}{c}(10) \\
10 \text { th perc }\end{array}$ & $\begin{array}{c}\text { (11) } \\
\text { Average }\end{array}$ & $\begin{array}{c}(12) \\
\text { Median }\end{array}$ & $\begin{array}{c}\text { (13) } \\
\text { Standard } \\
\text { deviation } \\
\end{array}$ & $\begin{array}{c}(14) \\
90 \text { th perc }\end{array}$ & $\begin{array}{c}(15) \\
\text { 10th per }\end{array}$ \\
\hline & \multicolumn{5}{|c|}{ Panel A: Firm donor } & \multicolumn{5}{|c|}{ Panel B: Manager donor } & \multicolumn{5}{|c|}{ Panel C: Politician } \\
\hline Share of PC employment & 0.012 & 0 & 0.062 & 0.013 & 0 & 0.009 & 0 & 0.055 & 0.0004 & 0 & 0.002 & 0 & 0.025 & 0 & 0 \\
\hline Share of PC establishments & 0.003 & 0 & 0.017 & 0.007 & 0 & 0.001 & 0 & 0.009 & 0.001 & 0 & 0.0003 & 0 & 0.005 & 0 & 0 \\
\hline Share of PC employment in GD-P & 0.011 & 0 & 0.057 & 0.008 & 0 & 0.006 & 0 & 0.042 & 0 & 0 & 0.0008 & 0 & 0.018 & 0 & 0 \\
\hline Share of PC employment in GD-C & 0.011 & 0 & 0.057 & 0.007 & 0 & 0.005 & 0 & 0.042 & 0 & 0 & 0.0008 & 0 & 0.018 & 0 & 0 \\
\hline Share of PC establishments in GD-P & 0.005 & 0 & 0.028 & 0.006 & 0 & 0.001 & 0 & 0.012 & 0 & 0 & 0.0002 & 0 & 0.007 & 0 & 0 \\
\hline Share of PC establishments in GD-C & 0.005 & 0 & 0.028 & 0.005 & 0 & 0.002 & 0 & 0.013 & 0 & 0 & 0.0002 & 0 & 0.008 & 0 & 0 \\
\hline Share of PC employment in Non-GD-P & 0.010 & 0 & 0.064 & 0 & 0 & 0.008 & 0 & 0.062 & 0 & 0 & 0.002 & 0 & 0.028 & 0 & 0 \\
\hline Share of PC employment in Non-GD-C & 0.010 & 0 & 0.063 & 0 & 0 & 0.008 & 0 & 0.061 & 0 & 0 & 0.002 & 0 & 0.028 & 0 & 0 \\
\hline Share of PC establishments in Non-GD-P & 0.002 & 0 & 0.014 & 0 & 0 & 0.002 & 0 & 0.013 & 0 & 0 & 0.0003 & 0 & 0.006 & 0 & 0 \\
\hline \multirow[t]{2}{*}{ Share of PC establishments in Non-GD-C } & 0.002 & 0 & 0.013 & 0 & 0 & 0.002 & 0 & 0.012 & 0 & 0 & 0.0002 & 0 & 0.005 & 0 & 0 \\
\hline & \multicolumn{5}{|c|}{ Panel D: Candidate } & \multicolumn{5}{|c|}{ Panel E: Party member } & \multicolumn{5}{|c|}{ Panel F: Any connection } \\
\hline Share of PC employment & 0.007 & 0 & 0.053 & 0 & 0 & 0.195 & 0.118 & 0.222 & 0.526 & 0 & 0.201 & 0.127 & 0.224 & 0.534 & 0 \\
\hline Share of PC establishments & 0.001 & 0 & 0.008 & 0 & 0 & 0.050 & 0.045 & 0.055 & 0.106 & 0 & 0.054 & 0.048 & 0.057 & 0.111 & 0 \\
\hline Share of PC employment in GD-P & 0.004 & 0 & 0.036 & 0 & 0 & 0.151 & 0.073 & 0.195 & 0.428 & 0 & 0.159 & 0.083 & 0.199 & 0.440 & 0 \\
\hline Share of PC employment in GD-C & 0.004 & 0 & 0.034 & 0 & 0 & 0.145 & 0.066 & 0.191 & 0.412 & 0 & 0.152 & 0.075 & 0.195 & 0.426 & 0 \\
\hline Share of PC establishments in GD-P & 0.001 & 0 & 0.011 & 0 & 0 & 0.049 & 0.038 & 0.068 & 0.111 & 0 & 0.054 & 0.042 & 0.074 & 0.125 & 0 \\
\hline Share of PC establishments in GD-C & 0.001 & 0 & 0.012 & 0 & 0 & 0.049 & 0.037 & 0.067 & 0.112 & 0 & 0.054 & 0.041 & 0.073 & 0.125 & 0 \\
\hline Share of PC employment in Non-GD-P & 0.007 & 0 & 0.060 & 0 & 0 & 0.190 & 0.069 & 0.250 & 0.587 & 0 & 0.194 & 0.075 & 0.252 & 0.595 & 0 \\
\hline Share of PC employment in Non-GD-C & 0.007 & 0 & 0.060 & 0 & 0 & 0.192 & 0.075 & 0.250 & 0.587 & 0 & 0.197 & 0.080 & 0.252 & 0.594 & 0 \\
\hline Share of PC establishments in Non-GD-P & 0.001 & 0 & 0.011 & 0 & 0 & 0.052 & 0.037 & 0.075 & 0.125 & 0 & 0.054 & 0.039 & 0.077 & 0.127 & 0 \\
\hline Share of PC establishments in Non-GD-C & 0.001 & 0 & 0.011 & 0 & 0 & 0.052 & 0.038 & 0.075 & 0.125 & 0 & 0.054 & 0.040 & 0.076 & 0.125 & 0 \\
\hline
\end{tabular}

Notes: This table shows the relevance of politically connected firms across all eligible municipalities. The variables that capture a firm's political connection status are: Firm Donor for firm that donated to a political campaign, Manager Donor for firms whose manager donated to a political campaign, Politician for firms whose manager was an elected politician, Candidate for firms whose manager was a political candidate (elected or not), Party Member for firms whose manager was a registered member of a political party, and Any connection for firms with any type of connection. We present the summary statistics for shares taken at the municipality-year-quarter level. These shares are computed as the total employment (establishments) in politically connected firms over the total employment (establishments) in the private sector. When taking the share in GD-P (GD-C/Non-GD-P/NonGD-C), we use the total employment (establishments) in politically connected firms and in a GD-Procurement (Corrupt/Non-GD Procurement/NonGD-Corrupt) sector over the total employment (establishments) in the GD-Procurement (Corrupt/Non-GD Procurement/Non-GD-Corrupt) and private sector. 


\section{Appendix A.2. Model}

We introduce corruption distortions in a standard monopolistic competition framework of heterogeneous firms. This stylized model is used to illustrate the intuition behind our empirical analysis by means of a set of testable predictions. We consider only the static one-period version of the model and its essential ingredients.

A.1. Preferences. Consumer preferences are defined over the consumption of goods produced in $J$ sectors:

$$
U=\sum_{j=0}^{J} \beta_{j} \log Q_{j}, \quad \sum_{j=0}^{J} \beta_{j}=1, \beta_{j} \geq 0
$$

Sector $j=0$ is the numeraire, which refers to a homogeneous good produced with a unit input requirement. Within each of the remaining $j \geq 1$ sectors, there is a continuum of horizontally differentiated varieties, and preferences take the Constant Elasticity of Substitution (CES) form:

$$
Q_{j}=\left[\int_{i \in \Omega_{j}} q_{j i}^{\left(\sigma_{j}-1\right) / \sigma_{j}} d i\right]^{\sigma_{j} /\left(\sigma_{j}-1\right)}, \quad \sigma_{j}>1, j \geq 1 .
$$

Note that $i \in \Omega_{j}$ indexes the universe of differentiated goods in the industry as well as the universe of firms. Moreover, notice that for the sake of simplicity, we do not model government's preferences explicitly and differently from consumer preferences. The demand for each differentiated variety within sector $j$ is given by:

$$
\begin{aligned}
q_{j i}=\left(1-\tau_{i}\right) A_{j} p_{j i}^{-\sigma_{j}}, \quad A_{j} & =X_{j} P_{j}^{\sigma_{j}-1} \\
X_{j}=\beta_{j} Y, \quad P_{j} & =\left[\int_{i \in \Omega_{j}} p_{j i}^{1-\sigma_{j}} d i\right]^{1 /\left(1-\sigma_{j}\right)}
\end{aligned}
$$

where $Y$ denotes the aggregate income, $X_{j}$ denotes the fraction consumers spend on goods from industry $j, P_{j}$ is the price index, and $A_{j}$ represents an index of market demand taken as given by firms, which proportionally scales every firm's residual demand.

In a world with corruption, firm-level demand is subject to a wedge. That is, each firm will face a corruption wedge $\tau \in(-\infty, 1)$, which is heterogeneous across firms in a given industry. Some firms could have $\tau<0$, thus receiving a subsidy on their demand. Other firms could have $\tau \in(0,1)$, and be subject to a tax on their demand. The case of $\tau \equiv 0$ is one with no corruption-induced heterogeneity across firms within a sector (which could be thought of as a non-government dependent firm). We assume all the revenues accrued because of $\tau>0$ are not spent on the local economy, as they are instead stolen and wasted by politicians.

A.2. Technology. Firms in sector $j$ produce varieties using a composite factor of production $L_{j}$, at unit cost $w_{j}$, and sector 0 is characterized by $w_{0}=1$. Within each industry, each firm chooses to supply a distinct horizontally differentiated variety. To produce, all firms need to incur a fixed cost $f_{j}$. There is also a constant marginal cost that is inversely proportional to firm productivity $\varphi_{i}$. The total amount of input required for firm $i$ in industry $j$ to produce $q_{j i}\left(1-\tau_{i}\right)$ units of a variety 
is:

$$
l_{j i}=f_{j}+\frac{q_{j i}\left(1-\tau_{i}\right)}{\varphi_{i}}
$$

A.3. Firm Behavior. In equilibrium, firms maximize profits by choosing a price that is a constant mark-up over marginal cost. The first order condition (FOC) yields:

$$
p_{j i}=\frac{\sigma_{j}}{\sigma_{j}-1} \frac{w_{j}}{\varphi_{i}}
$$

As a result, revenue is given by:

$$
r_{j i}=r_{j}\left(\varphi_{i}, \tau_{i}\right)=\left(1-\tau_{i}\right) A_{j} p_{j i}^{1-\sigma_{j}}=\left(1-\tau_{i}\right) A_{j}\left[\frac{\sigma_{j}-1}{\sigma_{j}}\right]^{\sigma_{j}-1} w_{j}^{1-\sigma_{j}} \varphi_{i}^{\sigma_{j}-1}
$$

while profits are given by:

$$
\begin{aligned}
& \pi_{j i}=\pi_{j}\left(\varphi_{i}, \tau_{i}\right)=\frac{r_{j}\left(\varphi_{i}, \tau_{i}\right)}{\sigma_{j}}-w_{j} f_{j}=\left(1-\tau_{i}\right) B_{j} \varphi_{i}^{\sigma_{j}-1}-w_{j} f_{j} \\
& B_{j}=\frac{\left(\sigma_{j}-1\right)^{\sigma_{j}-1}}{\sigma_{j}^{\sigma_{j}}} w_{j}^{1-\sigma_{j}} A_{j}
\end{aligned}
$$

A.4. Firm Entry And Exits. The zero profits condition is the following:

$$
\pi_{j}\left(\varphi_{i}^{*}, \tau_{i}^{*}\right)=\left(1-\tau_{i}^{*}\right) B_{j}\left(\varphi_{i}^{*}\right)^{\sigma_{j}-1}-w_{j} f_{j}=0
$$

while the free entry condition can be obtained as:

$$
\int_{-\infty}^{1} \int_{\varphi_{i}^{*}}^{+\infty}\left[\left(1-\tau_{i}\right) B_{j}\left(\varphi_{i}\right)^{\sigma_{j}-1}-w_{j} f_{j}\right] d G(\varphi) d H(\tau)=w_{j}\left(f_{E}\right)_{j}
$$

After a firm pays $\left(f_{E}\right)_{j}$ to enter an industry, it draws its productivity $\varphi$ from $G(\varphi)$ and its corruption tax parameter $\tau$ from $H(\tau)$. As illustrated in Figure A6, the combination $\left(\varphi_{i}^{*}, \tau_{i}^{*}\right)$ gives a boundary such that firms in the upper-left of the area will continue producing, while others will exit. $\left(f_{E}\right)_{j}$ is the sunk entry cost.

A.5. Equilibrium. General equilibrium can be characterized by the following variables for each sector: the survival productivity and corruption tax boundary $\left(\varphi_{i}^{*}, \tau_{i}^{*}\right)$, the price $w_{j}$, the supply of the composite input $L_{j}$, the mass of entrants $\left(M_{E}\right)_{j}$, and aggregate expenditure $X_{j}$.

A.5.1. Sectoral Equilibrium. The zero-profit condition (A8) and the free entry condition (A9) provide two equations involving three endogenous variables: $\varphi^{*}, \tau^{*}$ and market demand $B / w$. Combining these two conditions, we obtain a single equation that determines the boundary:

$$
\begin{aligned}
f_{j} J\left(\varphi_{i}^{*}, \tau_{i}^{*}\right) & =\left(f_{E}\right)_{j} \\
J\left(\varphi_{i}^{*}, \tau_{i}^{*}\right) & =\int_{-\infty}^{1} \int_{\varphi^{*}}^{+\infty}\left[\left(\frac{1-\tau_{i}}{1-\tau_{i}^{*}}\right)\left(\frac{\varphi_{i}}{\varphi_{i}^{*}}\right)^{\sigma_{j}-1}-1\right] d G(\varphi) d H(\tau)
\end{aligned}
$$

$J$ is monotonically decreasing with respect to $\varphi_{i}^{*}$ and increasing with respect to $\tau$. The limit of $J$ with $\tau_{i}$ approaching 1 and $\varphi_{i}$ approaching 0 approaches $\infty$, while the limit with $\tau_{i}$ approaching $-\infty$ and $\varphi_{i}$ approaching $\infty$ approaches 0 . 
We can then write down firm performance in terms of $\varphi_{i}, \tau_{i}$, and market demand $B / w:^{58}$

$$
\begin{aligned}
\frac{p\left(\varphi_{i}, \tau_{i}\right)}{w} & =\frac{\sigma}{\sigma-1} \frac{1}{\varphi_{i}} \\
\frac{\pi\left(\varphi_{i}, \tau_{i}\right)}{w} & =\left(1-\tau_{i}\right) \frac{B}{w} \varphi_{i}^{\sigma-1}-f \\
\frac{r\left(\varphi_{i}, \tau_{i}\right)}{w} & =\sigma\left[\frac{\pi\left(\varphi_{i}, \tau_{i}\right)}{w}+f\right] \\
q\left(\varphi_{i}, \tau_{i}\right) & =\frac{r\left(\varphi_{i}, \tau_{i}\right)}{\left(1-\tau_{i}\right) p\left(\varphi_{i}, \tau_{i}\right)} \\
l\left(\varphi_{i}, \tau_{i}\right) & =\frac{\left(1-\tau_{i}\right) q\left(\varphi_{i}, \tau_{i}\right)}{\varphi_{i}}+f
\end{aligned}
$$

This setting ensures that sector aggregates such as expenditures and input supply do not affect the firm selection boundary and the distribution of any firm performance measure in equilibrium. Sector aggregates will only affect the mass of firms in the sector. We can look at properties of the distribution of the firm performance measures, so as to derive the relationship between sector aggregates and the mass of firms. We can first pin down the average profits and revenue of active firms using the free entry condition (A9):

$$
\begin{aligned}
\frac{\bar{\pi}}{w} & =\frac{f_{E}}{\int_{-\infty}^{1} \int_{\varphi^{*}}^{+\infty} d G(\varphi) d H(\tau)}=\frac{f_{E}}{\int_{-\infty}^{1}\left[1-G\left(\varphi^{*}\right](\tau)\right) d H(\tau)}=\frac{f_{E}}{1-E\left[G\left(\varphi^{*}(\tau)\right)\right]} \\
\frac{\bar{r}}{w} & =\sigma\left(\frac{\bar{\pi}}{w}+f\right)
\end{aligned}
$$

The representative firm's productivity is given by:

$$
\widetilde{\widetilde{\varphi}}^{\sigma-1}=\frac{\int_{-\infty}^{1} \int_{\varphi^{*}}^{+\infty} \varphi^{\sigma-1} d G(\varphi) d H(\tau)}{\int_{-\infty}^{1} \int_{\varphi^{*}}^{+\infty} d G(\varphi) d H(\tau)}
$$

The corresponding $\widetilde{\widetilde{\tau}}$ is pinned down by the average profit. This indicates a hypothetical monopolistic competition equilibrium with $M$ representative firms sharing the same productivity and corruption tax parameter. Given the same input supply $L$ and expenditures $X$ for the sector, the hypothetical equilibrium with representative firms would also feature the same mass $M$ of active firms.

In the heterogeneous firm setting, the $M$ active firms represent the portion of the mass of entrants $M_{E}$ that survive. This portion is pinned down by the boundary of $\left(\varphi^{*}, \tau^{*}\right)$, so that $M=[1-$ $\left.E\left[G\left(\varphi^{*}(\tau)\right)\right]\right] M_{E}$. The sector's input supply $L$ is used both for production by the $M$ active firms and to cover the sunk cost of all entrants. The factor market equilibrium condition equating demand and supply for the sector's composite input is as follows:

$$
L=\frac{R-\Pi}{w}+M_{E} f_{E}
$$

The free entry condition ensures that aggregate profits cover the aggregate entry cost: $\Pi=M \bar{\pi}=$ $w M_{E} f_{E}$. Therefore, aggregate sector revenue is determined by the input supply: $R / w=L$. In a closed economy this must also equal the sector's expenditure $X / w$. In our sector with corruption

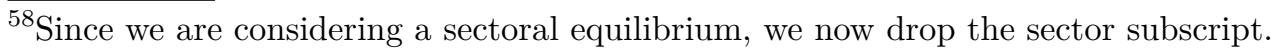


wedges, a certain proportion of the total expenditures are stolen and wasted by politicians, and thus $\frac{R}{w}=\frac{X(1-E[\tau])}{w} .^{59}$

A.5.2. General Equilibrium. We close the economy by fixing a single factor of production (labor $\bar{L}$ ) that is mobile across sectors and indexes the size of economy. Labor mobility ensures that the wage $w$ is the same for all sectors $j$, and $w_{j}=w_{0}=1$ for the numeraire.

With the zero-profit cutoff boundaries $\left(\varphi^{*}, \tau^{*}\right)$ and $w$ determined, the other elements of the equilibrium vector follow immediately. Aggregate income is $Y=w \bar{L}$ and industry revenue and expenditure follow from $R_{j}=X_{j}(1-E[\tau])=\beta_{j} Y(1-E[\tau])=\beta_{j} w \bar{L}(1-E[\tau])$. Therefore, the mass of firms in each sector is as follows:

$$
M_{j}=\frac{R_{j}}{\bar{r}_{j}}=\frac{\beta_{j} \bar{L}(1-E[\tau])}{\sigma_{j}\left[\frac{\left(f_{E}\right)_{j}}{1-E\left[G\left(\varphi^{*}(\tau)\right)\right]}\right]+f_{j}}
$$

A.6. Effects of An Anti-corruption Program. We model the anti-corruption audit as a shock that reduces the corruption wedge $\tau$ (i.e., $|\tau| \downarrow$ ). Without loss of generality, let us assume that after the audit $\tau \equiv 0$ for every firm.

Proposition 1 (Government-Dependent Sectors). After an audit, the total number of firms increases if the productivity has a lower bound larger than $\frac{w f}{B}$, and if there exists a large enough $\tau$ such that $G\left(\frac{w f}{B(1-\tau)}\right)>0$. Hence, the number of firms increases more in sectors where the average $\tau$ is higher.

Proof:

To show that the number of firms increases after the audit program, we would have to show that:

$$
1-G\left(\frac{w f}{B}\right)>1-E\left[G\left(\frac{w f}{B(1-\tau)}\right)\right]
$$

The expectation can be expressed as an integral, so that:

$$
\int_{-\infty}^{1} G\left(\frac{w f}{B(1-\tau)}\right) d H(\tau)-G\left(\frac{w f}{B}\right)>0
$$

which can be separated into two parts of non-negative integrals:

$$
\int_{0}^{1}\left[G\left(\frac{w f}{B(1-\tau)}\right)-G\left(\frac{w f}{B}\right)\right] d H(\tau)-\int_{-\infty}^{0}\left[G\left(\frac{w f}{B}\right)-G\left(\frac{w f}{B(1-\tau)}\right)\right] d H(\tau)>0
$$

${ }^{59} \mathrm{~A}$ simple proof comes from the integration of firm-level revenue:

$$
\begin{aligned}
R & =\int_{i \in \Omega} \sigma B\left(1-\tau_{i}\right) \varphi_{i}^{\sigma-1} d i=\sigma B \int_{i \in \Omega}\left(1-\tau_{i}\right) \varphi_{i}^{\sigma-1} d i=\sigma B E\left[\varphi^{\sigma-1}\right](1-E[\tau]) \\
B & =\frac{(\sigma-1)^{\sigma-1}}{\sigma^{\sigma}} w^{1-\sigma} A \\
A & =X P^{\sigma-1} \\
P & =\left[\int_{i \in \Omega} p^{1-\sigma} d i\right]^{1 /(1-\sigma)}=\frac{\sigma w}{\sigma-1}\left[\int_{i \in \Omega} \varphi^{\sigma-1} d i\right]^{1 /(1-\sigma)} \\
B & =\frac{X}{\sigma E\left[\varphi^{\sigma-1}\right]} \\
R & =X(1-E[\tau])
\end{aligned}
$$


The lower bound of the productivity indicates that:

$$
G(x)=0, \forall x \leq \frac{w f}{B}
$$

so that (A19) can be rewritten as:

$$
\int_{0}^{1} G\left(\frac{w f}{B(1-\tau)}\right) d H(\tau)>0
$$

Due to the non-negativity of $G(\varphi)$ and $d H(\tau)$, we can see that:

$$
\int_{0}^{1} G\left(\frac{w f}{B(1-\tau)}\right) d H(\tau) \geq 0
$$

To ensure that the integral is strictly positive, we need a $\tau$ such that $G\left(\frac{w f}{B(1-\tau)}\right)$ and $d H(\tau)$ are both positive. Suppose that the lower bound of $\varphi$ is $C>\frac{w f}{B}$, then we would need a $\tau$ which satisfies $\frac{w f}{B(1-\tau)}>C$, namely a large enough $\tau$ such that:

$$
\tau>1-\frac{w f}{B C}
$$

To show that an audit leads to a higher increase in number of operating firms in sectors where the average $\tau$ is higher, we can show that a sector is harmed by corruption if:

$$
\int_{0}^{1} d H(\tau) \gg \int_{-\infty}^{0} d H(\tau)
$$

which follows directly from (A19), where the first part of the left hand side is larger than the second part. Indeed, if the probability density of $\tau$ concentrates more in $(0,1)$, note that $G\left(\frac{w f}{B(1-\tau)}\right)-G\left(\frac{w f}{B}\right)$ is constant for a given $\tau$, which means there will be higher entry and lower exit of firms.

Proposition 2 (Government-Dependent Firms). Labor, profits, revenue, and revenue-based productivity are decreasing in $\tau$. This implies that for firms subject to a corruption $\operatorname{tax}(\tau>0)$, labor, revenue, profits, and revenue-based productivity increase after the audit. For firms obtaining corruption subsidies $(\tau<0)$, all the performance measures decrease after the audit.

Proof:

The firm-level predictions are immediately derived by taking the partial derivatives of labor $\left(l_{j}(\varphi, \tau)\right)$, revenue $\left(r_{j}(\varphi, \tau)\right)$, profits $\left(\pi_{j}(\varphi, \tau)\right)$, and revenue-based productivity $\left(\frac{r_{j}(\varphi, \tau)}{l_{j}(\varphi, \tau)}\right)$ with respect to $\tau$, 


\section{Figure A6. Visualization Of Productivity Boundary}

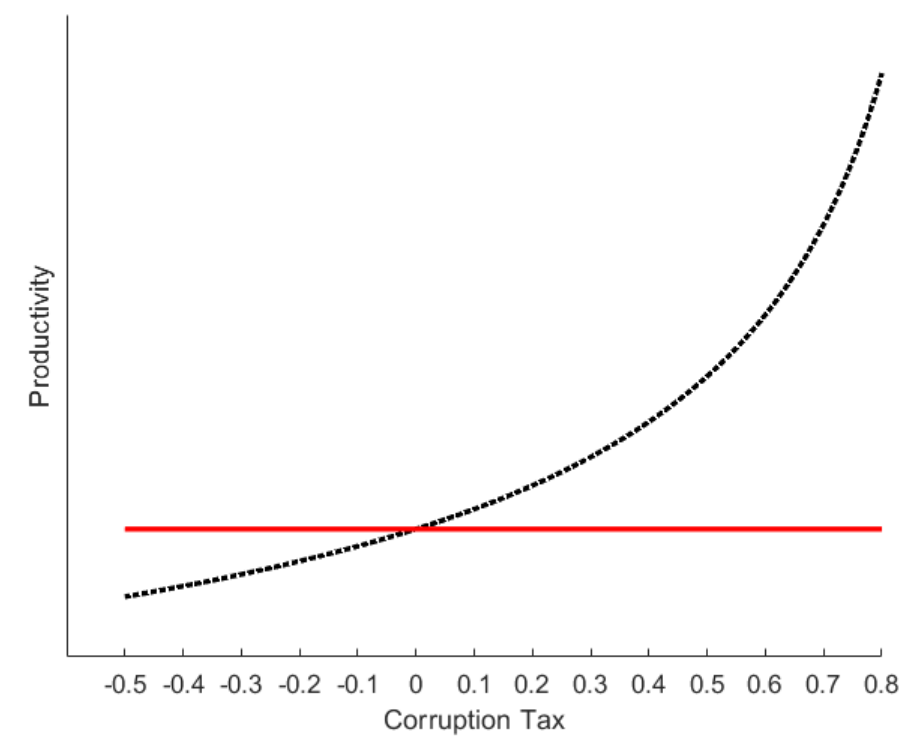

Notes: This figure illustrates the basic intuition of the model. The two axes are the firm level productivity and corruption wedge, respectively. The red horizontal line represents the minimum productivity above which firms can profitably operate when there are no corruption distortions. The black dotted line shows instead the minimum productivity above which firms can profitably operate in presence of corruption distortions. The two lines intersect at $\tau=0$. This implies that higher levels of distortions change the firms' performance and the compositions of firms that decide to enter the market. The simulation assumes the following: $f=0.5, \beta=0.1, \bar{L}=2000, \sigma=3, w=1$.

namely:

$$
\begin{aligned}
\frac{\partial \pi(\varphi, \tau)}{\partial \tau} & =-\frac{B}{w} \varphi^{\sigma-1}<0 \\
\frac{\partial r(\varphi, \tau)}{\partial \tau} & =\sigma \frac{\partial \pi(\varphi, \tau)}{\partial \tau}<0 \\
\frac{\partial l(\varphi, \tau)}{\partial \tau} & =-\frac{A p^{-\sigma}}{\varphi}<0 \\
\frac{r(\varphi, \tau)}{l(\varphi, \tau)} & =\frac{\sigma w}{\sigma-1} \frac{1}{1+\frac{(f+c) \frac{w}{\sigma-1}}{B(1-\tau) \varphi^{\sigma-1}}} \\
\frac{\partial \frac{r(\varphi, \tau)}{l(\varphi, \tau)}}{\partial \tau}=-\frac{\sigma w}{\sigma-1} & \frac{1}{\left(1+\frac{(f+c) \frac{w}{\sigma-1}}{B(1-\tau) \varphi^{\sigma-1}}\right)^{2}} \frac{(f+c) \frac{w}{\sigma-1}}{B \varphi^{\sigma-1}} \frac{1}{(1-\tau)^{2}}<0
\end{aligned}
$$

A.7. Visualization and Back-of-the-Envelope Calculation. The basic implications of the model can be illustrated through a simple depiction of the boundary of the combination $(\varphi, \tau)$, which we show in Figure A6. The red horizontal line is the productivity boundary in a model without corruption taxes, and the black dotted line is the model with corruption. All firms above the lines would enter the market, while those below would exit the market. As is apparent from Figure A6, the higher the $\tau$, the higher the productivity needed to be profitable for the firm to enter the market. 
For the simulation in Figure A6, we make several choices. First, we set $w=1$ as in the equilibrium. Therefore, other numerical parameters, such as $f$ for fixed costs, and $f_{E}$ for sunk costs, can be thought of as ratios of wages, or labor costs. The choice of $\beta$ and $\bar{L}$ is without loss of generality, and so we choose $\beta=0.1$ and $\bar{L}=2000$. As is standard in the literature, we choose $\sigma=4$. Similarly, we set $f=f_{E}=0.5$. Finally, for $\varphi$, we borrow from the distribution used by Hsieh and Klenow (2009) for China and India. Notice that this set of parameters would imply an increase in the number of firms after the audit in the range of $0.58 \%$ to $2.62 \%$, which are indeed in line with our main empirical results.

Using the same calibration choices, we conclude with a back-of-the-envelope calculation to understand what benchmark corruption distortions may rationalize our empirical results. Starting from (A15), we can rewrite the revenue after the audit as:

$$
R=X[1-(1-x \%) E[\tau]]
$$

where $x$ denotes the percentage decrease in the corruption tax. Since the municipal budget remains constant after the audit, $X$ does not change. As a result, the increase in total revenues $R$ is given by:

$$
\Delta R \%=\frac{[1-(1-x \%) E[\tau]]-(1-E[\tau])}{1-E[\tau]}=\frac{x \% E[\tau]}{1-E[\tau]}=\frac{x \%}{\frac{1}{E[\tau]}-1}
$$

We know from Avis, Ferraz, and Finan (2018) that audits reduce corruption by 20\%, hence we can set $x=20$. Similarly, while we do not observe the impact of audits on total revenues for all firms in the economy, we can provide an estimate that ranges from 1\% (from Table 3 on number of firms) to $6 \%$ (from Table 4 on total sales for firms in the PAC/PAS census datasets). Using this range of estimates, we can back out the average corruption tax faced by firms that would be needed to rationalize our findings. For example, assuming $\Delta R \%=2 \%$, we can see that $\frac{1}{\frac{1}{E[\tau]}-1}=0.1$, which leads to an average corruption tax of $E[\tau]=\frac{1}{11}=9.1 \%$. In Table A21 we report the range of back of the envelope estimates for the average corruption tax, depending on different values of $\Delta R$. We find a corruption tax in the range of 5\%-23\% to fit our empirical findings.

\section{TABle A21. Range for Corruption Tax}

\begin{tabular}{lc}
\hline$\Delta R \%$ & $E[\tau]$ \\
\hline 1 & $4.8 \%$ \\
2 & $9.1 \%$ \\
3 & $13.0 \%$ \\
4 & $16.7 \%$ \\
5 & $20.0 \%$ \\
6 & $23.1 \%$ \\
\hline
\end{tabular}

